\title{
Keeping girls in schools to reduce child marriage in rural Bangladesh: Endline assessment
}

\author{
Sigma Ainul \\ Population Council \\ Forhana Rahman Noor \\ Population Council \\ Md. Irfan Hossain \\ Population Council \\ Iqbal Ehsan \\ Population Council \\ Mehnaz Manzur \\ Population Council
}

See next page for additional authors

Follow this and additional works at: https://knowledgecommons.popcouncil.org/departments_sbsr-pgy

Part of the Family, Life Course, and Society Commons, and the Gender Equity in Education Commons How does access to this work benefit you? Let us know!

\section{Recommended Citation}

Ainul, Sigma, Forhana Rahman Noor, Md. Irfan Hossain, Iqbal Ehsan, Mehnaz Manzur, Ubaidur Rob, and Sajeda Amin. 2022. "Keeping girls in schools to reduce child marriage in rural Bangladesh: Endline assessment." Dhaka: Population Council. 


\section{Authors}

Sigma Ainul, Forhana Rahman Noor, Md. Irfan Hossain, Iqbal Ehsan, Mehnaz Manzur, Ubaidur Rob, and Sajeda Amin

This report is available at Knowledge Commons: https://knowledgecommons.popcouncil.org/departments_sbsr-pgy/ 


\section{KEEPING GIRLS IN SCHOOLS TO REDUCE CHILD MARRIAGE IN RURAL BANGLADESH}

Endline Assessment

Sigma Ainul Forhana Rahman Noor Md. Irfan Hossain Iqbal Ehsan Mehnaz Manzur Ubaidur Rob Sajeda Amin
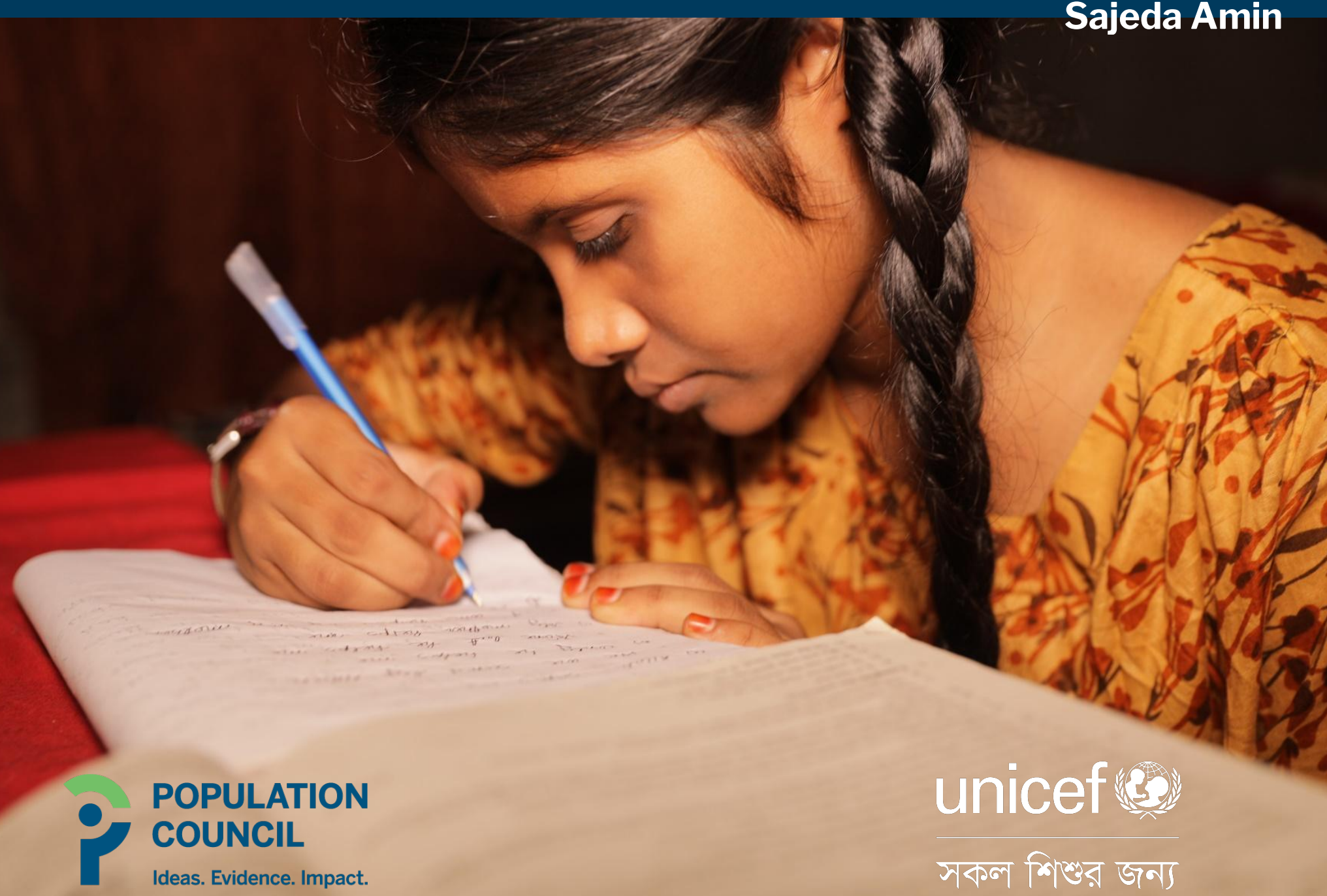


\section{KEEPING GIRLS IN SCHOOLS TO REDUCE CHILD MARRIAGE IN RURAL BANGLADESH}

\section{Endline Assessment}

Sigma Ainul Forhana Rahman Noor

Md. Irfan Hossain

Iqbal Ehsan

Mehnaz Manzur

Ubaidur Rob

Sajeda Amin 


\section{POPULATION}

COUNCIL

Ideas. Evidence. Impact.

The Population Council confronts critical health and development issues-from stopping the spread of HIV to improving reproductive health and ensuring that young people lead full and productive lives. Through biomedical, social science, and public health research in 50 countries, we work with our partners to deliver solutions that lead to more effective policies, programs, and technologies that improve lives around the world. Established in 1952 and headquartered in New York, the Council is a nongovernmental, nonprofit organization governed by an international board of trustees.

Population Council

House 12, Road 25/30

Gulshan, Dhaka 1212

Bangladesh

Tel: $880258812384,880258811964,88029842276$

Email address: info.bangladesh@popcouncil.org

popcouncil.org

Keeping Girls in Schools to Reduce Child Marriage in Rural Bangladesh is an intervention research study testing a life-skills and tutoring support model to keep girls in school and reduce child marriage. The study is a scale-up of the BALIKA (Bangladeshi Association for Life Skills, Income, and Knowledge for Adolescents) project.

Keeping Girls in Schools to Reduce Child Marriage in Rural Bangladesh is part of UNICEF's “Education for Adolescents” and UNFPA-UNICEF “Global Programme to Accelerate Action to End Child Marriage." The Global Programme promotes adolescent girls' rights to avert child marriage and pregnancy and enables them to achieve their aspirations through education and alternative pathways.

Suggested citation: Ainul, Sigma, Forhana Rahman Noor, Md. Irfan Hossain, Iqbal Ehsan, Mehnaz Manzur, Ubaidur Rob and Sajeda Amin. 2021. Keeping Girls in Schools to Reduce Child Marriage in Rural Bangladesh: Endline Assessment, Dhaka: Population Council.

This study has been funded by UNICEF.

(C) 2022 The Population Council, Inc. 


\section{Table of Contents}

ACKNOWLEDGMENTS ---

EXECUTIVE SUMMARY ---

1. INTRODUCTION-1 1

Keeping Girls in Schools (KGIS): Intervention Design---

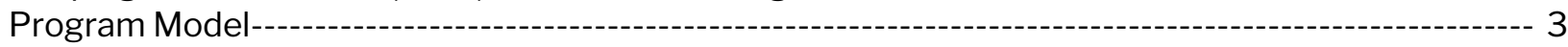

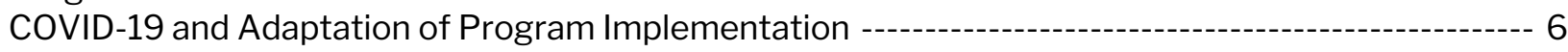

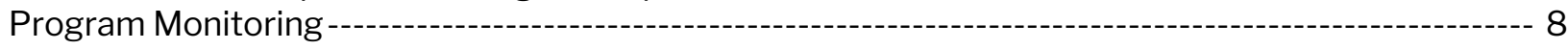

2. RESEARCH DESIGN AND INTERVENTION ASSESSMENT- 10

Intervention Assignment --- 10

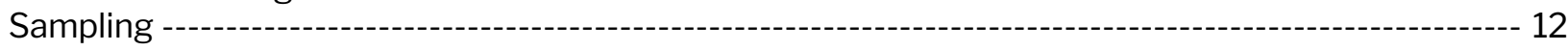

Endline Data Collection ----o 13

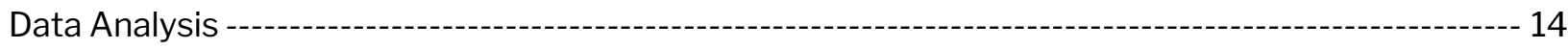

3. COVID-19 AND ITS EFFECT ON THE LIVES OF ADOLESCENT GIRLS ------------16

Bangladesh COVID-19 Context----o- 16

Rapid Survey with Adolescent Girls --- 16

School Closure and Learning 18

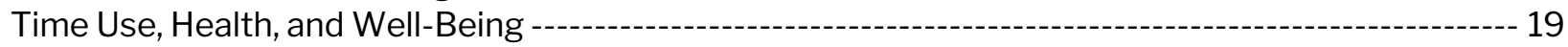

Child Marriage ---.-------on

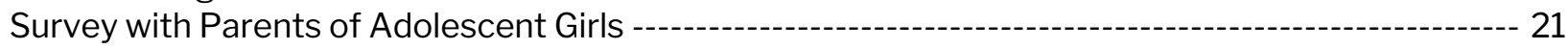

4. PROGRAM IMPACT --- 24

Education and Learning Outcomes -------on

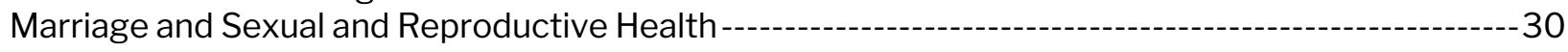

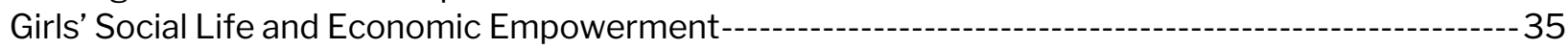

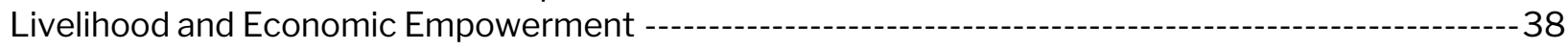

Intervention Impact --- 42

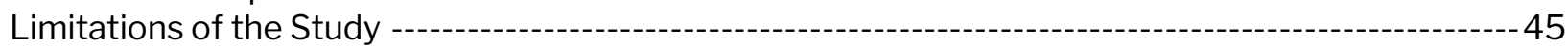

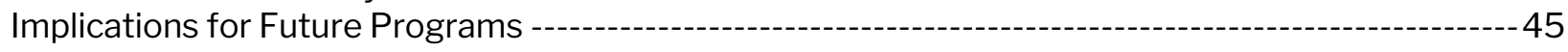

REFERENCES--- 47

APPENDIX 1: MONITORING

APPENDIX 2: COST ANALYSIS --

APPENDIX 3: OUTCOME INDICATORS--.-- 66

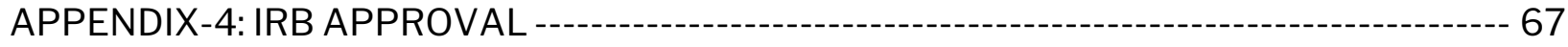




\section{List of tables, figures and photos}

Table 1. Distribution of intervention and control areas in study districts ..........................................................3

Table 2. Education and skill-building intervention of KGIS .................................................................................6

Table 3. Program implementation: Pre-COVID-19 and during COVID-19 ......................................................... 7

Table 4. Comparison of arms, for random allocation of schools, 2018 (in percent) ................................... 11

Table 5. Sample size for population-based survey ..................................................................................................12

Table 6. Sample size by data-collection method....................................................................................................14

Table 7. Timeline of Bangladesh's response during the COVID-19 pandemic and adaptation of

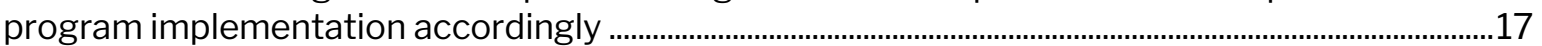

Table 8. Parents' responses on some selected indicators on the impact of COVID-19 ..........................23

Table 9. Percentage of adolescent girls by schooling status, according to study arm and survey time

Table

Table 10. Percentage of adolescent girls who have left school, by reason for discontinuation, according to study arm and survey time ...................................................................................................26

Table 11. Percentage of adolescent girls who are privately tutored, by age, wealth, and parental education, according to study arm and survey time ................................................................................ 27

Table 12. Changes in adolescent girls' competency scores by schooling status, according to study

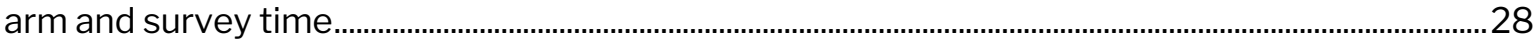

Table 13. Percentage of adolescent girls ever married, by age at marriage and schooling status, according to study arm and survey time .......................................................................................................

Table 14. Percentage of girls who were ever married, by different marriage related practice indicators, according to study arm and survey time ...................................................................................... 32

Table 15. Percentage of adolescent girls who are aware of laws regarding marriage and adverse effects of child marriage, according to study arm and survey time.

Table 16. Percentage of adolescent girls by knowledge regarding sexual and reproductive health and practices, according to study arm and survey time.

Table 17. Percentage of ever-married and girls who ever conceived by pregnancy-related indicators, according to study arm and survey time

Table 18. Percentage of adolescent girls reporting exposure to technology and mass media and institutional affiliations, according to study arm and survey time ........................................................36

Table 19. Percentage of adolescent girls by safety, security, and mobility-related indicators, according to study arm and survey time ................................................................................................. 37

Table 20. Percentage of adolescent girls by employment status and related indicators, according to study arm and survey time.

Table 21. Percentage of adolescent girls by perception about gender rights and norms, according to study arm and survey time.

Table 22. Results summary of the impact of the intervention on education, marriage, sexual and reproductive health rights, livelihood, and gender perception ..................................................................4

Table 23. Enrollment summary of the sessions pre- and during COVID-19..................................................50

Table 24. Attendance summary of the sessions pre- and during COVID-19................................................53

Table 25. Quality of the sessions at a glance .......................................................................................................59

Table 26. Center setup cost (per center) …………………………………………………………….................61

Table 27. Total training cost..................................................................................................................................62

Table 28. Implementation costs for conducting sessions per center for in-school girls .........................63

Table 29. Implementation cost for conducting sessions with out-of-school girls in YR1 ........................64

Table 30. Monitoring costs of YR1 .................................................................................................................64

Table 31. Summary of costs for the project implementation (March 2019 to March 2021) ....................65

Table 32. Main outcomes with indicators used to measure impact of the intervention............................66 


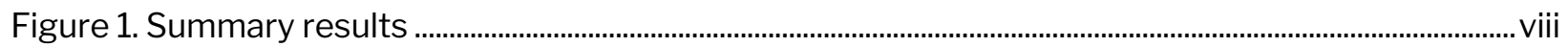

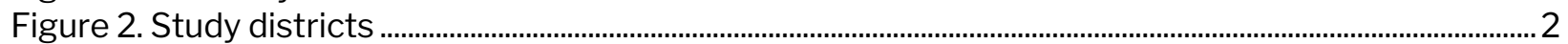

Figure 3. Theory of change for the KGIS intervention model.......................................................................... 4

Figure 4. SurveyCTO monitoring app for a smartphone .......................................................................................9

Figure 5. Attendance screenshot of phone session during COVID-19 ..................................................................9

Figure 6. COVID-19 impact on adolescent girls' mental health............................................................................. 18

Figure 7. COVID-19 impact on adolescent girls' mental health .............................................................................19

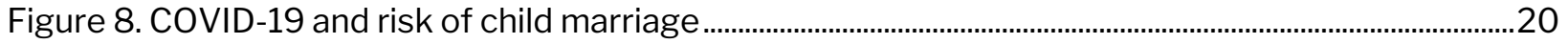

Figure 9. Average attendance of girls (\%) in in-school and out-of-school sessions, 2019 and 2020 ...51

Figure 10. Average attendance of girls in in-school and out-of-school sessions by month, 2019.........52

Figure 11. Average attendance of girls in in-school and out-of-school sessions by month, 2020 .........52

Figure 12. Performance of teachers and mentors during session facilitation in selected quality

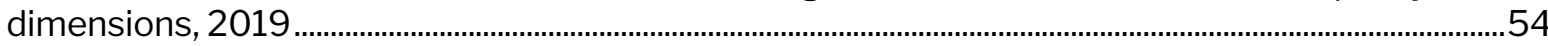

Figure 13. Performance of mentors during session facilitation in selected quality dimensions, 2020

Figure 14. Average performance score (assessing quality of interaction between facilitators and students) for environment of in-school and out-of-school sessions by month, 2019......................55

Figure 15. Average performance score for environment of the sessions (assessing quality of interaction between facilitators and students) by month and by district, 2019 ...................................56

Figure 16. Average score for overall environment performance of the in-school and out-of-school sessions, 2020

Figure 17. Average score for overall environment performance of the sessions by month and district, 2020 57

Figure 18. Average performance score in “interactive” environment by session topic, 2019.................58

Figure 19. Average overall performance score by session topic, 2020

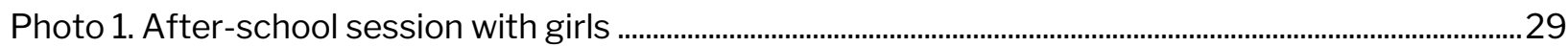

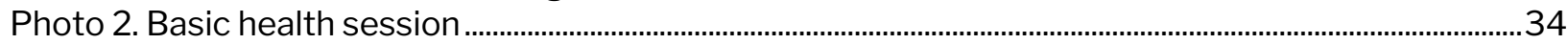

Photo 3. Girls and mentor in life-skills session ...................................................................................................... 37

Photo 4. Mentor providing BASIC computing lesson to out-of-school girls ..................................................38 


\section{ACKNOWLEDGMENTS}

The Population Council, with technical and financial assistance from UNICEF, implemented an intervention research study to test a life-skills and tutoring support model to reduce school dropouts among secondary-school girls and to build the livelihood skills of unmarried girls who have dropped out of school, with the goal of delaying marriage in Chapainawabganj, Kushtia, and Sherpur districts in Bangladesh. This project is one component of UNICEF's “Education for Adolescents" program under the Directorate of Secondary and Higher Education, Ministry of Education, and "UNFPA-UNICEF Global Programme to Accelerate Action to End Child Marriage." The Global Programme promotes the rights of adolescent girls to avert child marriage and pregnancy and enables them to achieve their aspirations through education and alternative pathways.

The study team would like to acknowledge the contributions of many individuals and institutions that made this intervention possible. We are grateful to UNICEF colleagues Iqbal Hossain, Education Specialist, UNICEF and Sheikh Nishat Nazmi, Education Officer, UNICEF for their technical support throughout the implementation of the intervention. We thank the District Education Officer, Upazila Secondary Education Officer, and Academic Supervisors of the Directorate of Secondary and Higher Education, Ministry of Education of Bangladesh and local government representatives for their support in implementation of the intervention.

A special thanks also goes to 96 schoolteachers, head teachers, and the school management committee and 24 mentors from 24 intervention schools who implemented the intervention among adolescent girls. We thank three district coordinators from the Population Council-Liton Acharya, Arifur Rahman, and Sanjit Kumar Nath-who were engaged in coordinating and monitoring overall field activities throughout the period. We also thank the supervisors and interviewers who participated in the data collection for the endline study.

A special thanks goes to Population Council colleagues who made important contributions to this study and report. We also thank Dipak Kumar Shil for managing the study funding, budget, and expenditure reports. We thank Joynal Abedin and Rakibul Hossain who provided day-to-day administrative support for this project. We want to specially thank Noorunnabi Talukder, Monitoring and Evaluation Advisor from the Population Council, for his valuable contribution during designing and developing the research protocol.

Finally, we express our gratefulness to the adolescent girls and their parents in six upazilas under three districts who shared their experiences and perspectives by participating in the endline adolescent survey and parent survey interviews, without whom this study report would not have been possible. 


\section{EXECUTIVE SUMMARY}

This report describes findings of changes over time attributable to the "Keeping Girls in Schools" (KGIS) program study in Bangladesh that implemented skill-building activities for a two-year period in the districts of Chapainawabganj, Kushtia, and Sherpur. The interventions sought to bring about change in child marriage norms prevalent in the area by offering young girls a safe place to meet after school hours with mentors and teachers and to offer girls tutoring support and life-skills. The project was implemented by the Population Council with the cooperation of secondary schools in the community and was supported by UNICEF under the aegis of the UNICEF-UNFPA Global Programme to End Child Marriage. The interventions offered were designed to align with gender-transformative programming. ${ }^{1}$ The program targeted the most marginalized adolescent girls in the community who had dropped out of school and girls who were underperforming at school which put them at higher risk of child marriage. The program made tailored investments to enhance their social, health, cognitive and economic assets. The intervention provided specially designed tutoring support in math and English for underperforming girls in school, skill-building and life-skills awareness sessions that challenged norms and restrictions for adolescent girls. Skills sessions included computer training, financial literacy, and basic health service skills. The program actively engaged female mentors from the community who led girls' groups at the sessions, liaised with teachers, school management committees $(\mathrm{SMC})$, and the community at large.

The main questions of interest for the project were as follows: can a community-based safe space program be scaled up in the secondary school system? Rather than offering skills to all adolescent girls, can the program conserve scarce resources by targeting girls who have already dropped out and underperforming girls in Grade 7 and 8? Also, to conserve scarce resources while reaching greater numbers, would a shorter duration of program exposure of 12 months for each cohort work? The skills package was targeted accordingly and reduced from the original 144 hours to 72 hours. The study otherwise replicated previously successful programs in its emphasis on local mentors, opportunities to meet regularly with mentors and teachers in safe spaces within the locality, and a structured curriculum of instruction. The program was adapted to COVID-era social distancing rules through reduced hours of virtual instruction conducted in phone sessions. However, mentors met with each girl with greater intensity-twice per week virtually in smaller groups of three as opposed to around 30-and complemented virtual sessions with the distribution of handouts and worksheets to top up learning and engagement.

The intervention included a full year of implementation during the COVID-19 pandemic. School closures generated considerable mental distress. Over 60 percent of girls reported being anxious about not being able to learn at the expected level because of learning loss and one in 10 girls said they might not go back to school after reopening. Loss of livelihoods also had an impact. Girls reported eating less protein, buying fewer household goods and food, and not accessing requisite health services. Increased household chores during

\footnotetext{
${ }^{1} \underline{\text { https://www.unicef.org/documents/gender-transformative-accelerator-tool-brief }}$
} 
pandemic and increased caregiving for family illness was also reported by adolescent girls. The effect of COVID-19 on girls' education and learning, household economic situation, and relevant social and emotional challenges are described in Chapter 3.

The study sought to measure the impact of the intervention at the community level through a rigorous, repeated cross-sectional design with a baseline (2018) and an endline survey (2021). Surveys were conducted in person with samples of over 3,000 girls each to assess the impact of the interventions on all girls in the communities. The measure of program impact is the change in key outcomes of interest from baseline to endline by comparing aggregate levels of marriage, education, livelihood activities, and knowledge and behaviors related to sexual and reproductive health rights (SRHR) among intervention and control areas.

\section{Figure 1. Summary results}

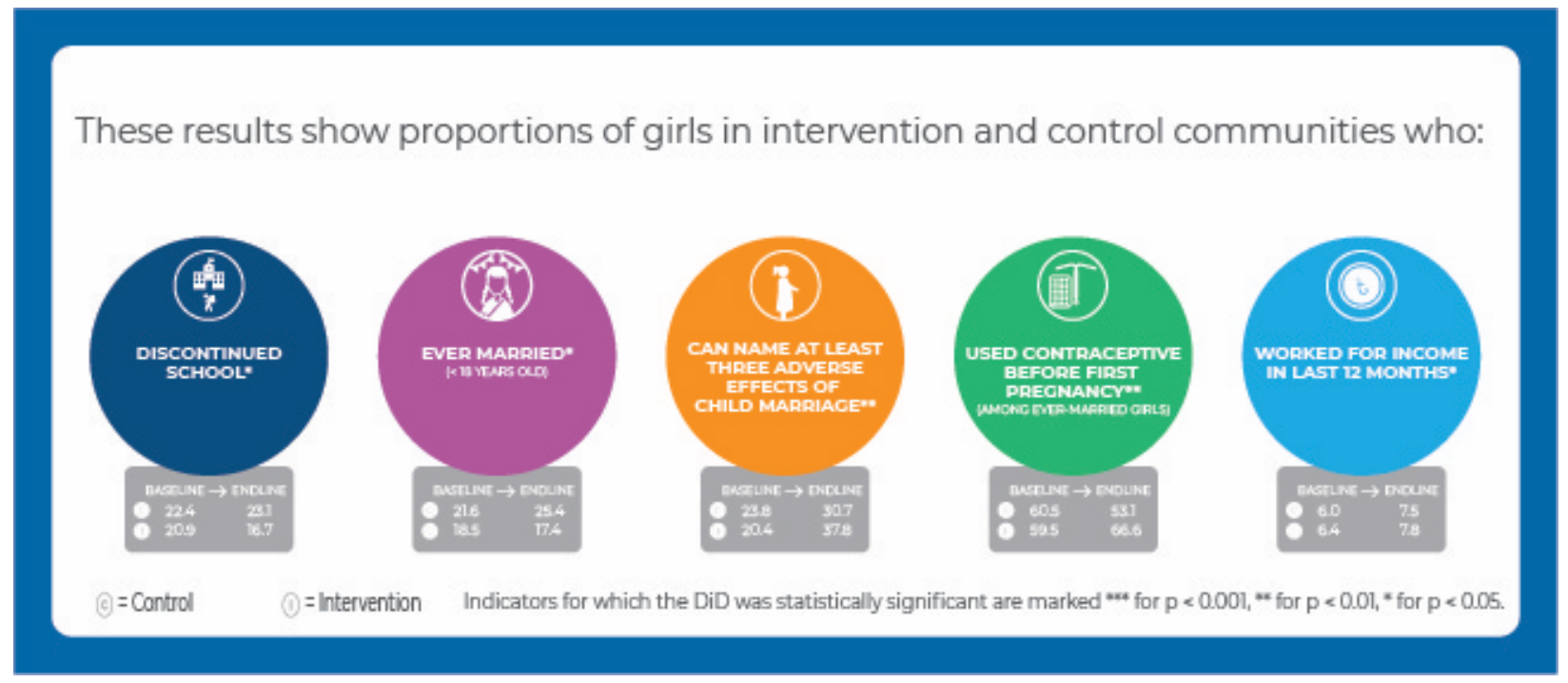

The KGIS program had a protective impact on child marriage-relative to the baseline, girls were more likely to be married at endline in control areas whereas there was no discernible increase in child marriage prevalence in the intervention areas; similarly, school dropout as a result of marriage and learning loss in analytical skills were significantly greater in control areas. The program also raised critical awareness skills and girls in the intervention areas were significantly more likely than girls in control areas to list adverse effects of child marriage, initiated use of modern contraception before first birth, had increased confidence and trust of parents in terms of mobility, including girls being able to go home after sunset and visit friends alone. However, on a range of other measures, such as use of menstrual hygiene products, likelihood of accessing and using cell phones, or giving more gender aware responses, there was no discernible impact of the program. Regarding economic aspiration, work for pay and earnings increased in intervention areas at endline, however girls' control over expenses as well as savings declined in both areas because of financial strain on families during the pandemic. Thus, these changes could not be considered as attributable to girls' empowerment. 
These measurable successes in reducing marriage, raising critical awareness, and changing behaviors of contraception use, freedom of mobility or earning money, despite the challenges of school closure and social distancing during the COVID era, offer several important lessons. Local mentors successfully used group calls and scheduled weekly phone sessions to stay in touch with girls during the COVID-19 pandemic which may have helped with developing protective assets for girls. The findings from qualitative interviews with girls reflect how these virtual phone sessions worked as an antidote to isolation and acted as virtual "safe spaces" for connecting with peers and mentors, and helped them to continue their education and give a sense of normalcy in their lives during the COVID-19 pandemic and prolonged school closures. These protective effects were not available to girls living in the control areas. Beyond protecting against early marriage and possibly premature childbearing, the program may have also helped to develop cognitive and critical-thinking skills with likely longer-term impact. 


\section{INTRODUCTION}

For the last two decades, Bangladesh has made considerable progress in improving access to education at all levels. Despite these impressive gains, Bangladesh continues to face challenges of student dropout at the secondary level (BANBEIS 2018).

The Population Council, with UNICEF funding, implemented the project "Keeping Girls in Schools to Reduce Child Marriage in Rural Bangladesh." The project is premised on the notion that targeted policies and interventions designed to improve mainstream educational attainment may be effective and sustainable ways of addressing the interlinked issues of school dropout and child marriage.

The project's goal is to provide after-school skill sessions as a strategy for offering remedial education

- More than one-third of students who complete primary school (40\%) do not complete the full cycle of secondary education.

- Dropout rates from secondary school are higher for girls (46\%) compared to boys (34\%).

- Of girls who drop out, twothirds quit school because of marriage. Girls drop out of school earlier than boys because of child marriage. for girls who are falling behind or have dropped out of school. The target outcomes were keeping girls in school and reducing child marriage through skills development and a supportive social environment. Locally recruited mentors played a key role in offering social support to girls at risk. An intervention research study, the project tested a life-skills and tutoring support model.

While Bangladesh has achieved significant social progress, child marriage rates remain stubbornly high despite concerted action taken by the government and civil society across a range of sectors (UNICEF 2018). Although there is a limited but growing body of rigorous evidence to address child marriage, with a disproportionate contribution from rigorous studies conducted in Bangladesh (Lee-Rife et al. 2012; Kalamar, Lee-Rife, and Hindin 2016; Chae and Ngo 2017; Malhotra and Elnakib 2021) there is no clear consensus on the conclusions of these reviews regarding generalizable evidence on what works.

This project tested the scale-up of the BALIKA (Bangladeshi Association for Life Skills, Income, and Knowledge for Adolescents), one such intervention on proven approaches (Amin, Saha, and Ahmed 2018). This project addressed some key questions about scalability and replicability of a program proven to be effective in a carefully conducted, monitored, and evaluated model. By implementing some essential elements of the BALIKA model in a different part of rural Bangladesh with somewhat different socioeconomic characteristics (more predominantly Muslim, less vulnerable to coastal-area climate impact), this project tested the external validity of the BALIKA approach. It also addressed scalability and specifically tested whether similar programs intervening to offer support and skills to young adolescent girls who are performing poorly in school can be scaled up by explicitly engaging the school system. Rather than offering skills to all girls who are interested, the KGIS project thus modified strategies to target girls who were underperforming in school or had already dropped out, with remedial education and life skills. 
COVID-19 brought the program to an effective halt in the initial months of the pandemic. The project staff decided to adapt the planned interventions to continue program activities in considerably modified form, but keeping some essential elements the same. The ability to continue program activities was made possible by the fact that mentors were based in the communities where intervention girls lived and were equipped with computers and phones through which they could be reached virtually. They were also able to contact girls in person even though the program abided by social distancing protocols and did not convene gatherings in person. The program was modified into shorter virtual sessions supplemented with handouts and worksheets to top up learning and engagement (more details available in subsequent section program model and COVID-19 adaptation).

\section{Keeping Girls in Schools (KGIS): Intervention Design}

\section{Target beneficiary}

The goal of this project is to engage secondary schools in skill-building through after-school activities to keep girls in school and test this approach to reduce school dropouts and study its implications through rigorous monitoring and evaluation for future scale-up of intervention components. This project targeted adolescent girls aged 12-15 years living in the surrounding community of 24 secondary schools in three high-child-marriage districtsSherpur, Kushtia, and Chapainawabganj-in Bangladesh. The program enrolled in-school and out-of-school girls living in the communities in after-school remedial and life-skills education sessions. Girls who were enrolled in Grades 7 and 8 and performing poorly in school were considered to be at higher risk of dropout and enrolled in the program. Program participants were selected based on their scores on the previous year's final school examination and an assessment test before enrollment in the project. Out-of-school girls were selected from the community who reside within a two-kilometer radius of the intervention schools and were not enrolled in school at the time of the study.

\section{Study areas}

All of the study villages are located in rural districts of Chapainawabganj in the north-west, Kushtia in the west, and Sherpur in the north. The districts varied in terms of economic development-while Kushtia is well connected by roads and relatively prosperous, Chapainawabganj and Sherpur are relatively impoverished. Of the three districts, Sherpur is the closest to the urban metropolitan area of Dhaka and there is significant migration to Dhaka. All three districts border the neighboring states of India.
Figure 2. Study districts

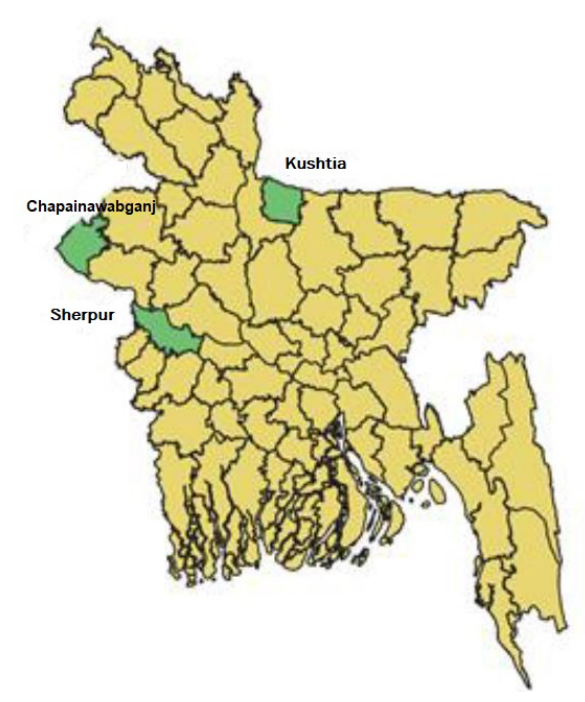


The project selected 48 schools in six upazilas (subdistricts) under the three districts, randomly divided between intervention and control groups.

Table 1. Distribution of intervention and control areas in study districts

\begin{tabular}{llcc}
\hline District & Upazila & Intervention schools & Control schools \\
\hline Sherpur & Shreebordi, Nalitabari & 8 & 5 \\
Kushtia & Bheramara, Daulatpur & 7 & 9 \\
Chapainawabganj & $\begin{array}{l}\text { Chapai Sadar, } \\
\text { Shibgonj }\end{array}$ & 9 & 10 \\
& & & \\
\hline
\end{tabular}

\section{Duration}

The project lasted $\mathbf{3 6}$ months, with three phases.

- Phase 1- Preparation (2018): engagement with schools and community, participant selection, baseline survey, development of intervention materials, orientation, and capacity-building of program managers and implementers.

- Phase 2- Intervention implementation: intervention activities were implemented over a two-year period from April 2019 to March 2021 with weekly life-skills and education sessions with adolescent girls.

- Phase 3- Study findings dissemination (2021): Intervention assessment of the intervention through an endline survey, qualitative data collection, and dissemination of research findings.

\section{Program Model}

\section{Girls' groups}

Three cohorts of girls were reached under the program. The beneficiary girls' groups in each of 24 intervention communities consisted of three groups-one Grade 7 in-school girls' group ( $n=20-30)$, one Grade 8 in-school girls' group ( $n=20-30)$, and one out-of-school girls' group ( $n=10-15)$. In year one, approximately 1,000 girls received intervention and in year two approximately 700 girls were reached through phone-based remote sessions during the COVID-19 pandemic. In two years of intervention in total approximately 2,700 adolescent girls received skill- and asset-building training under this project.

Figure 3 is a representation of the theory of change implicit in the KGIS approach. This theory of change places girls at the center of programming, removes isolation, and builds assets that help empower girls in a multidimensional way. The intervention model builds girls' educational, economic, health, and social assets through various components in the design. The program used high-quality learning materials that are tailored to address specific and diverse needs of the adolescent groups (in-school girls, out-of-school girls) and designed to meet girls' other educational needs. Remedial education materials used in the program were especially developed to meet the needs of in-school girls who are performing 
poorly at school and are at high risk of dropping out. The model included activities to empower participants by building their economic assets through financial literacy and livelihood training. Direct cash transfers were given to out-of-school girls by providing financial incentives to enhance girls' participation by counteracting opportunity costs, especially for out-of-school girls with financial responsibilities who usually belong to very poor families. Such transfers may also reduce parental opposition. Schools were used as the hub of the intervention where girls and families can feel safe and benefit from direct involvement and guidance from trusted and revered teachers who have high status in the community. Resource mobilization and capacity-development of teachers during the implementation of this program will sustain in the community beyond the duration of the project itself and the benefit will be received by future cohorts of adolescent girls. The constant engagement and support of mentors through weekly meetings with adolescent girls created opportunities to interact, share successes and challenges, exchange ideas and learning, and build adolescent girls' social networks. Effective family and community engagement was an integral part of the program, so that an enabling environment is created for girls and their participation in the program and the girls' group is not inhibited and the impact of girls' groups can be realized.

\section{Figure 3. Theory of change for the KGIS intervention model}

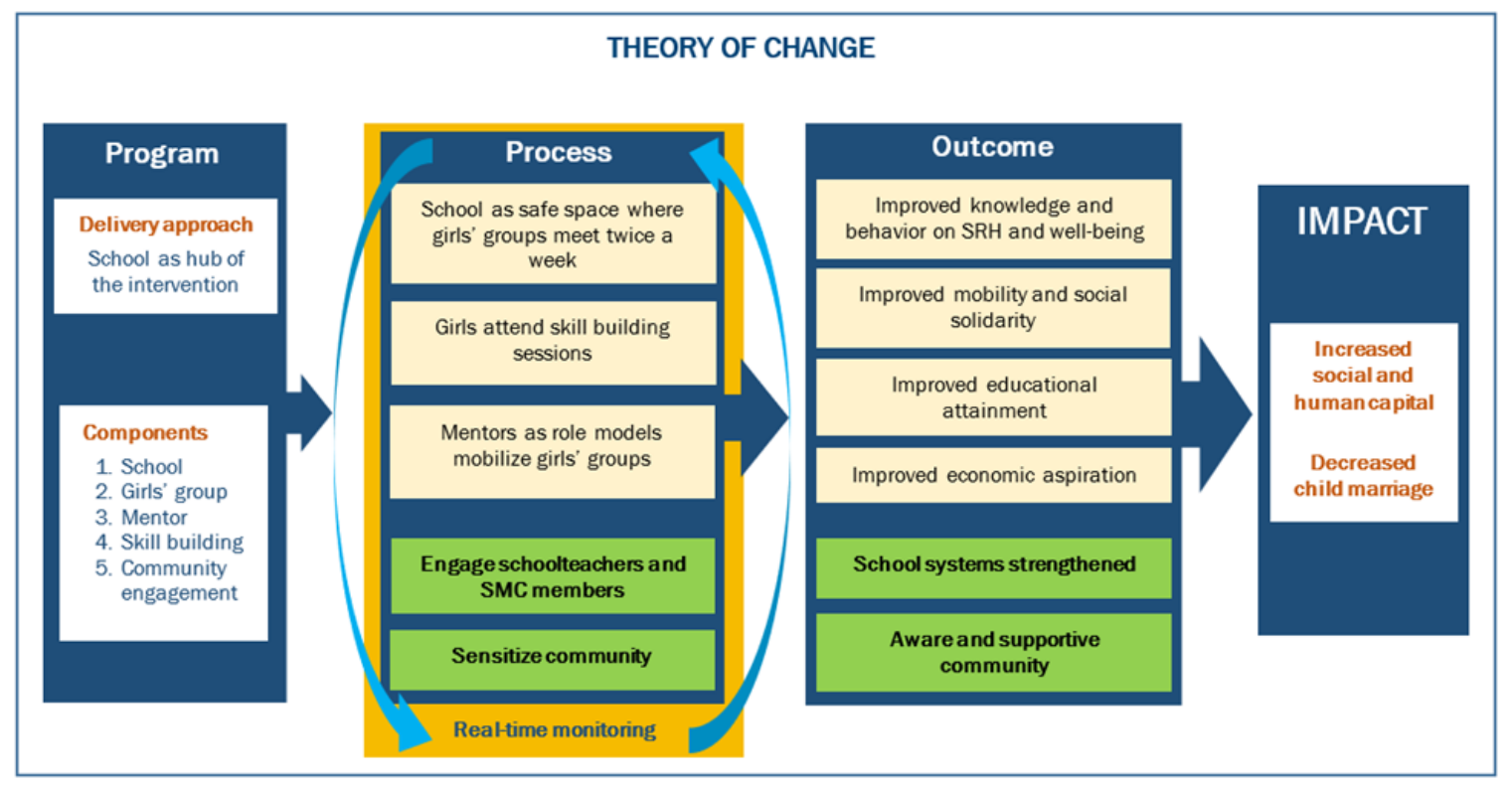

\section{Schools as an intervention hub and safe space}

Schools as a safe space were at the heart of the intervention. School capacity was strengthened through providing physical resources, capacity-building of teachers, and mentors from the community. Each intervention school was equipped with a laptop, internet modem, and multimedia projector to conduct after-school sessions with girls. Subject teachers received training on interactive and multimedia-based teaching. Four school teachers (two mathematics teachers and two English teachers) in each of the 24 intervention schools (total 96 schoolteachers) received training on developed digital remedial curricula particularly tailored for poorly performing girls. Teachers were chosen by 
the school, based on assigned and available subject teachers, and a majority of math and English teachers at the schools were male. Out of 96 teachers, 12 were females and the rest of teachers were male. Teachers were assisted by local mentors in each of these 24 schools who were all female. Investments in schoolteachers ensured a long-term capacity development of the most integral institution of the community and benefits will be received not only by adolescent girls enrolled in this program but beyond-to subsequent cohorts of adolescent girls in school who these teachers will encounter in future.

Each girls' group met twice a week at the intervention schools after school hours for two hours and received education and skill-building sessions. These meetings were intended to be beneficial to adolescent girls in multiple ways. First, in-school girls would get the benefit of remedial classes. Similarly, out-of-school girls were oriented with life-skills-based education, i.e, sexual and reproductive health $(\mathrm{SRH})$ and livelihood training. Second, the program used information and communication technology (ICT)-based classrooms and new digital content and made more use of online material than is used in the regular school curriculum and emphasized practical problem-solving skills through interactive learning processes. Third, girls were connected to a mentor-a young, empowered woman from their own community. As a role model for the girls, mentors led sessions on some topics and assisted a teacher on others. This opportunity to get together regularly with mentors and other girls was expected to create lasting social assets and reduce social isolation, through peer networks and regular opportunities to share real life experiences. The opportunity to participate regularly in social activities outside the home is expected to empower girls.

\section{Mentors as a bridge between adolescent girls and the community}

One mentor for each of the 24 interventions was recruited from the local community, living in the geographic area of the intervention schools. Mentors were young unmarried women between 20-25 years of age, mostly college or university students. They were selected on the basis of their technological savvy; confidence in use of mobile phones and computers; organizing capacity to lead girls' groups; and ability to work effectively with teachers, parents, and community members. The age gap between the mentor and the adolescent girls was 5-10 years. Engaging schoolteachers and school management committee (SMC) members in the recruitment process of mentors ensured that the mentor was from the local community and was known and trusted by the girls, their families, and the schools. As high achievers they had some social capital, and the project also helped to promote their elevated status. Mentors were responsible for identifying and forming girls' groups and leading the life-skills and livelihood sessions. Mentors also assisted schoolteachers in English and mathematics sessions by collecting digital attendance records and maintaining logistics to keep the digital class up and running. Mentors organized quarterly community group meetings with parents, schoolteachers, and SMC members to create a supportive environment for adolescent girls. The mentors received a two-week orientation training and regular on-the-job and refresher training throughout the project period. Training in small groups of mentors created networking opportunities among mentors and fostered group learning and problem-solving. Mentors received a monthly stipend from the project. Mentors potentially served as role models for other adolescent girls in the community and showed the capacity to challenge social barriers and community norms that limit girls' 
mobility. Investments in mentors thus strengthened leadership among local girls and ensured a knowledgeable and responsive young advocate for other adolescents inside the community.

\section{Education and skill-building interventions}

In-school girls followed a structured curriculum of $\mathbf{7 2}$ hours of mathematics, English, and life-skills education. Out-of-school girls received 72 hours of training in life skills, information and communication technology (ICT), basic health care, and financial literacy, adapted at appropriate literacy levels. Financial literacy and soft skills-based livelihood training included material to encourage nontraditional livelihood options and to encourage girls to aspire for greater education or employment opportunities.

Table 2. Education and skill-building intervention of KGIS

\begin{tabular}{lcc}
\hline Program component & $\begin{array}{c}\text { In-school girls } \\
\text { (Session hours) }\end{array}$ & $\begin{array}{c}\text { Out-of-school } \\
\text { girls } \\
\text { (Session hours) }\end{array}$ \\
\hline Gender and life skills & 24 & 24 \\
Education & & \\
- Math & 24 & --- \\
- English & 24 & ---- \\
Livelihood & & \\
• ICT & ---- & 18 \\
- Basic health care & --- & 18 \\
- Financial literacy & ---- & 12 \\
Total hours & $\mathbf{7 2}$ & 72 \\
\hline
\end{tabular}

\section{COVID-19 and Adaptation of Program Implementation}

Along with the rest of the world, Bangladesh has been adversely affected by the COVID-19 pandemic since March 2020. The government declared closure of all types of educational institutions on 18 March 2020. The intervention schools under this project have remained closed since then, halting all types of in-person field activities. To mitigate this loss and resume the skill-building interventions, a hybrid model of remote learning and limited inperson engagement (for instruction and distribution of study materials and worksheets) was developed with a particular view to reducing the negative effects of the girls' isolation from being detached from their schooling and girls' groups. Remaining mindful of the digital divide, sessions were held on group calls using regular mobile phones as opposed to smartphones and the internet. A study conducted by the Population Council among the targeted population found that only $20 \%$ of households own smartphones whereas over $95 \%$ of households own a regular mobile phone. Priority was given to the medium and method that can reach most adolescent girls and not to leave behind the most vulnerable, from poorest families, who are least likely to own smartphones. Small groups of 3-4 girls were formed for mentors to reach twice weekly over mobile conference calls for 15minute-long sessions. The intervention for the entire second year of project 
implementation continued in this mode, which was developed in consultation with the teachers from the intervention schools. In this adapted model, every girl in the intervention communities attended two remote learning sessions a week. While the same topics were covered, each session was limited to 15 minutes considering the limitations of phone-based sessions. The sessions were supplemented with handouts and written assignments which were assigned to girls once every two weeks. Assignments were distributed and collected by the mentors from their respective intervention schools and girls were given regular feedback.

The program intervention was delivered in two consecutive years, but the intervention years varied pre-COVID-19 and post-COVID-19 in timing and deliberation modality. The following table presents the commonality and distinctions between the modality and level of intervention pre- and post-COVID.

Table 3. Program implementation: Pre-COVID-19 and during COVID-19

\begin{tabular}{|c|c|c|}
\hline Components & $\begin{array}{l}2019 \text { session (pre-COVID-19 } \\
\text { period) }\end{array}$ & $\begin{array}{l}2020 \text { phone session (COVID-19 } \\
\text { period) }\end{array}$ \\
\hline $\begin{array}{l}\text { Session implementation } \\
\text { period }\end{array}$ & Mid-April to December 2019 & July 2020 to March 2021 \\
\hline Mode of deliberation & School-based in-person sessions & $\begin{array}{l}\text { Phone-based remote learning } \\
\text { sessions }\end{array}$ \\
\hline Session period & Mid-April to December 2019 & July 2020 to March 2021 \\
\hline Session curriculum & $\begin{array}{l}\text { For in-school sessions- } \\
\text { mathematics, English and life- } \\
\text { skills education. } \\
\text { For out-of-school sessions-life } \\
\text { skills, ICT, basic health, financial } \\
\text { literacy }\end{array}$ & $\begin{array}{l}\text { Same topics (tailored for } 15 \\
\text { minutes) } \\
{ }^{\star} \text { ICT and basic health practical } \\
\text { sessions could not be adapted for } \\
\text { the remote session }\end{array}$ \\
\hline Session duration & One hour & $\begin{array}{l}\text { 15-minute phone session } \\
\text { complemented with printed } \\
\text { handouts, worksheets }\end{array}$ \\
\hline Session facilitation & $\begin{array}{l}\text { For in-school girls- } \\
\text { schoolteachers } \\
\text { For out-of-school girls-mentors }\end{array}$ & Mentors \\
\hline $\begin{array}{l}\text { Frequency of session } \\
\text { and time }\end{array}$ & Twice a week, after school & $\begin{array}{l}\text { Twice a week, at convenience of } \\
\text { the girls (access to phone) }\end{array}$ \\
\hline
\end{tabular}

\section{Strengthening of school systems and community engagement}

Apart from equipping schools with digital devices and building capacity of schoolteachers on interactive and multimedia-based teaching, head teachers, the SMC, officials from education department, and local elected representatives were engaged from the start in designing and preparing for the project, including in the selection of the mentors. Community members were included in orientation workshops of the intervention at the upazila and district level. Officials from the Education Department, local government representatives, and members of the SMC, head teachers, and subject teachers were also engaged in preparing and implementing the action plan and reviewing progress. 
The project included targeted activities to engage community members at different points-during planning and preparation and throughout the intervention period. A key objective of engaging community members is to create an enabling environment for implementing the activities to promote support from the community and diffuse opposition. One community sensitization meeting was organized quarterly at each school in the first year of the intervention (2019). The meetings covered discussions on adverse effect of child marriage, the importance of education and work opportunities for girls, specific challenges faced by girls who perform poorly at school and risk of dropout, girls' mobility and safety, and how community can support the creation of an enabling environment for girls. The second year of the intervention was a challenging time because of the unprecedented COVID-19 pandemic, and community engagement suffered from school closures, restrictions imposed on mass gatherings, nationwide and localized lockdowns, and the oscillating situation of the pandemic in the country throughout 2020 and 2021 . In the second year of the intervention (2020 and 2021) parents were kept informed via mobile calls by the mentors and field staff, consultations with schoolteachers took place by way of virtual meetings (Zoom) and through mobile communications of project staff. In general, community interactions during the pandemic were much more limited relative to pracademic levels.

\section{Program Monitoring}

The study employed an extensive monitoring system to ensure smooth operation of the project activities and provide feedback for timely decision-making. The project activities were monitored through an online system in addition to physical monitoring by project staff. The Population Council developed a real-time online monitoring system for the program in the SurveyCTO platform. This cloud-based, android-friendly platform can show dashboards for all monitoring data which were particularly useful for managers who could track project activities immediately. These data were used as feedback loops on important matters (e.g., attendance, frequency of sessions, use of digital media, quality of sessions) to provide timely decision-making and solutions to programmatic challenges in the field. The data correspondingly served to document activities of the program in an efficient manner.

In addition, digital monitoring allows program implementers to show the exact location and time duration of each activity as well as a live photo of the session or event. This information allowed management to obtain an overall picture of project activities and ensured greater accountability of field staff. Project staff, donors, and implementers had open and equal access to this monitoring platform.

Two prescribed forms were developed as monitoring tools for the project to assess and monitor attendance and the quality of the sessions. These are (i) an attendance-tracking form for session participation, and (ii) an assessment form for measuring session quality.

Attendance-tracking form: The attendance form provided the individual girl's session attendance longitudinally. During each session, mentors registered attendance by scanning a unique bar code assigned to each girl's ID card using an android-based mobile phone and transmitting the attendance record to the SurveyCTO server. The associated dashboard 
allows remote visualization of attendance data, such as average number of girls in attendance by session, topic, and school, as well as with the date, time, duration and GPS locations. These entries were all either required for each session or generated automatically.

Quality-assessment form: Apart from the attendance form, a separate monitoring assessment form was developed to assess the management or quality of the sessions. Indicators in the form included: whether the mentor/teacher prepares adequately before the session, use of behavioral change communication (BCC) materials, use of digital materials, patience to conduct a session, use of practical examples, asking questions in order to identify the girls' knowledge and providing clear instructions during the session, etc. The form also had the option of measuring quality based on the abovementioned indicators through scoring. The data were analyzed and visualized in the dashboard to obtain an overall picture of the quality of the sessions.

Thus, the combined attendance and quality-assessment data helped to track ongoing progress and documented program activities and served as a historical record of the overall session performance for all 24 intervention schools.

During the COVID-19 pandemic, the program modality was adapted to virtual sessions with girls led by mentors, and accordingly a monitoring modality was also adapted. The monitoring attendance and quality forms were modified in SurveyCTO. In the session attendance form, girls who joined sent a screenshot of the conference call. The screenshot also registered the duration of the girls' participation in the session. At the same time, the quality-assessment form was also modified and updated accordingly.

Three district coordinators residing in the three districts ensured the smooth operation of the intervention by regular physical monitoring and through a monitoring app in SurveyCTO. In addition, program staff from Dhaka monitored activities periodically through in-person field visits over the first year of the intervention period and until the onset of the COVID-19 pandemic. In the second year of intervention during the pandemic, monitoring was continued virtually by joining the phone session. More details on monitoring data and lessons learned can be found in Appendix 1.

Figure 5. SurveyCTO monitoring app for a smartphone
Collect > Atten...

Name the topic of the session

- Life Skills class 7

English class 7

Mathematics class 7

Life Skills class 8

English class 8

Mathematics class 8

Life Skills out-of-school

Financial literacy

Basic Health screening

ICT

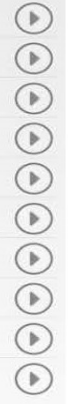

Figure 4. Attendance screenshot of phone session during COVID-19

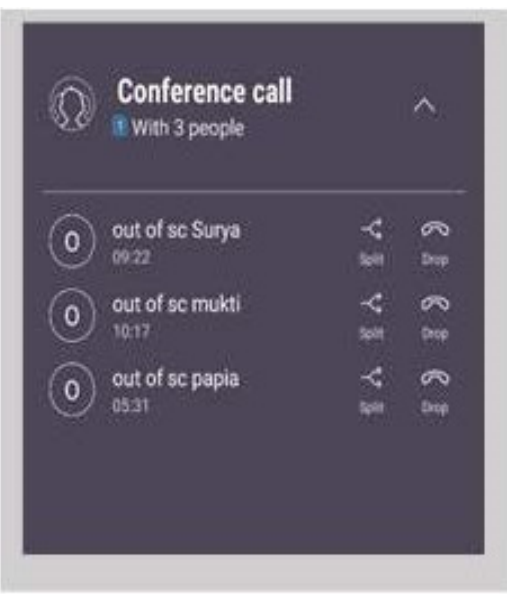




\section{RESEARCH DESIGN AND INTERVENTION ASSESSMENT}

To build an evidence base on the work to delay marriage, the KGIS project was aimed at keeping girls in school and reducing child marriage through skill development and a supportive social environment. The project, an intervention research study, tested a model by implementing intervention activities designed to bring about a change in child marriage norms prevalent in the area. It offered young girls a safe place to meet after school hours with mentors and teachers, as well as tutoring support and life-skills training.

The Population Council in collaboration with UNICEF implemented these activities at 24 intervention schools while 24 schools served as control sites not receiving the intervention.

\begin{tabular}{|l|c|c|}
\hline Intervention activities & $\begin{array}{c}\text { Intervention } \\
\text { arm }\end{array}$ & $\begin{array}{c}\text { Control } \\
\text { arm }\end{array}$ \\
\hline Tutoring and life-skills education to girls in grades 7 and 8 & Yes & No \\
\hline Livelihood and life-skills education to out-of-school girls & Yes & No \\
\hline $\begin{array}{l}\text { Implementation of digital classrooms and capacity- } \\
\text { strengthening of the teachers }\end{array}$ & Yes & No \\
\hline Strengthening the school management committee & Yes & No \\
\hline Engaging the community through sensitization meetings & Yes & No \\
\hline
\end{tabular}

There were two main questions of interest for the project: whether the community-based safe space program could be scaled up to the secondary school system; and whether, to conserve scarce resources, girls who had already dropped out or were underperforming in Grades 7 and 8 could be targeted with skills training rather than all adolescent girls, and whether, to reach more girls with these scarce resources, duration of program exposure could be reduced to 12 months for each cohort.

The study sought to measure the impact of the intervention at the community level through a rigorous repeated cross-sectional design with a baseline (2018) and an endline survey (2021). The program impact was measured by the changes in key outcomes of interest from baseline to endline by comparing aggregate levels of marriage, education, livelihood activities, and knowledge and behaviors related to SRHR in intervention and control areas. A table of the main outcomes with the indicators that have been used to measure impact is attached in Appendix 3.

\section{Intervention Assignment}

The original KGIS study was intended to test the model by using a cluster randomized controlled research design. The Population Council, in consultation with UNICEF, selected three districts for this study from eight high child marriage districts, previously identified by UNICEF as part of the "Education for Adolescents" program under Directorate of Secondary and HIgher Education of the Ministry of Education. UNICEF provided a list of the 60 secondary schools in six upazilas in three selected districts. For 60 UNICEF-selected 
schools, the Population Council generated random numbers using STATA and ranked these numbers from smallest to largest and assigned, first, 24 schools as the intervention arm, and, next, 24 observations to the control arm. The rest of the schools were excluded. After assigning these and in consultation with UNICEF some assigned schools were re-placed on the excluded list for not meeting the criteria set (details can be found in the baseline report [Ainul et al. 2020]). The following section highlights that the replacement of schools didn't affect the balance of the design.

\section{Summary of baseline and the balance across arms}

The study was scheduled to assess the change at the community level at two time points (baseline in 2018, and endline in 2021) by comparing aggregate levels of marriage, education, livelihood activities, and knowledge and behaviors related to SRHR. The surveys and analysis were to repeat in a cross-sectional design and not a panel. After collection of the endline data in 2021, the program impact was assessed using difference-in-differences (DiD), comparing changes in the intervention areas from baseline to endline to changes in control areas over the same period.

The following table provides results of the significance test between arms. We found the arms are balanced (at a 5\% level of significance) on selected indicators.

Table 4. Comparison of arms, for random allocation of schools, 2018 (in percent)

\begin{tabular}{lrrr}
\hline & \multicolumn{2}{c}{ Arm } & \\
Characteristics & 15.0 & 15.1 & 0.3291 \\
\cline { 2 - 3 } & Intervention & Control & P values \\
Mean age (years) & 15.1 & 15.0 & 0.4840 \\
Mean age at marriage (years) & 20.7 & 23.0 & 0.3229 \\
Girls who are married & & 76.9 & 0.5825 \\
Girls who are in school & 78.3 & & \\
Parental education & & 38.3 & 0.7501 \\
Mother has no education & 37.2 & 44.4 & 0.5989 \\
Father has no education & 42.6 & 1.2 & 0.2871 \\
Number of siblings (mean) & 1.3 & 65.4 & 0.8955 \\
Have Birth Registration Card & 68.2 & & \\
Household assets & & 93.4 & 0.5955 \\
Electricity & 94.7 & 53.6 & 0.7497 \\
Television & 55.5 & 97.2 & 0.8811 \\
Mobile phone & 97.3 & 3.8 & 0.3043 \\
Computer & 5.1 & & \\
Wealth quintile & & 20.0 & 0.8245 \\
Lowest & 20.5 & 22.4 & 0.0946 \\
Second & 18.6 & 20.6 & 0.4644 \\
Middle & 21.9 & 19.6 & 0.3552 \\
Fourth & 17.8 & 17.4 & 0.2291 \\
Highest & 21.2 & $\mathbf{1 5 4 7}$ & \\
$\mathbf{N}$ & $\mathbf{1 5 8 0}$ & & \\
\hline
\end{tabular}




\section{Sampling}

The endline survey was conducted among a representative sample of girls between the ages of 12 to 19 randomly chosen from girls living in the cluster of households surrounding the intervention and control schools at the time of the survey. Household clusters were identified for sampling purposes according to their proximity to the schools where the programs were to be located. The project restricted the sample to 12-19-year-old girls because of ethical considerations around interviewing younger girls.

Table 5. Sample size for population-based survey

\begin{tabular}{|l|c|c|c|c|c|c|}
\hline $\begin{array}{l}\text { Type of study } \\
\text { participants }\end{array}$ & Power $^{2}$ & $\begin{array}{c}\text { Number of } \\
\text { arms }\end{array}$ & $\begin{array}{c}\text { Clusters } \\
\text { per arm }\end{array}$ & $\begin{array}{c}\text { Cluster } \\
\text { size }\end{array}$ & $\begin{array}{c}\text { Total } \\
\text { clusters }\end{array}$ & $\begin{array}{c}\text { Total sample } \\
\text { for } 2 \text { arms }\end{array}$ \\
\hline Girls age 12-19 & 0.80 & 2 & 24 & 65 & 48 & 3,120 \\
\hline
\end{tabular}

At baseline, the household listing was conducted and girls 12-19 were sampled in the selected 48 clusters (unions) and information was collected from them. Nevertheless, in order to assess the impact at community level, the household listing and girls 12-19 in the same clusters were resampled again at endline. As a result of high mobility during the COVID-19 phase, we had to conduct a household re-listing. To identify potential respondents and develop a sample frame, the survey team listed households within two kilometers walking distance of the intervention school (the survey cluster). Approximately 700 households were listed in each cluster.

Using the software Optimal Design for Multi-level and Longitudinal Research, version 2.0 (HLM Software 2005-2009), we calculated, prior to baseline survey, that a minimum of 24 clusters (here union/school area) per arm and a sample of 65 adolescent girls in each cluster with 1,560 respondents per arm is sufficient to measure the impact of the program to detect $20 \%$ decline in the child marriage rate with an $80 \%$ power for a repeated crosssection survey design targeted to finding an impact at the community level.

\section{Ethical considerations}

The research protocol was approved by the Population Council Institutional Review Board (PC-IRB). The research team discussed and developed methods and procedural measures in relation to matters such as data-recording style, personal identifiers, transcription and processing procedures, the lifespan of unprocessed data, type and places of storage, and data safety and right to access. To maintain data confidentiality, all access to data is password-protected and strictly limited to the research team. Data were collected only after receiving informed consent from each respondent. Guardians' assent and participants'

\footnotetext{
2 The probability of rejecting the null hypothesis when it is actually false and should be rejected. In a perfectly implemented randomized experiment with correctly analyzed data, power is the probability of discovering a causal effect of treatment when such an effect truly exists.
} 
informed consent were obtained for minor unmarried girls (aged 12-17 years); married minor girls were considered emancipated minors and were able to consent to their own participation. All interviews were conducted in private. Confidentiality was maintained throughout the training of interviewers, including learning the definition of confidentiality and ways of maintaining confidentiality during data collection and afterward. Data were analyzed and presented with autonomy. The IRB approval letter is attached in Appendix- 4.

\section{Endline Data Collection}

\section{Quantitative}

The Population Council deployed 47 female interviewers and six female supervisors for the household listing and individual-level interviews. Each of them holds at least a bachelor's degree, mostly in social sciences. The team was closely supervised by staff members of the Population Council. All the supervisors and interviewers went through a rigorous in-person training session of five days about the survey questionnaire and mobile-based survey instrument, management of handheld devices, collecting data on GPS location, and other applications available as needed for the survey. The training also educated interviewers on general knowledge about the study area, the objectives of the research, and ethical issues in conducting research including the informed consent process prescribed by the IRB of the Population Council. Interviewers were trained extensively on how to conduct interviews and manage data security during data collection and afterward to ensure confidentiality and anonymity. Because of the COVID-19 pandemic, all of the interviewers and supervisors were tested negative before joining the in-house training. They were informed to follow guidelines given by the government and WHO during their field level data collection. Data were collected using smartphones and the mobile data-collection tool on a SurveyCTOaided, cloud-based platform. The endline survey includes 3,121 completed interviews.

\section{Qualitative}

To understand the effects of the COVID-19 pandemic on the study communities and to complement our quantitative data, the project also employed qualitative research. Qualitative data were collected remotely through telephone calls between January and February 2021. A total of 20 in-depth interviews (IDIs) were conducted with adolescent girls and 13 Key Informant interviews (KIIs) were conducted with schoolteachers, district and upazila secondary education officers, academic supervisors, and SMC members from three districts. The respondents for KIIs were sampled purposively, selecting those who were involved in the program from the beginning and knew the program well.

In-depth interviews were conducted with 20 adolescent girls (10 married and 10 unmarried) to understand the challenges they faced during the pandemic, and to understand its effects on their lives and well-being. Ten married program girls aged 13-16, who got married between March-December 2020 during the COVID-19 pandemic, were interviewed from three districts. The interviews focused on the context of their marriages, child marriage triggers, and related marriage rituals. For the IDIs with the unmarried respondents. Ten unmarried program girls were randomly selected from the three districts and were interviewed to understand the effect of school closures and capture the challenges faced in their education and learning. Data collectors followed ethical approval procedures for 
obtaining informed consent from all respondents. For unmarried adolescent girls under the age of 18, adolescent assent and parental consent were also obtained.

Table 6. Sample size by data-collection method

\begin{tabular}{|c|c|c|c|c|}
\hline & $\begin{array}{c}\text { IDI with } \\
\text { adolescent girls }\end{array}$ & $\begin{array}{c}\text { KII with } \\
\text { schoolteachers }\end{array}$ & $\begin{array}{l}\text { KII with secondary } \\
\text { education officials }\end{array}$ & $\begin{array}{l}\text { KII with SMC } \\
\text { members }\end{array}$ \\
\hline $\begin{array}{l}\text { Sample size } \\
\text { \& study } \\
\text { population }\end{array}$ & $\begin{array}{c}\mathbf{2 0} \\
\text { Adolescent girls } \\
(10 \text { married \& } 10 \\
\text { unmarried })\end{array}$ & $\begin{array}{c}\mathbf{6} \\
2 \text { teachers from } \\
\text { each district }\end{array}$ & $\begin{array}{c}\mathbf{5} \\
1 \text { District Education } \\
\text { Officer, } 2 \text { Upazila } \\
\text { Secondary Education } \\
\text { Officers; } 2 \text { academic } \\
\text { supervisor }\end{array}$ & $\begin{array}{c}\mathbf{2 S M C} \\
\text { members }\end{array}$ \\
\hline
\end{tabular}

\section{Data Analysis}

Quantitative data were extracted from the interviews and analyzed using STATA SE 15.1. We performed a difference-in-differences (DiD) analysis adjusting for key sociodemographic characteristic belonging to district (second level administrative boundaries of Bangladesh). After a number of trials, we selected a district only as other potential sociodemographic characteristics have strong correlation with district. DiD estimation compares the average changes in key outcomes between baseline $(t=0)$ and endline $(t=1)$ in the intervention groups, compared with average changes in the control areas over time, which provides evidence of program effectiveness (Gertler et al. 2011). The impact on an outcome measured for an adolescent "i" at time-point "t", $\boldsymbol{Y}_{\boldsymbol{i}}$ is estimated as follows:

$$
Y_{i t}=\alpha+\beta X_{i t}+\beta_{1} \text { Time }_{t}+\beta_{2} \text { Treat }+\gamma\left(\text { Time }_{t} \times \text { Treat }\right)+\varepsilon_{i t}
$$

Where,

$\mathrm{X}_{\mathrm{it}}$ is district identification for an adolescent "i" at time-point "t."

$\beta$ measures the effects of the covariates on the outcome for each of the two time points.

Time $_{\mathrm{t}}$ which is an indicator variable, equals 1 if the observation is measured at endline and 0 otherwise, which provides estimates of time trend common to control and intervention groups.

Treat equals 1 if respondent is assigned to be in the intervention strategy and 0 for the control group, which captures average differences between interventions and control. due to the program.

$\gamma$ constitutes the coefficient of interest, i.e., the additional change in outcome

$\varepsilon_{i t}$ is the difference between errors at time 1 and time 0

We also controlled our calculation for cluster effect of unions. 
Manual coding and word processors were used for organizing, coding, and thematic analysis of qualitative data. All qualitative interviews were recorded, and transcribed into Bengali. We followed an inductive and latent approach in thematic analysis of the transcripts. An initial codebook was prepared based on the data collection tools which we kept adding onto subthemes based on recurring themes emerging in the data. The codes were incorporated into broader themes they focused on based on the aspects of education/non-education outcomes of COVID-19 or the drivers of child marriage. Reviewing and comparing subgroups of transcripts led to simultaneous coding and further classification of the themes into subthemes. Afterward, selected quotes were translated into English, and the translated versions were compared with the Bengali version by another researcher to ensure no loss or misinterpretation happened during translation. Triangulation of data sets (IDIs and KIls) and triangulation from researchers were both part of the analysis of qualitative data. 


\section{COVID-19 AND ITS EFFECT ON THE LIVES OF ADOLESCENT GIRLS}

\section{Bangladesh COVID-19 Context}

In Bangladesh, the first COVID-19-positive patient was reported on 8 March 2020. The advent of COVID-19 triggered the closure of all educational institutions and after a long break of 543 days recently tens of thousands of students returned to school on 12 September 2021, amid the improvement of the coronavirus situation in the country and vaccination program picking up the pace.

Since onset, there have been more than 1.5 million confirmed cases of COVID-19 and more than 27,000 deaths as of September 2021 (WHO 2021). Meanwhile, since January 2021 more than 23 million citizens aged over 18 years have received the first dose and more than 15 million got a second dose of vaccine (DGHS 2021). Bangladesh has experienced the COVID-19 pandemic in three major waves (period of continuous rise to a peak followed by fall in number of confirmed daily cases and death tolls),

Profile of adolescent girls in COVID-19 survey

Round 1 (April 2020): 479 girls Round 2 (June 2020): 453 girls Round 3 (September 2020): 448 girls Average Age: 14 years In-school girls: $\mathbf{8 0 \%}$ Completed some secondary education: 91\%

Married girls (Round1): 7\% Participated in income generating activities (round1): $4 \%$ oscillating between varying degrees of infection rates in the last year and a half. Like other countries of the world, throughout the period, Bangladesh has taken several preventive steps to mitigate the spreading of virus infection since its onset, including declaration of a nationwide lockdown in several phases, a ban on passenger travel (by water, rail, and air), restrictions in localized movements, mass gatherings, limited operation and/or closing of financial and commercial institutions, factories etc. As part of the prevention plan, the decision of school closure was effective from 18 March 2020 which was later extended till 9 September 2021. Bangladesh has experienced the second longest COVID-19 school closure in the world and around 42 million enrolled students fell out of regular education for more than 77 weeks (UNICEF 2021).

\section{Rapid Survey with Adolescent Girls}

Three rounds of rapid surveys were conducted among a sample of program girls during the pandemic in 2020. The rapid surveys were done to assess the impact of COVID-19 on adolescent lives and to design and adapt our intervention model that would contribute to protecting girls while meeting through social distancing measures imposed by the government. The follow-up surveys also provided a snapshot of changes in lives of adolescent girls as the pandemic turned into a protracted crisis and started to raise multidimensional vulnerabilities of adolescent girls (Amin et al. 2020) Data collected from 
adolescent girls portrays their vulnerabilities in a myriad of different ways-economic, social, health, education, physical safety, and mental well-being.

\section{Table 7. Timeline of Bangladesh's response during the COVID-19 pandemic and adaptation of program implementation accordingly}

\begin{tabular}{|c|c|c|c|c|}
\hline Timeline of Pandemic & $\begin{array}{l}\text { Lockdown and } \\
\text { travel restrictions }\end{array}$ & Education response & Impact on economy & $\begin{array}{c}\text { Program } \\
\text { implementation } \\
\text { status }\end{array}$ \\
\hline $\begin{array}{l}\text { March-June } \mathbf{2 0 2 0} \\
\text { - } 8 \text { March: } 1^{\text {st }} \text { case } \\
\text { detected } \\
\text { - } 30 \text { June: } \\
\text { Total no. of cases- } \\
\text { 145,483 Total death- } \\
1847 \\
\text { Infection rate- } 20 \%\end{array}$ & $\begin{array}{l}\text { Lockdown Phase-1: } \\
\mathbf{2 6} \text { March-30 May } \\
\text { Domestic and } \\
\text { international flight } \\
\text { operations and } \\
\text { internal transport } \\
\text { suspended }\end{array}$ & $\begin{array}{l}\text { - All educational } \\
\text { institutions closed } \\
\text { from } 18 \text { March } \\
\text { - Televised classes } \\
\text { being broadcasted } \\
\text { from } 29 \text { March }\end{array}$ & $\begin{array}{l}\text { - All public and private } \\
\text { offices were closed } \\
\text { from } 26 \text { March- } 4 \\
\text { April. } \\
\text { - Offices resumed from } \\
31 \text { May. }\end{array}$ & $\begin{array}{l}\text { - } 1^{\text {st }} \text { round of survey } \\
\text { on COVID-19 KAP } \\
\text { conducted from 20- } \\
30 \text { April } \\
\text { - } 2^{\text {nd }} \text { round of survey } \\
\text { conducted from 12- } \\
22 \text { June } \\
\text { - Development of } \\
\text { adapted KGIS } \\
\text { sessions modules }\end{array}$ \\
\hline $\begin{array}{l}\text { July-December } \mathbf{2 0 2 0} \\
\text { 31 December: } \\
\text { - Total no. of cases- } \\
\quad 513,510 \\
\text { - Total deaths- } 7,559 \\
\text { - Infection rate- } 7.65 \%\end{array}$ & & $\begin{array}{l}\text { PEC, JSC and HSC } \\
\text { exams of } 2020 \\
\text { cohort canceled. } \\
\text { - Auto-promotion of } \\
\text { Primary and } \\
\text { Secondary students } \\
\text { declared } \\
\text { - Provision of weekly } \\
\text { assignments to the } \\
\text { students started. }\end{array}$ & $\begin{array}{l}\text { All kinds of restrictions } \\
\text { on public movement } \\
\text { and activities } \\
\text { withdrawn from } 1 \\
\text { September'2020. }\end{array}$ & $\begin{array}{l}\text { - KGIS Remote } \\
\text { learning sessions } \\
\text { started from } 1 \text { July } \\
2020 \\
\text { - } 3^{\text {rd }} \text { round of COVID- } \\
19 \text { survey on } \\
\text { adolescent girls } \\
\text { conducted from 5-11 } \\
\text { September }\end{array}$ \\
\hline $\begin{array}{l}\text { January - March } 2021 \\
\text { - Countrywide COVID- } \\
19 \text { vaccination started } \\
\text { from } 7 \text { February } \\
\text { - } 31 \text { March: } \\
\text { Total no. of cases- } \\
611,295 \\
\text { Total death- 9,046 } \\
\text { Infection rate- } 20 \% \\
\end{array}$ & & $\begin{array}{l}\text { Assessment based on } \\
\text { assignments continued } \\
\text { for academic year } 2021 \\
\text { All educational } \\
\text { institutions remained } \\
\text { closed }\end{array}$ & & $\begin{array}{l}\text { KGIS Remote learning } \\
\text { sessions ended on } 31 \\
\text { March } 2021 .\end{array}$ \\
\hline $\begin{array}{l}\text { April - August } \mathbf{2 0 2 1} \\
\text { - 2nd wave lasted till } \\
\text { mid-May, 3rd wave } \\
\text { lasted from mid-May } \\
\text { to August. } \\
\text { - } 31 \text { August: } \\
\text { Total no. of cases- } \\
\text { 1,500,618 } \\
\text { Total death- } 26,195 \\
\text { Infection rate- } 12 \%\end{array}$ & $\begin{array}{l}\text { Lockdown Phase-2: } \\
\text { 14-28 April } \\
\text { - Domestic and } \\
\text { international flight } \\
\text { operations, and } \\
\text { internal transport } \\
\text { suspended } \\
\text { - Bangladesh-India } \\
\text { border closed as } \\
\text { of } 25 \text { April } 2021 \\
\text { Lockdown Phase-3: } \\
\text { 1-14 July, and 23 } \\
\text { July - 10 August } \\
\text { Domestic and } \\
\text { international flight } \\
\text { operations, and } \\
\text { internal transport } \\
\text { suspended }\end{array}$ & $\begin{array}{l}\text { SSC and HSC } \\
\text { examinations } \\
\text { declared to be held in } \\
\text { November and } \\
\text { December } \\
\text { respectively. } \\
\text { All educational } \\
\text { institutions remained } \\
\text { closed }\end{array}$ & $\begin{array}{l}\text { - Factories including } \\
\text { RMG units shut down } \\
\text { from } 23 \text { July }-5 \\
\text { August } 2021 \text {. } \\
\text { - Lockdown lifted after } \\
11 \text { August } 2021 \text {. }\end{array}$ & $\begin{array}{l}\text { Endline survey } \\
\text { conducted from } 22 \\
\text { May-28 July } 2021\end{array}$ \\
\hline $\begin{array}{l}\text { September } \mathbf{2 0 2 1} \text { and } \\
\text { onward } \\
\text { 26 September: } \\
\text { Total no. of cases- } \\
\text { 1,550,371 } \\
\text { Total death- } 27,393 \\
\text { Infection rate: } 4.59 \%\end{array}$ & & $\begin{array}{l}\text { Schools and colleges } \\
\text { reopened as of } 12 \\
\text { September; } \\
\text { Universities permitted } \\
\text { to reopen after } 27 \\
\text { September }\end{array}$ & & \\
\hline
\end{tabular}




\section{Household finances and food insecurity}

The very first shock that girls and their families experienced with the onset of pandemic and lockdown measures are the effect on their households' finances and food shortages. At the beginning of the pandemic in Round 1 of data collection, half of the respondents said that their household income had stopped during the lockdown period and one-fifth reported an urgent need for food. Later in subsequent follow-up surveys a gradual recovery of household income was reported with cessation of lockdown but economic and food insecurity continued to be a major concern for girls and their families. Girls reported less protein intake in terms of

"My father couldn't go out during lockdown, there was a lot of trouble. Only we could understand the damage that my father has suffered during the pandemic. Earlier we used to have three meals every day, but during the pandemic we could afford two or even one meal a day, and sometimes we had to starve the whole day." (IDI-M-5, married girl, 17 years old, Chapainawabganj). eggs, meat, and fish; buying fewer household goods; and not seeking health services.

\section{Figure 6. COVID-19 impact on adolescent girls' mental health}

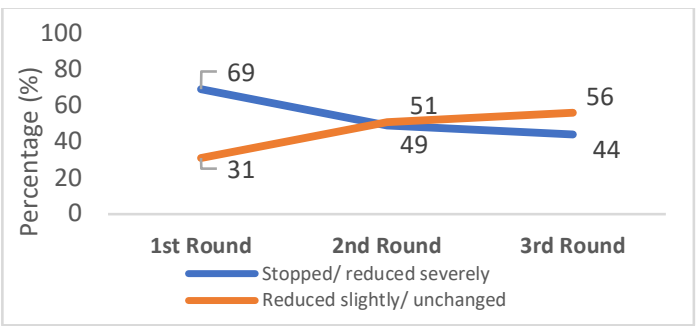

Household income trend during COVID-19

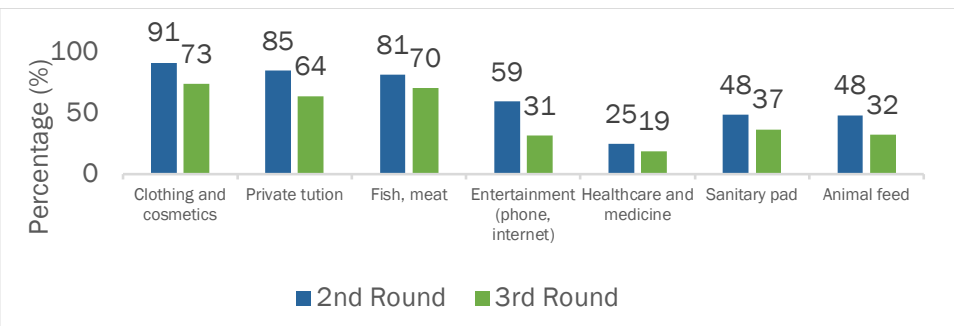

Cutting back on consumption during COVID-19

\section{School Closure and Learning}

Repeated surveys with adolescent girls clearly depict how prolonged school closures took a toll on their education. Girls reported spending an average of two hours in study compared to 7-8 hours spent in study prior to the COVID-19 pandemic and school closure. Classes broadcast by the Ministry of Education over national television were not widely followed throughout (21\%, 16\%, and 34\% in Round 1, Round 2, and Round 3, respectively).

In in-depth interviews with adolescent girls, teachers described challenges they faced including not having access or availability of digital media, not knowing the class routine, not being able to ask questions, and not being able to follow the pace of presentation of the digital class, among others. A majority of the girls reported selfstudy with some help from family members and a percentage of girls who reported "not
"I used to attend televised classes. But I didn't always have the routine, as broadcast on different days. The English classes would span between 10 to 15 minutes. So, I couldn't understand that subject well. Moreover, I couldn't get enough time to note down the homework quickly. It wasn't possible in televised classes." (IDI-UM-15, in-school girl, 15 years old, Grade 8, Chapainawabganj). classes for different subjects were 
studying at all" increased from $1 \%$ to $5 \%$ to $10 \%$ (in Round 1, Round 2, and Round 3, respectively) within the first six months of school closure.

Anxiety about automatic grade promotion was evident; most girls (63\%) expressed fear about not keeping up with the next grade's lesson. One in 10 girls said they might not go back to school after reopening for reasons including gaps in learning, household economic problems, and marriage.

\section{Time Use, Health, and Well-Being}

The survey sought to understand how the pandemic and associated school closures has impacted girls' time use and shift in their time distribution between domestic work and care responsibilities, learning, and education, etc. About 1 in 5 girls reported increased household chores during the pandemic and about 1 in 10 girls reported increased caregiving for a family illness. Increased tension, abuse, and violence was reported by girls as the pandemic protracted. Twelve percent of girls reported observing increased violence in their community in the past month-which was reported by $3 \%$ in the initial months of the pandemic (in Round 1). Also, 1\% to $3 \%$ adolescent girls reported facing some form of violence (rebuke, anger, beating) at their parental home across these three rounds. Nearly 8 in 10 adolescent girls reported feeling depressed sometimes or most of the time which was found to be increasing between rounds.
"There was no other reason other than the pandemic. I was staying idle at home. That is why everyone used to send a marriage proposal telling my parents that all the girls in the neighborhood were bad, and their daughter is good." (IDI-M-6, married girl, 16 years old, Sherpur).

"Many girls in our community have gotten married, child marriages have occurred, as parents could not afford to continue their daughters' study. When they went to school, they would have listened to teachers to continue their daughters' education. But since the school was closed, contact with teachers was lost, so many parents may have got their daughter married. There's been a lot of problems like this." (IDI-UM-17, unmarried girl, 15 years old, Grade 9, Kushtia)

Figure 7. COVID-19 impact on adolescent girls' mental health

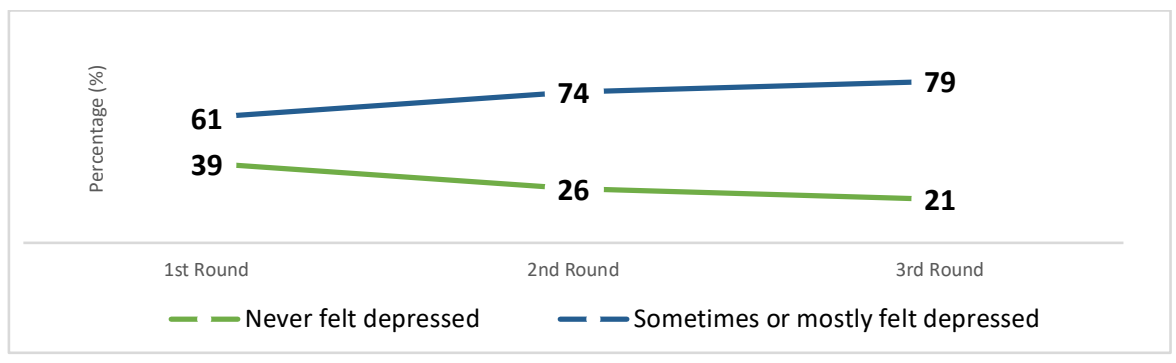




\section{Child Marriage}

In later rounds of the COVID-19 rapid survey, girls reported an increase in their own marriages and marriages of their peers in the community. More girls also reported hearing their parents talk about their marriage plans.

Figure 8. COVID-19 and risk of child marriage

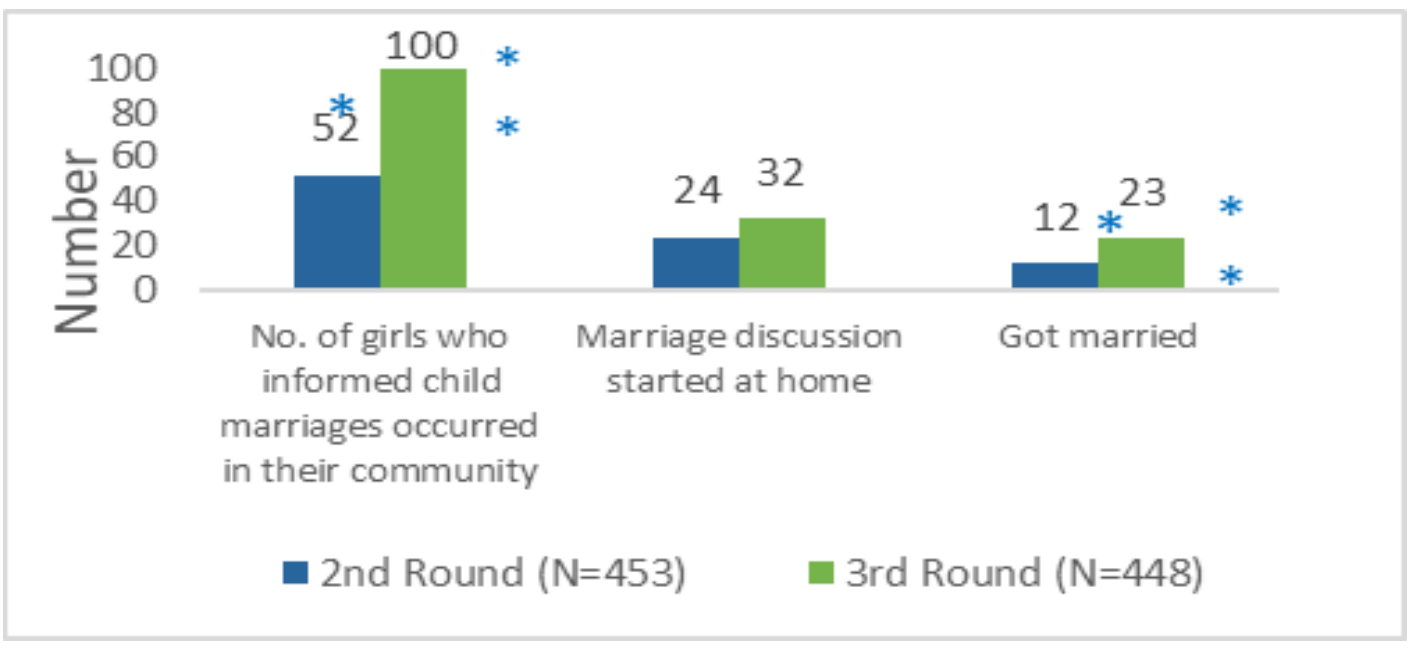

While the country was struggling to mitigate waves of COVID-19, adolescent girls and their needs remained nearly invisible in responses to the COVID-19 pandemic and in planning. In a conservative society like Bangladesh where girls' mobility is restricted, school closure manifested into much broader implications for adolescent girls.

It did not only cause disruption to their education, it also translated to girls' confinement in their homes and isolation from their peers, teachers, and the social safety net and posed are increased risk of financial and social insecurity, violence, child marriage, and negative effects in mental health which were documented during pandemic.

"During school closure children are staying at home idle and parents with poor income would try to reduce the burden by organizing the marriage of their daughter and for their son involving them in work. But if the school was functional, parents would not have the scope of thinking of their children as a burden... There are possibilities for getting involved in love relations at immature ages which I think is also a main reason for organizing early marriage of girls" (KII 6, Teacher, Chapainawabganj) 


\section{Survey with Parents of Adolescent Girls}

A phone survey was conducted with a subsample of parents of the adolescent girls interviewed at the endline. The Parent Survey was aimed at gaining perspective to assess the financial and social impact of the pandemic on households, families, and adolescent girls. In total 1,563 parents were interviewed.

Table 8 summarizes the responses of parents. Findings from the Parent Survey corroborates findings from rapid surveys with adolescent girls. Half of the respondents (parents) reported that their family income stopped or was reduced drastically while the other half reported having managed to keep well financially during the pandemic. A major concern of

\section{Proffle of the Parents}

No. of parents surveyed: 1563

Mother: 797

Father: 766

Average age

Mother: 39 years

Father: 46 years

Education

-No education

(Mother: 27\%, Father: 38\%) parents during the pandemic was reported to be education of their children (68.6\%), increased food prices and decreased income (60\% and $49 \%$, respectively), followed by mental stress and concern around uncertainty (50\%) and fear of COVID-19 infection (37\%).

A majority (95\%) of parents acknowledged that the daily life of their adolescent daughters was strongly affected by the pandemic. About three-fourth of parents (76\%) reported observing frustration observed among their adolescent daughters and two-thirds of parents (66\%) reported their girls were detached from their studies. Parents also reported increased household work for adolescent girls (27\%) and 5\% reported that their daughter experienced domestic violence, abuse, or beatings.

Limited awareness was found among parents about remote initiatives taken by the government to enable continuation of studies during school closure. Only $37 \%$ of parents were aware of initiatives being taken by authorities to continue classes and among these $37 \%$ of parents, a majority could only mention students' assignments directed by the government at the end of school year. Overall, less than $15 \%$ of interviewed parents knew about classes through TV and social media which continued throughout the year. This finding corroborates the limited exposure of adolescent girls to televised classes reported by adolescent girls in rapid phone surveys, and highlights how parents were also not informed enough to give the required support to their children to attend online classes broadcast on national television and on other digital platforms.

Three-fourths of parents (77\%) opined that school closure would increase the chances of girls dropping out. At the time of the interview 38\% of parents reported their adolescent girls had stopped studying and $5 \%$ reported their daughter had gotten married already. Half of the parents (52\%) reported incidents of child marriage in their neighborhood. 
Mishu (pseudonym) was a 14-year-old student in Grade 7 when she got married to one of her distant cousins amidst the COVID-19 pandemic in 2020. Before lockdown started, she used to lead the life of a regular schoolgoing adolescent girl-waking up in the morning, saying her prayers, having breakfast prepared by her mother, attending school and meeting with friends, attending private tuition, and studying again. These happy days of her life changed drastically with the outbreak of the pandemic. When the schools closed during the pandemic, Mishu was confined within her home. In addition to that, her mother was diagnosed with a cardiac illness. Mishu got involved in household chores and taking care of her mother instead of studying. Her father was the only earning member in their family. During the pandemic, they couldn't go out of their house. This affected their family income and forced them to go through financial hardship.

On the other hand, before the pandemic, Mishu's husband used to work in Dhaka. Then in May 2020, after the offices were shut down, he returned to his village unemployed, and came to visit Mishu's family. He took a liking to her and sent a proposal to her parents. The groom's family didn't demand any dowry. Also, the ongoing lockdown implied that the wedding ceremony would be arranged on a much smaller scale, meaning less expense on the bride's parents' end. Considering all of these options along with their own financial insolvency, the proposal seemed lucrative to Mishu's parents. It never occurred to Mishu to disagree for once with her parents' decision, as she believed she was obliged to them for her upbringing. So she had to give her consent in the marriage.

The marriage was arranged suddenly, within 4-5 days. As Mishu was 14 years old at that time, they had problems registering at their own locality. So, she got married at her maternal grandmother's house. A man called the Kazi there to preside over the marriage. Though the Denmohor (amount of money pledged to be paid to the bride by the bridegroom in a Muslim marriage) was fixed to be 80,000 Taka (approximately 934 USD), only half the amount (around 467 USD) was paid to her during the wedding, the rest being promised to be paid later. Because of the pandemic, the marriage ceremony was arranged on a small scale with only 15-20 people. Still Mishu's father had to take out loans and sell a goat to arrange the ceremony. Though the groom's family didn't demand any expensive dowry, Mishu's father gave winter clothing and quilts as gifts.

Mishu and her parents did not want her to get married so soon. She wanted to pursue her studies. But in her own words, her world "turned upside down" after her marriage. Her husband and in-laws did not allow her to study anymore, as they think that looking after the family is her only responsibility now. Her household workload has increased since marriage. Now every morning she sweeps the house, cleans dishes, prepares meals for everyone, i.e., she has to do all the household chores. She anticipates that this workload will increase even more after she becomes a mother in the future. She is not allowed to go out of the house now as she maintains Purdah. Now she doesn't have any friend other than her husband to share her feelings and thoughts. 
Indicators

Impact on family's income

Stopped/reduced severely 49.9

Unchanged/reduced slightly 50.1

$N$ (all respondents)

Kind of impact school closure had on adolescent girls' daily lives†
Staying at home has increased stress and frustration

Children have become detached from studies 65.7

The pressure of household work has increased 26.9

Communication with the outside world /friends has stopped /decreased 18.7

Girls are experiencing domestic violence/ abuse/beatings 5.4

$N$ (among those who said daily life was impacted)

Opined that school closures would increase girls' chances of dropping out of school 76.5 $N$ (all respondents)

Awareness of initiative taken by the government to continue lessons during school closure 37.3

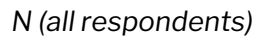

Knowledge of initiatives taken $\dagger$

Assessment of students' assignments as directed by the Board of Education 82.8

Taking classes through TV and social media (Facebook/Zoom/WhatsApp/ Viber) 37.0

Taking classes via phone 15.1

$N$ (among those who knows about initiatives)

Effect on daughter's education due to school closure $†$

Lessons seems hard due to long gap $\quad 80.3$

Dropped study due to long gap $\quad 37.6$

Got married so dropped from study $\quad 4.5$ (65)

$N$ (among in-school girls' parents)

Reported incidents of child marriage in your village/neighborhood during the pandemic? 51.6 $N$ (all respondents)

Kind of social impact the COVID-19 global pandemic had on the community? † $\begin{array}{lr}\text { Halt of education } & 77.2 \\ \text { Unemployment increased } & 70.6\end{array}$

$\begin{array}{lr}\text { Child marriage increased } & 37.2\end{array}$

$\begin{array}{lr}\text { Insecurity increased } & 13.7\end{array}$

$\begin{array}{lr}\text { Tension/quarrels have increased in the family and all around } & 22.8\end{array}$

Crime is increasing in the area /neighborhood $\quad 16.4$

Restricted/limited my social life $\quad 40.3$

$N$ (all respondents)

Main concerns during the COVID-19 pandemic †
Education of the children

$\begin{array}{ll}\text { Education of the children } & 68.6 \\ \text { Losing job /decrease in income } & 49.3\end{array}$

$\begin{array}{lr}\text { Increase in food price } & 60.2 \\ \end{array}$

$\begin{array}{lr}\text { Uncertainty/mental Stress } & 50.4\end{array}$

$\begin{array}{lr}\text { COVID-19 infection } & 37.1\end{array}$

$\begin{array}{lr}\text { Lack of healthcare services } & 19.8\end{array}$

$N$ (among respondents with concerns)

Effects of the COVID-19 pandemic on the family †
Reduced earnings/lost job

$\begin{array}{lr}\text { Worry about children's education } & 62.0\end{array}$

$\begin{array}{lr}\text { Restricted/limited my social life } & 30.2\end{array}$

$\begin{array}{lr}\text { Worry about exposure at home/work } & 22.0\end{array}$

Family member got sick $\quad 5.7$

$N$ (among those whose family has been affected)

Feeling lonely, depressed, or irritable during COVID-19
Most of the times

$\begin{array}{lr}\text { Sometimes } & 51.8\end{array}$

$\begin{array}{lr}\text { Never } & 10.4\end{array}$

$N$ (all respondents)

†Multiple responses 


\section{PROGRAM IMPACT}

\section{Education and Learning Outcomes}

This section reports on the indicators that describe respondents' education level, current schooling status, discontinuation of schooling, and access to private tutoring. It also describes learning outcomes based on assessment of girls' competency levels. Data related to education collected in baseline and endline surveys are discussed in terms of comparison between intervention and control arms.

\section{Education status of girls}

Table 9 shows that it is nearly universal among girls aged 12-19 to have ever attended school, regardless of area and survey time. Only about one percent of the girls have never attended school with almost no difference between intervention and control areas in both baseline and endline.

Over the period, a positive result is observed in increasing school enrollment in the intervention area with a DiD of 4.9 percentage points. The proportion of in-school girls increased from $78 \%$ to $82 \%$ in intervention area leading to a decline in the proportion of out-of-school girls from $21 \%$ to $17 \%$. On the other hand, the percentage of in-school and out-of-school girls stayed almost the same in the control area.

The findings also suggest that school enrollment decreases with age. Around $90 \%$ of girls aged 12-15 attend school, but this rate decreases sharply among girls aged 16-19. School enrollment is almost identical in intervention and control areas for both younger and older girls at baseline, but at endline, there is a notable increase in enrollment among older girls in the intervention area, indicating a positive impact on enrollment by the intervention program. This impact is also reflected through a greater increase in the mean number of schooling years among intervention girls $(0.28$ years in the intervention vs. 0.21 years in the control group).

Looking at the highest grade completed by the respondents shows variations in distribution between baseline and endline. Among in-school girls, the highest proportions were in Grades 6 and 7 at baseline, while at the endline the highest proportion is in Grade 9, which is an inspiring sign of more girls staying in school at an older age.

Among out-of-school girls, the largest proportion drop out after completing Grade 7. This may be because of the fear of appearing for Junior School Certificate (JSC) exams at the end of Grade 8, highlighting a large group of girls in need of further intervention to keep them in school. 
Table 9. Percentage of adolescent girls by schooling status, according to study arm and survey time

\begin{tabular}{|c|c|c|c|c|c|}
\hline \multirow[t]{2}{*}{ Schooling status } & \multicolumn{2}{|c|}{ Baseline } & \multicolumn{2}{|c|}{ Endline } & \multirow[b]{2}{*}{ DiD } \\
\hline & Intervention & Control & Intervention & Control & \\
\hline Never attended school & 0.8 & 0.8 & 1.2 & 0.4 & 0.8 \\
\hline Currently in school & 78.4 & 76.9 & 82.1 & 76.4 & 4.1 \\
\hline Attended in past, discontinued & 20.9 & 22.4 & 16.7 & 23.1 & $-4.9 *$ \\
\hline$N$ & 1580 & 1547 & 1563 & 1558 & \\
\hline \multicolumn{6}{|l|}{ Age group } \\
\hline $12-15$ (Currently in school) & 91.9 & 89.9 & 92.8 & 93.8 & -3.0 \\
\hline$N$ & 968 & 923 & 922 & 874 & \\
\hline 16-19 (Currently in school) & 56.9 & 57.5 & 66.6 & 54.2 & $13.3^{* \star}$ \\
\hline$N$ & 612 & 624 & 641 & 684 & \\
\hline Average number of years in school/ & 7.03 & 7.09 & 7.31 & 7.30 & 0.06 \\
\hline \multirow{2}{*}{\multicolumn{6}{|c|}{$\begin{array}{l}\text { Mean no. of years of education completed } \\
\text { Highest grade completed (for enrolled) }\end{array}$}} \\
\hline & & & & & \\
\hline Less than Grade 5 & 9.3 & 9.9 & 7.3 & 6.3 & \\
\hline Grade 5 & 13.6 & 11.9 & 12.5 & 11.2 & \\
\hline Grade 6 & 18.4 & 15.7 & 12.5 & 16.0 & \\
\hline Grade 7 & 16.3 & 18.3 & 16.4 & 18.1 & \\
\hline Grade 8 & 12.9 & 14.6 & 15.3 & 14.1 & \\
\hline Grade 9 & 13.7 & 14.1 & 22.1 & 21.7 & \\
\hline More than Grade 9 & 15.8 & 15.6 & 13.9 & 12.6 & \\
\hline & 1238 & 1189 & 1283 & 1191 & \\
\hline \multicolumn{6}{|c|}{ Highest grade completed (for unenrolled) } \\
\hline Less than Grade 5 & 17.6 & 17.1 & 16.5 & 11.7 & \\
\hline Grade 5 & 13.6 & 16.2 & 11.5 & 12.5 & \\
\hline Grade 6 & 15.2 & 14.2 & 13.8 & 14.4 & \\
\hline Grade 7 & 23.3 & 21.4 & 25.7 & 21.9 & \\
\hline Grade 8 & 11.8 & 13.9 & 14.2 & 15.8 & \\
\hline Grade 9 & 8.2 & 7.5 & 8.8 & 12.2 & \\
\hline More than Grade 9 & 10.3 & 9.8 & 9.6 & 11.4 & \\
\hline $\mathrm{N}$ & 330 & 346 & 261 & 360 & \\
\hline
\end{tabular}

\section{Reasons for leaving school}

Respondents who were no longer in school were asked to provide the main reasons for dropping out. Findings show that the primary reason is marriage. The intervention-control gap in reporting marriage as the reason for school discontinuation was negligible at baseline (3.2\%) but was noteworthy at the endline (15.7\%) due to an increase in the control area, while it stayed the same in the intervention area with a significant DiD of 12.3 percentage points. 
"Many girls are getting married. There is nothing to do at home, no pressure to study. Boys don't study much either. They either work on the farms or go out to work. This is how many students are dropping out.

It's been a long time since the school was closed. Those who are not very good at studies, who are not focused on studies, are going to work. If the school was open, they would have studied. Teachers would forbid them to work. Now even teachers can't say anything." (IDI-UM-18, unmarried girl, age unknown, Class-9, Chapainawabganj).

Other reported reasons for dropping out of school include cost of schooling, lack of interest, poor school performance, thinking higher education is not needed, and household chores, most of which slightly increased between baseline and endline. This can be attributed to prolonged school closure as a result of the COVID-19 pandemic.

Approximately one-fifth of school dropouts occurred at the primary level. At the secondary level, girls who had last attended Grade 8 comprised the highest proportion of girls who were no longer in school.

“We couldn't learn or know anything because of auto-promotion, we were promoted up from one class to another. We couldn't learn the lessons of the previous class anymore. We can't attend the classes of the previous grade anymore. So, the books of the new class will be difficult. Aren't we harmed this way?" (IDI-UM-12, unmarried girl, age unknown, Class9, Sherpur).

Table 10. Percentage of adolescent girls who have left school, by reason for discontinuation, according to study arm and survey time

\begin{tabular}{|c|c|c|c|c|c|}
\hline \multirow{2}{*}{$\begin{array}{l}\text { Discontinuation } \\
\text { characteristic }\end{array}$} & \multicolumn{2}{|c|}{ Baseline } & \multicolumn{2}{|c|}{ Endline } & \multirow[b]{2}{*}{ DiD } \\
\hline & Intervention & Control & Intervention & Control & \\
\hline \multicolumn{6}{|l|}{$\begin{array}{l}\text { Reasons for school } \\
\text { discontinuation } \dagger\end{array}$} \\
\hline Got married/marriage arranged & 67.6 & 70.8 & 67.4 & 83.1 & $-12.3^{\star *}$ \\
\hline Costs of schooling & 18.8 & 17.6 & 24.9 & 19.4 & 4.3 \\
\hline Poor school performance & 8.5 & 8.1 & 9.6 & 4.4 & 4.7 \\
\hline Lack of interest & 10.0 & 9.0 & 22.6 & 11.7 & 9.9 \\
\hline $\begin{array}{l}\text { Thinks higher education is not } \\
\text { needed }\end{array}$ & 3.3 & 3.8 & 8.1 & 5.8 & 2.6 \\
\hline Household chores & 2.7 & 3.5 & 3.5 & 2.2 & 2.0 \\
\hline \multicolumn{6}{|l|}{$\begin{array}{l}\text { Last grade attended before } \\
\text { discontinuation }\end{array}$} \\
\hline Up to Grade Five & 21.2 & 20.5 & 21.5 & 15.6 & 5.2 \\
\hline Grade Six & 13.6 & 15.0 & 10.7 & 11.9 & 0.2 \\
\hline Grade Seven & 16.4 & 15.6 & 19.9 & 16.1 & 3.1 \\
\hline Grade Eight & 20.9 & 20.5 & 21.1 & 23.1 & -2.4 \\
\hline Grade Nine & 13.9 & 16.5 & 18.8 & 20.0 & 1.3 \\
\hline SSC or higher & 13.9 & 11.9 & 8.1 & 13.3 & -7.4 \\
\hline$N$ & 330 & 346 & 261 & 360 & \\
\hline
\end{tabular}

${ }^{\star \star *} \mathrm{p}<.001,{ }^{\star \star} \mathrm{p}<.01,{ }^{\star} \mathrm{p}<.05$. †Multiple responses. DiDs were calculated controlling for district effect. 


\section{Status of private tutoring}

In Bangladesh, it is common practice to receive private tutoring in addition to attending regular school. During the surveys, respondents were asked whether they were currently receiving private tutoring beyond school hours. Nearly 80 percent of girls reported being privately tutored at baseline, but this rate dropped drastically in endline due to the pandemic. Table 11 indicates that the likelihood of receiving private tutoring is associated with household wealth and parental education. Girls from wealthier households and whose parents are more educated were more likely to be privately tutored than girls from poorer households and whose parents are less educated.

No noticeable difference in percentages of girls receiving private tutoring can be found between the intervention and control areas at baseline, regardless of age, wealth, and parental education. However, at the endline, the percentage receiving private tutoring dropped less in the intervention areas compared to the control areas, which may be a result of the program intervention.

Table 11. Percentage of adolescent girls who are privately tutored, by age, wealth, and parental education, according to study arm and survey time

\begin{tabular}{|c|c|c|c|c|c|}
\hline \multirow[t]{2}{*}{ Variable } & \multicolumn{2}{|c|}{ Baseline } & \multicolumn{2}{|c|}{ Endline } & \multirow[b]{2}{*}{ DiD } \\
\hline & Intervention & Control & Intervention & Control & \\
\hline Currently privately tutored & 77.2 & 77.1 & 47.8 & 34.4 & 13.3 \\
\hline$N$ & 1005 & 995 & 1003 & 959 & \\
\hline \multicolumn{6}{|l|}{$\begin{array}{l}\text { Age group (Currently privately } \\
\text { tutored) }\end{array}$} \\
\hline $12-15$ & 78.0 & 80.5 & 52.4 & 37.7 & 17.3 \\
\hline $16-19$ & 75.1 & 69.2 & 38.6 & 27.0 & 6.0 \\
\hline \multicolumn{6}{|l|}{$\begin{array}{l}\text { Wealth quintile (Currently } \\
\text { privately tutored) }\end{array}$} \\
\hline Lowest & 73.6 & 73.0 & 39.7 & 26.3 & 12.8 \\
\hline Second & 69.4 & 74.4 & 36.1 & 28.5 & 13.0 \\
\hline Middle & 75.6 & 73.6 & 46.2 & 33.5 & 10.1 \\
\hline Fourth & 81.9 & 76.8 & 47.1 & 37.8 & 4.2 \\
\hline Highest & 83.2 & 86.6 & 62.9 & 45.0 & 21.5 \\
\hline \multicolumn{6}{|l|}{$\begin{array}{l}\text { Mother's education (Currently } \\
\text { privately tutored) }\end{array}$} \\
\hline No education & 72.3 & 71.0 & 36.6 & 26.4 & 9.2 \\
\hline Primary or less & 73.0 & 77.7 & 40.2 & 31.5 & 13.5 \\
\hline Secondary incomplete & 84.2 & 82.6 & 54.6 & 37.2 & 15.8 \\
\hline Secondary complete or higher & 82.6 & 83.1 & 62.1 & 55.4 & 7.6 \\
\hline \multicolumn{6}{|l|}{$\begin{array}{l}\text { Father's education (Currently } \\
\text { privately tutored) }\end{array}$} \\
\hline No education & 72.9 & 71.8 & 38.3 & 27.3 & 9.9 \\
\hline Primary or less & 76.3 & 78.7 & 41.3 & 34.1 & 9.8 \\
\hline Secondary incomplete & 80.9 & 84.5 & 56.3 & 42.1 & 17.8 \\
\hline Secondary complete or higher & 84.8 & 79.7 & 62.4 & 47.4 & 10.0 \\
\hline$N$ & & & & & \\
\hline
\end{tabular}




\section{Learning outcomes}

The baseline and endline surveys attempted to measure learning outcomes by assessing the competency level of the girls who ever attended school. Competency was assessed through a small test of math, English and Bangla questions in both areas during baseline and endline surveys.

Analytical competency was assessed with mathematical questions on addition, subtraction, multiplication, division, fraction manipulation, and several conceptual and word problems for a total of 19 questions. Language competency was assessed by asking the respondent to read two Bangla and two English statements. All participants were asked the same questions in both surveys, regardless of schooling, grade, or age. Correct answers were converted into a composite score, with a total of 23.

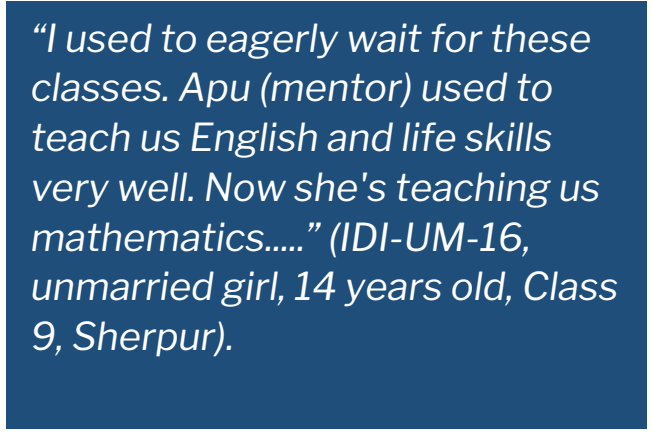

Table 12 demonstrates a comparison in average competency scores (language, analytical, and total) between intervention and control areas over the period. As expected, the average competency score was higher among in-school girls than out-of-school girls. This may be because girls who are not in school are susceptible to de-learning as correct mathematical calculation depends on regular practice. Analyses of learning-loss data suggest there was significant learning loss during COVID-19. It is evident that the average score declined more for in-school girls than out-of-school girls across the areas. This is likely because school closure has caused greater de-learning among in-school girls as they became detached from their regular learning environment.

Table 12. Changes in adolescent girls' competency scores by schooling status, according to study arm and survey time

\begin{tabular}{|c|c|c|c|c|c|}
\hline \multirow[t]{2}{*}{ Competency scores } & \multicolumn{2}{|c|}{ Baseline } & \multicolumn{2}{|c|}{ Endline } & \multirow[b]{2}{*}{ DiD } \\
\hline & Intervention & Control & Intervention & Control & \\
\hline \multicolumn{6}{|c|}{ All girls (ever attended school) } \\
\hline Total score (23) & 14.799 & 14.763 & 14.605 & 14.144 & 0.424 \\
\hline Language score (4) & 2.716 & 2.719 & 2.572 & 2.592 & -0.017 \\
\hline Analytical score (19) & 12.083 & 12.043 & 12.033 & 11.552 & $0.441^{*}$ \\
\hline N & 1568 & 1535 & 1544 & 1551 & \\
\hline \multicolumn{6}{|l|}{ In-school girls } \\
\hline Total score & 15.518 & 15.523 & 15.1 & 14.727 & 0.378 \\
\hline Language score & 2.856 & 2.895 & 2.650 & 2.684 & 0.004 \\
\hline Analytical score & 12.661 & 12.628 & 12.451 & 12.043 & 0.374 \\
\hline N & 1238 & 1189 & 1283 & 1191 & \\
\hline \multicolumn{6}{|l|}{ Out-of-school girls } \\
\hline Total score & 12.489 & 12.479 & 12.317 & 12.489 & -0.182 \\
\hline Language score & 2.267 & 2.185 & 2.198 & 2.342 & -0.225 \\
\hline Analytical score & 10.223 & 10.293 & 10.119 & 10.147 & 0.042 \\
\hline$N$ & 330 & 346 & 261 & 360 & \\
\hline
\end{tabular}


The data show that between baseline and endline, the girls' overall competency score dropped in both areas, but less in the intervention than in the control areas (from 14.8 to 14.6 versus from 14.8 to 14.1). The language scores dropped in the same manner in both areas but there was a greater drop in analytical score in the control areas than in the intervention areas, with a statistically significant DiD of 0.441 points.

The findings indicate that the learning losses or de-learning faced by girls as result of the COVID-19 pandemic and related school closures was lower in intervention areas than in control areas because remote learning sessions kept girls connected and in touch with their studies.

Photo 1. After-school session with girls

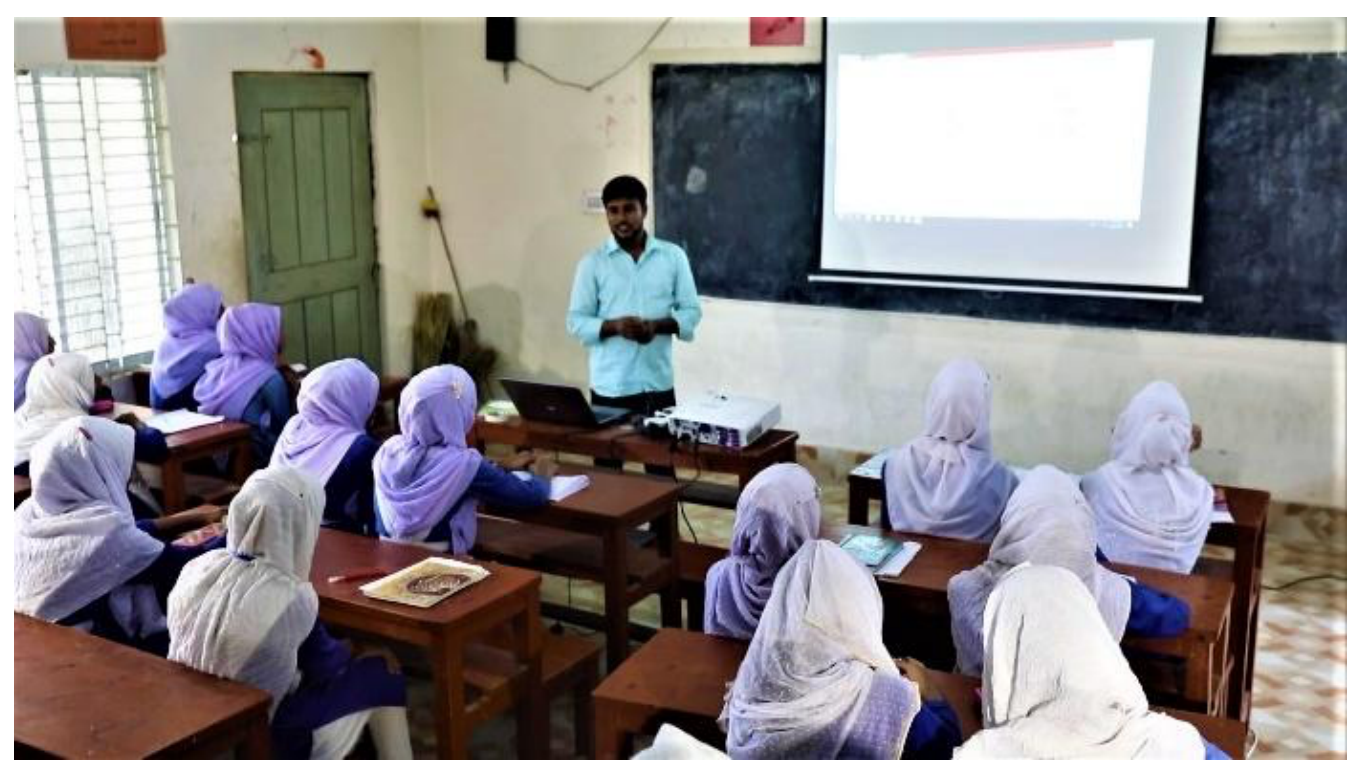




\section{Marriage and Sexual and Reproductive Health}

This section reports on age at marriage among girls, marriage-related indicators such as marriage timing, marriage process, marriage decisions, and dowry etc. Some key findings on respondents' awareness of legal age at marriage, marriage registration, dowry act, and divorce law are also described.

This section also highlights knowledge and practices on a range of sexual and reproductive health $(\mathrm{SRH})$ indicators and describes some key indicators on reproductive history of married girls. Data related to marriage and SRH collected in baseline and endline surveys are discussed in terms of a comparison between the intervention and control arms.

\section{Marriage}

Table 13 presents information on the marital status of girls aged $12-19$ by study arms (intervention and control areas), age groups, and schooling status in the baseline and endline periods. Findings show that overall, one-fifth of girls aged 12-19 are married in the intervention areas and more than one-fourth are married in the control areas in the endline.

\section{HIGHLIGHTS}

Early and Child marriages remain high-more than one-fifth of the girls aged 1219 are married

At endline child marriage rates were significantly lower in intervention areas compared to control areas (DiD of 4.8 percentage points) - these significant differences emerged because of a significant increase in marriage in control areas and a small decline in intervention areas

Interventions significantly protected marriage registration-at endline intervention areas were likely to register marriages than control areas but registration of marriage declined in control areas.

One-third of the girls could name three adverse effects of child marriageintervention girls were more likely to name adverse effects than control girls suggesting interventions increase critical awareness.

Over the study period, the proportion of child marriage (marriage before age 18) declined from $19 \%$ to $17 \%$ in intervention areas while it increased from $22 \%$ to $25 \%$ in control areas with a significant DiD of 4.8 percentage points. The changes suggest that the intervention may have an influence on delaying marriage of girls to later years.

Proportions of ever-married girls disaggregated by age group replicates a similar impact of the interventions. Both among 15-17-year-olds and among 18-19-year-olds, the married proportion was lower in the intervention area compared to the control area. A closer look into the 15-17 age group shows a significant jump from $26 \%$ to $35 \%$ in proportion of marriage in the control area. However, the proportion in this group declined from $24 \%$ to $22 \%$ in the intervention area which prevented the increase of child marriage in this area.

The following table illustrates changes in a number of marriage practices between baseline and endline. These are based on questions of whether the marriage was registered, whether girls were consulted for marriage, the nature of the marriage (love marriage or arranged by family), involvement of dowry in marriage, etc. 
Table 13. Percentage of adolescent girls ever married, by age at marriage and schooling status, according to study arm and survey time

\begin{tabular}{|c|c|c|c|c|c|}
\hline \multirow[t]{2}{*}{ Marital status } & \multicolumn{2}{|c|}{ Baseline } & \multicolumn{2}{|c|}{ Endline } & \multirow[b]{2}{*}{ DiD } \\
\hline & Intervention & Control & Intervention & Control & \\
\hline \multicolumn{6}{|l|}{ Ever married } \\
\hline 12-19 years old & 20.6 & 23.1 & 19.3 & 27.0 & $-5.2^{*}$ \\
\hline$<18$ years old & 18.5 & 21.6 & 17.4 & 25.4 & $-4.8^{\star}$ \\
\hline$N(A l l$ girls) & 1580 & 1547 & 1563 & 1558 & \\
\hline \multicolumn{6}{|l|}{ By age group: (<18 at marriage) } \\
\hline $12-14$ & 3.1 & 3.6 & 3.9 & 3.4 & 1.1 \\
\hline (n) & $(745)$ & (669) & (713) & (668) & \\
\hline 15-17 & 24.2 & 26.3 & 22.4 & 34.6 & $-10.6^{*}$ \\
\hline (n) & $(550)$ & $(601)$ & (593) & $(601)$ & \\
\hline 18-19 & 47.7 & 54.9 & 43.2 & 56.8 & -6.2 \\
\hline (n) & $(285)$ & $(277)$ & $(257)$ & (289) & \\
\hline$N$ (All girls) & 1580 & 1547 & 1563 & 1558 & \\
\hline Median age at marriage (years) & 15.0 & 15.0 & 15.0 & 15.0 & \\
\hline Mean age at marriage (vears) [SE\} & 15.11 & 14.97 & 15.15 & 15.00 & \\
\hline Mean age at marriage (years) [S.E.\} & [0.09] & [0.09] & [0.09] & {$[0.07]$} & 0.06 \\
\hline$N($ Ever married) & 326 & 357 & 302 & 420 & \\
\hline \multicolumn{6}{|l|}{ By schooling status } \\
\hline In school & 4.2 & 4.9 & 5.5 & 7.1 & -0.8 \\
\hline (n) & $(1238)$ & (1189) & (1283) & (1191) & \\
\hline Out-of-school & 80.1 & 83.5 & 82.5 & 91.6 & -5.7 \\
\hline & $(342)$ & (358) & $(280)$ & $(367)$ & \\
\hline$N(A l l$ girls) & 1580 & 1547 & 1563 & 1558 & \\
\hline
\end{tabular}

${ }^{* \star \star} \mathrm{p}<.001,{ }^{* \star} \mathrm{p}<.01,{ }^{\star} \mathrm{p}<.05$. DiDs were calculated controlling for district effect.

Findings show that marriages where the girls choose their partners have increased from about one-fifth at baseline to about one-fourth at endline in both areas. A higher percentage of dowry demanded, and lower percentage of dowry discussed as reported by girls in the control area compared to girls in the intervention area may be an indication of the impact of the program. However, the average amounts of dowry demanded and dowry paid slightly increased between baseline and endline in both areas. This could be the result of the inflation during the intervention period.

Several recent studies have referred to the fact that the majority of marriages in Bangladesh are now registered (Amin, et al. 2016; Hossain, et al. 2017). It is evident from Table 14 that younger girls are less likely to have registered their marriages than their older counterparts. The proportion of marriage registration in the control area decreased (from $70 \%$ to $66 \%)$ over the study period while it stayed the same $(76 \%)$ in the intervention area. 
Table 14. Percentage of girls who were ever married, by different marriage related practice indicators, according to study arm and survey time

\begin{tabular}{|c|c|c|c|c|c|}
\hline \multirow[t]{2}{*}{ Marriage-related indicators } & \multicolumn{2}{|c|}{ Baseline } & \multicolumn{2}{|c|}{ Endline } & \multirow[b]{2}{*}{ DiD } \\
\hline & Intervention & Control & Intervention & Control & \\
\hline \multicolumn{6}{|l|}{ Marriage-related decisions } \\
\hline Love marriage/ chose each other & 20.6 & 19.6 & 24.2 & 23.1 & 0.7 \\
\hline $\begin{array}{l}\text { Girl's consent taken before } \\
\text { marriage }\end{array}$ & 58.3 & 58.8 & 67.2 & 67.6 & 0.6 \\
\hline Demanded dowry & 34.4 & 36.4 & 35.8 & 41.2 & -3.4 \\
\hline$N($ Ever married $)$ & 326 & 357 & 302 & 420 & \\
\hline \multicolumn{6}{|l|}{ Dowry-related outcome } \\
\hline Family discussed dowry & 44.6 & 40.8 & 50.9 & 44.5 & 4.0 \\
\hline Average dowry demanded (Tk.) & 62,472 & 64,532 & 75,831 & 71,977 & 7,283 \\
\hline Average dowry given (Tk.) & 58,213 & 60,083 & 68,253 & 63,575 & 11,873 \\
\hline$N$ (Married with dowry demanded) & 112 & 130 & 108 & 173 & \\
\hline \multicolumn{6}{|l|}{ Marriage registered } \\
\hline All age groups & 75.8 & 70.3 & 75.8 & 65.7 & 6.6 \\
\hline $12-14$ & 47.8 & 50.0 & 64.3 & 34.8 & \\
\hline (n) & (23) & (24) & $(28)$ & $(23)$ & \\
\hline $15-17$ & 73.7 & 63.9 & 69.9 & 57.2 & \\
\hline (n) & (133) & (158) & (133) & $(208)$ & \\
\hline $18-19$ & 81.2 & 78.9 & 78.8 & 83.7 & \\
\hline (n) & (170) & (175) & (141) & (189) & \\
\hline $\mathrm{N}$ (Ever married) & 326 & 357 & 302 & 420 & \\
\hline
\end{tabular}

${ }^{\star \star \star} \mathrm{p}<.001,{ }^{\star \star} \mathrm{p}<.01,{ }^{\star} \mathrm{p}<.05$. DiDs were calculated controlling for district effect. None of the DiDs in this table are significant.

Table 15 proves the extent to which girls in both intervention and control areas were aware of the laws regarding marriage, dowry, and divorce at both baseline and endline. Knowledge of the legal age of girls at marriage is almost universal across the areas, though it slightly decreased at the endline. The survey exposed an immense increase in knowledge about marriage registration (to about three-fourths) between baseline and endline in both areas, which is undoubtedly encouraging.

\section{Table 15. Percentage of adolescent girls who are aware of laws regarding marriage and adverse effects of child marriage, according to study arm and survey time}

\begin{tabular}{|c|c|c|c|c|c|}
\hline \multirow{2}{*}{$\begin{array}{l}\text { Awareness of laws and effects of } \\
\text { child marriage }\end{array}$} & \multicolumn{2}{|c|}{ Baseline } & \multicolumn{2}{|c|}{ Endline } & \multirow[b]{2}{*}{ DiD } \\
\hline & Intervention & Control & Intervention & Control & \\
\hline \multicolumn{6}{|l|}{ Awareness of laws } \\
\hline $\begin{array}{l}\text { Knowledge about legal age at } \\
\text { marriage }\end{array}$ & 91.0 & 91.6 & 87.6 & 87.5 & 0.6 \\
\hline $\begin{array}{l}\text { Knowledge about marriage } \\
\text { registration }\end{array}$ & 57.0 & 53.1 & 73.7 & 74.0 & -4.1 \\
\hline Knowledge about dowry act & 80.1 & 83.6 & 77.2 & 84.3 & -3.7 \\
\hline $\begin{array}{l}\text { Knowledge about women's right to } \\
\text { divorce }\end{array}$ & 51.4 & 51.1 & 55.7 & 56.4 & -0.9 \\
\hline $\begin{array}{l}\text { Can name at least three adverse } \\
\text { effects of child marriage }\end{array}$ & 20.4 & 23.8 & 37.8 & 30.7 & $10.4^{\star *}$ \\
\hline $\mathbf{N}($ All girls) & 1580 & 1547 & 1563 & 1558 & \\
\hline
\end{tabular}

${ }^{\star \star \star} \mathrm{p}<.001,{ }^{\star \star} \mathrm{p}<.01,{ }^{\star} \mathrm{p}<.05$. DiDs were calculated controlling for district effect. 
Looking at awareness of adverse effects of child marriage among the adolescent girls, only one-third of the girls could name three adverse effects of child marriage though they had reasonable knowledge about marriage-related laws. However, the awareness of these effects increased over the period. This proportion increased from $20 \%$ to $38 \%$ in intervention areas and from $24 \%$ to $31 \%$ in control areas (a significant DiD of 10.4), suggesting that effective intervention can improve consciousness and save adolescent girls from the consequences of child marriage.

\section{Sexual and reproductive health}

Table 16 shows a comparison between intervention and control areas on girls' knowledge and practices on a range of sexual and reproductive health $(\mathrm{SRH})$ indicators over the study period.

A pattern of knowledge and behavior regarding menstrual hygiene management was quite similar between intervention and control areas at both baseline and endline. Over the period, there was a positive change observed in knowledge about menstruation before experiencing it, as well as use of sanitary pads. The findings show that there was a significant DiD in the level of knowledge on sexually transmitted diseases (syphilis/gonorrhea). However, knowledge of HIV/AIDS declined over the period in both areas.

Reporting on both experiencing SRH problems and receiving treatment increased across all areas. This may be because girls were now more aware of these problems and therefore more likely to seek help. The change was found to be greater in intervention areas than in control areas. There was also an increase in knowledge about the fertile period and family planning, but the change was similar in both areas.

\section{Table 16. Percentage of adolescent girls by knowledge regarding sexual and reproductive} health and practices, according to study arm and survey time

\begin{tabular}{lrrrrr}
\hline SRHR knowledge and practices & \multicolumn{2}{c}{ Baseline } & \multicolumn{2}{c}{ Endline } \\
& Intervention & Control & Intervention & Control & DiD \\
\hline Know about menstruation & 93.5 & 96.0 & 93.7 & 95.3 & 0.9 \\
$N$ (All girls) & 1580 & 1547 & 1563 & 1558 & \\
Knew about menstruation before & 40.0 & 36.4 & 51.2 & 51.3 & -3.7 \\
experiencing it & & & & & \\
$N$ (Girls who know about menstruation) & 1478 & 1485 & 1464 & 1484 & \\
Uses sanitary pad & 48.8 & 51.6 & 67.8 & 71.8 & -1.3 \\
N (Menstruating girls) & 1438 & 1456 & 1414 & 1438 & \\
Heard about menstrual regulation & 21.0 & 20.7 & 20.3 & 20.2 & -0.3 \\
Received menstrual regulation services & 1.3 & 1.2 & 1.6 & 1.2 & 0.3 \\
Heard about STDs (syphilis/gonorrhea) & 5.0 & 5.4 & 6.9 & 4.5 & $2.8^{\star}$ \\
Heard about HIV/AIDS & 52.2 & 55.7 & 47.6 & 43.8 & $7.3^{\star}$ \\
Ever experienced any SRH-related & 6.5 & 6.1 & 10.3 & 8.1 & 1.9 \\
problems & & & & & \\
Received treatment for SRH problems & 3.7 & 3.4 & 5.4 & 4.8 & 0.5 \\
Knowledge about FP methods & 39.8 & 41.8 & 57.1 & 55.1 & 4.0 \\
Correct knowledge about fertile period & 7.5 & 8.7 & 11.9 & 14.4 & -1.2
\end{tabular}


Correct knowledge about timing of the first birth

Correct knowledge on suitable place to give birth

$\mathbf{N}$ (All girls)

$$
66.4
$$

66.3

64.5

65.3

1580

1547
72.7

68.7

1563

"I won't have a baby unless

I'm 20-21 years old. Because

we were told in the program

(KGIS) that having a child

under the age of 20 years has

a higher rate of maternal

death and infant

mortality." (IDI-M-3, married

girl) this result needs to be interpreted with caution as the number of ever-married girls in the sample is small.

Table 17. Percentage of ever-married and girls who ever conceived by pregnancy-related indicators, according to study arm and survey time

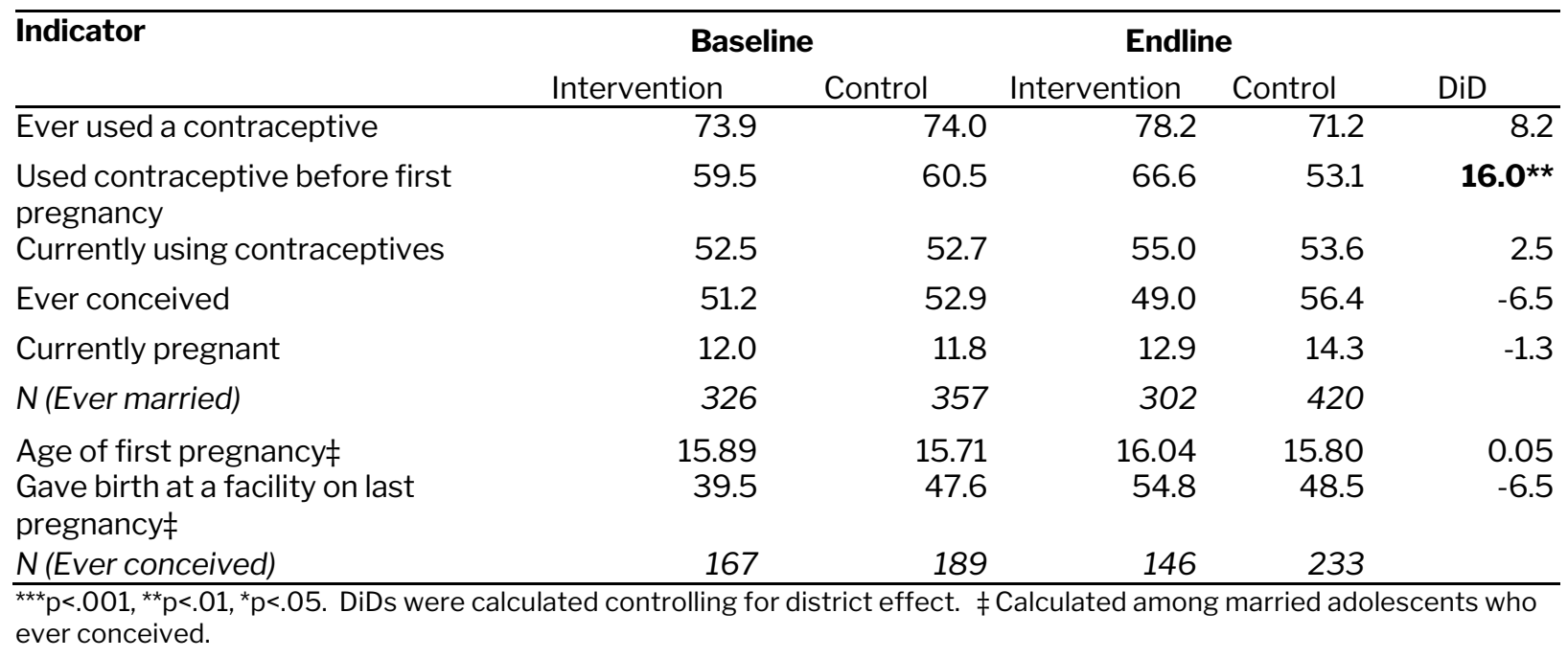

Among girls who ever conceived (about half of the ever-married girls), health-seeking behavior of giving birth at a facility increased notably from $40 \%$ to $55 \%$ in the intervention area in comparison to the control area between baseline and endline. These practices reflect the changes in knowledge and awareness among the adolescent girls over the study period. The improved reproductive health behavior of the adolescent girls is indicative of the impact of the awareness-giving intervention

Photo 2. Basic health session

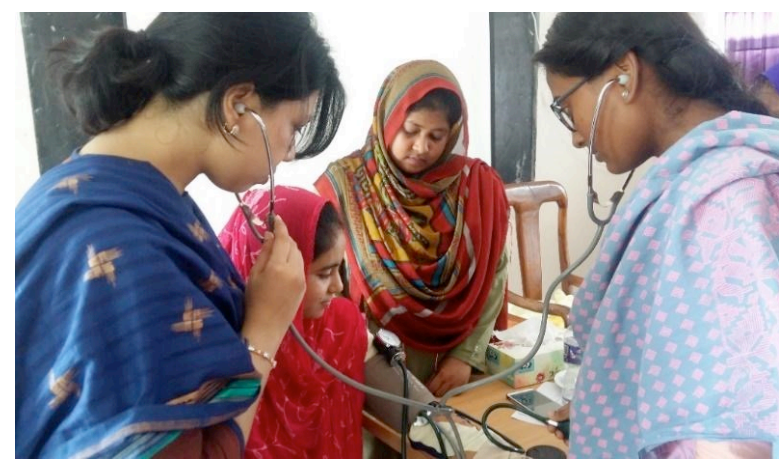
program. 


\section{Girls' Social Life and Economic Empowerment}

This section highlights a range of indicators that reflect the social life of surveyed girls. Selected indicators such as affiliation with clubs or local associations, access to technology and mass media, livelihood opportunities, and economic involvement are discussed. Information related to safety, security, harassment, and mobility have been analyzed to understand girls' status in society. The section also explores girls' perceptions on gender rights and genderequitable norms, which is measured through a series of questions.

Data related to the mentioned indicators collected in baseline and endline surveys are discussed in terms of a comparison between the intervention and control areas.

\section{Girls' exposure to technology and mass media}

The survey included questions about access to mobile phones and computers as well as ownership and their usage. Table 18 shows an increase in owning a mobile phone in both intervention and control areas which may be reflected by an in usage skills like making phone calls, sending SMS, and transferring a balance over the period. However, overall access to mobile phones (includes personal and household

\section{HIGHLIGHTS}

One in five girls own personal mobile phone and four in five have access to mobile phone.

There is high exposure (around 75\%) to mass media through TV and mobile across the areas. Reporting of parents being concerned about girl's safety increased meaningfully, and proportions of experiencing harassment halved in all sets over the period.

Participation in home-based income generating activities increased remarkably across the areas over the period due to prolonged school closure and economic constraints faced by families.

Since baseline, there has been a positive change in perception regarding gender equitable norms but findings suggest immediate intervention is needed to improve married adolescents' perception about SRHR. member's mobile) declined in both areas over the period. Using mobile phones for entertainment is widespread (more than $80 \%$ ) among girls, and it did not show notable differences across area and survey period.

The survey also collected exposure to print and electronic media by asking respondents if they read newspapers, listened to the radio, or watched television in the week preceding the interview. Unfortunately, the data show that for all three indicators, respondents' replies showed decreases in both areas between baseline and endline.

\section{Girls' engagement with local clubs}

Regarding institutional affiliations, data also showed that "no affiliation" slightly decreased in intervention areas, and in contrast, increased in control areas over the time. This led to an increase in the proportion of affiliations with adolescent/youth clubs from $2 \%$ to $4 \%$, a change that may be related to increased participation of girls in this program. 
Table 18. Percentage of adolescent girls reporting exposure to technology and mass media and institutional affiliations, according to study arm and survey time

\begin{tabular}{|c|c|c|c|c|c|}
\hline \multirow[t]{2}{*}{ Variable } & \multicolumn{2}{|c|}{ Baseline } & \multicolumn{2}{|c|}{ Endline } & \multirow[b]{2}{*}{ DiD } \\
\hline & Intervention & Control & Intervention & Control & \\
\hline Access to mobile (personal and/or $\mathrm{HH}$ ) & 83.2 & 84.0 & 68.8 & 72.3 & -2.6 \\
\hline Owns personal computer & 5.1 & 3.8 & 4.0 & 2.8 & -0.2 \\
\hline Owns mobile phone & 18.6 & 16.6 & 20.6 & 23.0 & -4.4 \\
\hline \multicolumn{6}{|l|}{ Mobile phone usage skills } \\
\hline Make phone call & 92.0 & 93.0 & 94.6 & 96.2 & -0.7 \\
\hline Send SMS & 43.0 & 41.8 & 48.1 & 49.7 & -2.9 \\
\hline Airtime balance transfer & 1.1 & 1.0 & 6.0 & 4.0 & 1.9 \\
\hline Listen to music/news & 84.0 & 86.6 & 80.2 & 86.0 & -3.2 \\
\hline$N$ & 1580 & 1547 & 1563 & 1558 & \\
\hline \multicolumn{6}{|l|}{ Exposure to mass media (last week) } \\
\hline Listened to radio & 2.1 & 3.1 & 1.8 & 1.5 & 1.3 \\
\hline Watched TV & 73.1 & 71.2 & 73.1 & 67.8 & 3.5 \\
\hline Read newspaper & 6.1 & 6.0 & 3.8 & 2.3 & 1.5 \\
\hline Played outdoors & 7.9 & 7.6 & 8.6 & 8.5 & -0.2 \\
\hline$N$ & 1580 & 1547 & 1563 & 1558 & \\
\hline \multicolumn{6}{|l|}{ Affiliated with/member of $†$} \\
\hline Social/cultural association & 0.6 & 0.4 & 1.1 & 0.6 & 0.3 \\
\hline Adolescent/youth club & 2.1 & 0.8 & 4.0 & 1.2 & 1.6 \\
\hline NGO & 0.9 & 0.8 & 0.9 & 0.6 & 0.2 \\
\hline No affiliation & 95.3 & 96.1 & 94.2 & 97.1 & -2.0 \\
\hline$N$ & 1580 & 1547 & 1563 & 1558 & \\
\hline
\end{tabular}

\section{Safety, security, and mobility}

Female autonomy in mobility, safety, security, and experience of harassment are presented in the following table. Responses suggest that the number of girls girls perceiving that parents are concerned for their safety meaningfully increased and reported use of purdah as a security measure also increased with a nonsignificant DiD in both areas over the period.

A positive indication observed in the findings was that the proportion of girls who reported that they can go outside of their homes after sunset increased (from 11\% to 16\%) in intervention areas while it slightly decreased (from $13 \%$ to $12 \%$ ) in control areas. Girls were also asked to mention the places they were allowed to visit alone. At baseline, $26 \%$ of girls reported that they were allowed to visit friends, which increased to $29 \%$ at endline in the intervention areas, while it remained more or less stable (22\%) in the control area.

\section{Harassment}

Girls were asked whether they faced any kind of harassment (for example any type of offensive words or physical assault) in their daily life, and if so, where it occurred. The following table shows variations in harassment exposure (in the last 12 months) that was 
reported to take place at or outside their homes. We found that harassment exposure occurred more outside the home: almost three times higher, than at home. An almost similar pattern exists between intervention and control areas. These findings suggest that at the endline, proportions experiencing harassment declined to half in both areas over the intervention period.

Table 19. Percentage of adolescent girls by safety, security, and mobility-related indicators, according to study arm and survey time

\begin{tabular}{|c|c|c|c|c|c|}
\hline \multirow[t]{2}{*}{ Variable } & \multicolumn{2}{|c|}{ Baseline } & \multicolumn{2}{|c|}{ Endline } & \multirow[b]{2}{*}{ DiD } \\
\hline & Intervention & Control & Intervention & Control & \\
\hline Parents are concerned about girl's safety & 55.2 & 56.8 & 63.4 & 60.4 & 4.6 \\
\hline Use purdah & 72.9 & 73.7 & 79.1 & 81.8 & -1.9 \\
\hline Allowed to go outside alone after sunset & 11.3 & 13.4 & 15.6 & 12.4 & 5.3 \\
\hline \multicolumn{6}{|l|}{ Allowed to go to these places } \\
\hline Go to club/association & 0.8 & 0.5 & 0.3 & 0.2 & -0.3 \\
\hline Go to library & 2.7 & 1.9 & 5.3 & 3.1 & 1.4 \\
\hline Go to market & 7.7 & 4.9 & 5.5 & 5.3 & -2.6 \\
\hline Go to playground & 2.7 & 2.6 & 2.1 & 1.9 & 0.2 \\
\hline Visit friends & 26.3 & 22.6 & 28.7 & 22.3 & 2.6 \\
\hline N & 1580 & 1547 & 1563 & 1558 & \\
\hline \multicolumn{6}{|l|}{ Experiencing harassment (in last 12 months) } \\
\hline $\begin{array}{l}\text { Experienced harassment at home } \\
\text { Experienced harassment in the community } \\
N \\
\text { Experienced harassment at school } \\
N\end{array}$ & $\begin{array}{r}3.4 \\
11.1 \\
1580 \\
4.3 \\
1568 \\
\end{array}$ & $\begin{array}{r}3.4 \\
10.6 \\
1547 \\
5.5 \\
1535 \\
\end{array}$ & $\begin{array}{r}2.2 \\
5.6 \\
1563 \\
1.6 \\
1544 \\
\end{array}$ & $\begin{array}{r}1.5 \\
5.3 \\
1558 \\
0.9 \\
1551 \\
\end{array}$ & $\begin{array}{r}0.8 \\
-0.3\end{array}$ \\
\hline
\end{tabular}

Photo 3. Girls and mentor in life-skills session

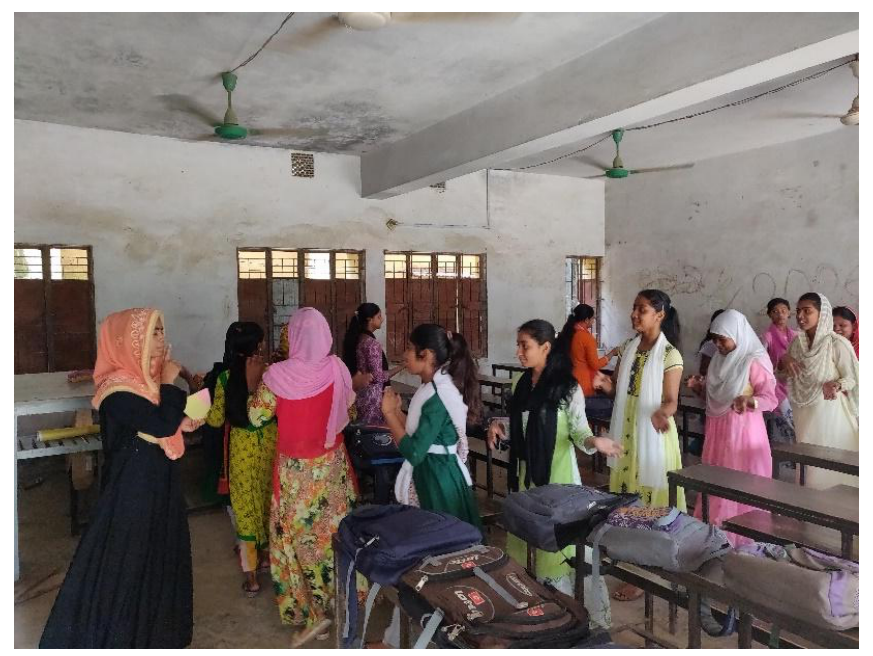




\section{Livelihood and Economic Empowerment}

\section{Employment status}

Data in Table 19 shows that among 12-19-year-old girls, approximately $10 \%$ of girls reported at the endline having ever worked for income; this was about $7 \%$ at baseline, displaying a similar trend in both areas over the period.

Between the baseline and the endline, the proportion who worked for income in the last 12 months increased in both intervention and control areas with a statistically significant DiD. The proportion of those currently working also increased in both areas, suggesting that school closure and economic constraints faced by families because of the o COVID-19 situation may have played a role in connecting girls to work opportunities.

Looking at occupation patterns among the adolescent girls, we observed that the percentages in tailoring and home-based piecework increased remarkably across the areas over the period. Private tutoring was reduced by half (from 32\% to 16\%) in intervention areas and became one-third (from $24 \%$ to $8 \%$ ) in control areas. Changes in the pattern of income-generating activities among girls in both areas were brought about by the COVID19 pandemic. Less decline in private tutoring in intervention areas indicates better connection with education, suggesting program influence in the area.

\section{Savings and expenses}

The data revealed that over the study period, the average hours worked in a week increased from 10.3 to 12.4 in intervention areas and from 12.6 to 15.9 in control areas, but average monthly wages increased only in intervention areas whereas it slightly decreased in control areas. The cause may be that girls in intervention areas were more involved in less time-consuming work with higher pay, while, in control areas, girls were more involved in laborious work with long hours and lower pay.

To know about girls' control over expenses, they were asked about how much of their income they could spend without permission from their family members. From the data, it is evident that the percentage of girls who had control over expenses

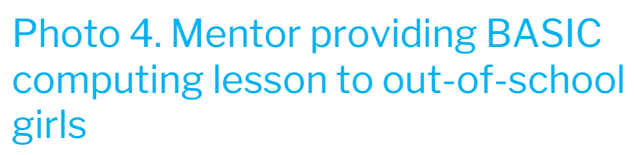

Photo 4. Mentor providing BASIC computing lesson to out-of-school girls

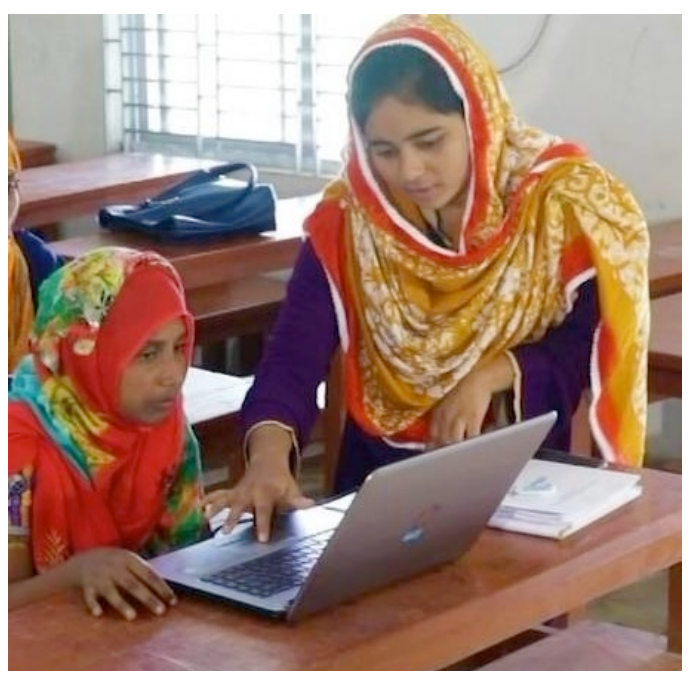
and who can save money declined in both areas. This increased earnings could not be attributed to the issue of empowerment due to financial strain on families caused by the pandemic as girl's do not necessarily have say over her earnings and the earned money used for the family expenses by the decision of household head. 
Table 20. Percentage of adolescent girls by employment status and related indicators, according to study arm and survey time

\begin{tabular}{|c|c|c|c|c|c|}
\hline \multirow{2}{*}{ Work characteristic } & \multicolumn{2}{|c|}{ Baseline } & \multicolumn{2}{|c|}{ Endline } & \multirow[b]{2}{*}{ DiD } \\
\hline & Intervention & Control & Intervention & Control & \\
\hline Ever worked for income & 7.5 & 7.1 & 10.2 & 9.7 & 0.1 \\
\hline $\begin{array}{l}\text { Worked for income in last } 12 \\
\text { months }\end{array}$ & 6.4 & 6.0 & 7.8 & 7.5 & $-0.1^{*}$ \\
\hline $\begin{array}{l}\text { Currently working } \\
N\end{array}$ & $\begin{array}{c}5.2 \\
1580\end{array}$ & $\begin{array}{c}5.4 \\
1547\end{array}$ & $\begin{array}{c}5.8 \\
1563\end{array}$ & $\begin{array}{c}6.2 \\
1558\end{array}$ & -0.2 \\
\hline \multicolumn{6}{|l|}{ Occupation } \\
\hline Private tutoring & 31.7 & 23.8 & 15.6 & 8.3 & -2.5 \\
\hline Tailoring & 30.5 & 35.7 & 45.6 & 47.9 & 8.4 \\
\hline $\begin{array}{l}\text { Home based piecework } \\
\text { (Packet/chocolate/bidi/wig- } \\
\text { making/kantha-stitching, etc.) }\end{array}$ & 25.6 & 25.0 & 33.3 & 38.5 & -8.9 \\
\hline $\begin{array}{l}\text { Other } \\
\text { Savings and expenses }\end{array}$ & 12.2 & 15.5 & 5.5 & 5.3 & 2.9 \\
\hline Average hours worked in a week & 10.28 & 12.6 & 12.37 & 15.89 & -1.32 \\
\hline Average monthly wages (Tk.) $\dagger$ & $836 /=$ & $1083 /=$ & $978 /=$ & $999 /=$ & $226 /=$ \\
\hline Have control over expenses & 65.9 & 48.8 & 39.9 & 45.8 & -22.8 \\
\hline Can save money & 33.2 & 31.5 & 23.0 & 21.8 & -0.5 \\
\hline N (Currently working) & 82 & 84 & 90 & 96 & \\
\hline \multicolumn{6}{|l|}{ Livelihood training } \\
\hline Ever received training & 6.9 & 7.6 & 9.3 & 8.5 & 1.4 \\
\hline$N$ & 1580 & 1547 & 1563 & 1558 & \\
\hline \multicolumn{6}{|l|}{ Training received on } \\
\hline Tailoring/dressmaking & 76.2 & 71.8 & 54.5 & 59.4 & -9.3 \\
\hline Other & 16.5 & 13.7 & 19.3 & 9.8 & 6.7 \\
\hline Not received any within 12 months & 7.3 & 14.5 & 26.2 & 30.8 & 2.6 \\
\hline$N$ & 109 & 117 & 145 & 133 & \\
\hline
\end{tabular}

Livelihood training

Participation in livelihood training in the last 12 months decreased, possibly as a result of the COVID-19 pandemic in both areas. However, the proportion of girls who ever participated in livelihood training increased slightly in both areas between baseline and endline. 


\section{Gender equality}

Table 21 presents the data on girls' perceptions regarding gender norms and gender roles in various aspects related to rights. Three-quarters of all girls in both areas agreed in the baseline that girls have a right to refuse an arranged marriage. This proportion decreased slightly in control areas while it stayed the same in intervention areas at the endline.

Table 21. Percentage of adolescent girls by perception about gender rights and norms, according to study arm and survey time

\begin{tabular}{|c|c|c|c|c|c|}
\hline \multirow[t]{2}{*}{ Variable } & \multicolumn{2}{|c|}{ Baseline } & \multicolumn{2}{|c|}{ Endline } & \multirow[b]{2}{*}{ DiD } \\
\hline & Intervention & Control & Intervention & Control & \\
\hline \multicolumn{6}{|l|}{ Women's rights and roles } \\
\hline $\begin{array}{l}\text { Girls are allowed to say "no" to an arranged } \\
\text { marriage }\end{array}$ & 75.4 & 77.1 & 75.8 & 71.7 & 5.7 \\
\hline A woman should have the right to divorce & 64.4 & 65.0 & 72.2 & 69.0 & 3.8 \\
\hline A woman should always obey her husband & 85.0 & 88.0 & 77.2 & 80.9 & -0.7 \\
\hline $\begin{array}{l}\text { Girl/women should be involved in income- } \\
\text { generating activities }\end{array}$ & 94.3 & 94.8 & 94.7 & 93.7 & 1.6 \\
\hline Men should assist women with household chores & 84.1 & 83.3 & 84.8 & 85.6 & -1.6 \\
\hline $\begin{array}{l}\text { A man's decisions should be final in family } \\
\text { matters }\end{array}$ & 47.7 & 50.7 & 39.9 & 46.8 & -4.0 \\
\hline $\begin{array}{l}\text { A woman should tolerate violence for the sake of } \\
\text { her family }\end{array}$ & 40.7 & 44.0 & 31.1 & 35.9 & -1.5 \\
\hline $\begin{array}{l}\text { A woman deserves to be beaten in some } \\
\text { instances }\end{array}$ & 48.9 & 54.2 & 45.7 & 49.4 & 1.6 \\
\hline $\begin{array}{l}\text { N } \\
\text { Sexual rights (married adolescents) }\end{array}$ & 1580 & 1547 & 1563 & 1558 & \\
\hline $\begin{array}{l}\text { Women should not refuse to have sex with their } \\
\text { husband }\end{array}$ & 43.6 & 46.2 & 46.0 & 42.4 & 6.2 \\
\hline Avoiding pregnancy is a woman's responsibility & 22.7 & 22.4 & 27.8 & 22.6 & 5.5 \\
\hline Girls are to blame for being raped & 29.1 & 29.7 & 35.8 & 31.2 & 4.7 \\
\hline $\mathbf{N}$ & 326 & 357 & 302 & 420 & \\
\hline
\end{tabular}

${ }^{* * *} \mathrm{p}<.001,{ }^{* *} \mathrm{p}<.01,{ }^{*} \mathrm{p}<.05$. DiDs were calculated controlling for district effect. None of the DiDs in this table are significant.

Since baseline, there was a positive change in perception regarding other statements about women's rights and roles mentioned in the table, such as "a woman should have the right to divorce," "a man's decisions should be final in family matters," and "a woman should tolerate violence for the sake of her family," in both areas, though these findings were not statistically significant.

However, data on married adolescents' responses about sexual rights show that genderequitable perceptions and trends were not always moving in the desired direction.

Unfortunately, the table demonstrates negative changes in perception of sexual rights in both areas, suggesting effective and immediate measures need to be taken to change gender perception. 


\section{CONCLUSIONS AND DISCUSSION}

The KGIS program's most significant and largest impact was on child marriage prevention which is a main objective of the study-relative to the baseline, girls were more likely to be married at endline in control areas whereas there was no discernible increase in child marriage prevalence in intervention areas. There were protective effects of preventing a decline in school dropout due to marriage and preventing learning loss in analytical skills. Both were significantly greater in control areas. The program also brought positive changes to adolescent girls' social, health, cognitive, and economic assets, autonomy and their life choices (described below and summarized in Table 21).

An overarching conclusion that we draw from this impact analysis of the "Keeping Girls in Schools" program in Bangladesh is that the main positive effects of the program derive from its protective effects. These effects are measured in relative terms comparing trends in the control areas versus those in the intervention areas. There were small positive trends in the intervention areas, and relatively large negative trends in the control areas, resulting in significant positive impact assessments of the program in terms of difference-indifferences analysis. Thus, we conclude that the program essentially worked to benefit girls in intervention areas by preventing deterioration of well-being as was documented in control areas.

Given the quite limited nature of the intervention and disruption by COVID-19 we are surprised by positive trends in the program in ways that we cannot quite explain. There was a significant increase in critical awareness and in behaviors of using contraception or earning money, despite the challenges of school closure and social distancing.

These measurable successes in reducing marriage, raising critical awareness, and in behaviors of using contraception or earning money, despite the challenges of school closure and social distancing, offer several important lessons. Possibly most relevant is that local mentors successfully used phone-based group calls to stay in touch with the girls, and continuation of the intervention during isolation may have helped with developing protective assets for the girls. These protective effects were not available to girls living in control areas. Beyond protecting against early marriage and possibly premature childbearing, the program may also have helped to develop cognitive and critical thinking skills with likely longer-term impact. However, on a range of other measures, such as use of menstrual hygiene products, likelihood of accessing and using cell phones, or giving more gender-aware responses there was no discernible impact of the program.

\section{Interventions hampered by the COVID-19 pandemic}

The interventions sought to bring about change in child marriage norms prevalent in the area by offering young girls a safe place to meet after school hours with mentors and teachers and to offer them tutoring support and life skills. Creating safe spaces for girls to meet, fostering safe and protective relationships with mentors and teachers, and creating positive learning environments and opportunities for interactions, were all greatly hampered by the economic and social disruptions associated with the COVID-19 pandemic. After an initial period of complete stoppage of activities, the program resumed activities on 
a considerably reduced scale. Engagement of schoolteachers, who played a central role in the implementation of the program in the first year, all but stopped and activities continued through virtual outreach by mentors to small groups of girls. While the program was compelled to reduce the total hours of instruction considerably during the pandemic, the intensity of interaction increased. Mentors reached out to girls twice a week for short durations. They used conference calls to reach smaller groups of three girls in each session thus allowing more direct instruction time for each group.

\section{Limited prospects for diffusion of impact}

The design of the study measured impact in the "whole of the community" encouraged by evidence from the earlier BALIKA study that it sought to replicate, where a significant positive impact was observed even among girls who lived in the area but did not participate directly in the program. The study documented the impact of the intervention through a rigorous, repeated cross-sectional study design, as opposed to a panel study design. The measure of program impact is the change in key outcomes among ALL girls between baseline and endline comparing differences in intervention and control communities. The data showed that on child marriage, for example, the program had much a greater impact on girls at ages where there are a higher proportion of beneficiaries. It is likely that the adaptive modifications that were required prevented the intervention from diffusing beyond the immediate beneficiaries since the program's presence was virtual and not visible to the community in a way that might facilitate these diffusion effects.

\section{Intervention Impact}

Table 22 below presents the main findings on key indicators of education, marriage, sexual and reproductive health rights, livelihood, and gender perception of adolescent girls. The arrows indicate the direction of change from baseline to endline for each indicator in the intervention (INT) and the control (CON) areas, respectively. Results highlighted in blue show indicators for which the DiD was significant and the intervention area performed better than the control area during the study period.

- Findings show that the intervention had a notable impact on some indicators related to education, such as increasing the proportion of in-school girls and subsequently decreasing the proportion of out-of-school girls in the intervention area, with a significant DiD of 4.9 percentage points. On the other hand, the percentage of inschool and out-of-school girls stayed almost the same in the control area.

- The intervention was aimed at reducing child marriage by way of keeping girls in school and was able to demonstrate a significant impact when girls were asked the reason for discontinuation of school. Dropping out of school for reason of marriage stayed the same in intervention areas, while it increased in control areas.

- The data revealed that learning losses or de-learning faced by girls as result of the COVID-19 pandemic and related school closures, were significantly lower in the than in control areas. The result evidenced the impact of remote learning sessions keeping girls connected and in touch with their studies during the pandemic.

- Several recent studies noted that child marriage has become manifold during the COVID-19 pandemic. Over the study period, which includes the pandemic, the DiD of child marriage between intervention and control areas was found to be significant. 
This difference emerged because of a significant increase in marriage in the control area and a small decline in the intervention area. The changes suggest that the intervention may have had an influence on delaying marriage of girls to later years.

- Other indicators related to marriage also show positive results in intervention areas. The intervention protected marriage registration-at the endline, intervention areas were more likely to register marriages than control areas. The proportion of registered marriages declined in control areas even though the number of marriages increased. Girls in intervention areas were also more likely to be able to name at least three adverse effects of child marriage than girls in control areas suggesting that intervention increases critical awareness.

- Beyond child marriage, an impact was detected on a few other indicators related to SRHR knowledge and practices, namely increasing the proportion of girls who know about family planning methods, the proportion of ever-married girls who used contraceptives before first pregnancy, and those who gave birth at a facility on their last pregnancy.

- A positive indication was observed from the findings of autonomy in mobility. The proportion of girls who reported that they can go outside their homes after sunset and can also visit friends alone increased in intervention areas though it slightly decreased or remained the same in control areas.

- Looking at the livelihood data, between baseline and endline, the proportion who worked for income in the last 12 months increased significantly in both the intervention and the control areas. The proportion of girls currently working also increased in both areas, suggesting that the workforce participation is a product of prolonged school closures and household economic constraints as a result of the COVID-19 pandemic.

- The COVID-19 pandemic brought about changes in income-generating activities among adolescent girls in both areas. Home-based activities increased in both areas but less decline in private tutoring in intervention areas indicates better connection with education, suggesting program influence in the area.

- The data reported that three-quarters of respondents in both areas agreed at baseline that girls have a right to refuse an arranged marriage. This proportion decreased slightly in the control area while it stayed the same in the intervention area at the endline. Unfortunately, undesirable trends in married adolescents' responses about sexual rights indicate a dire need for intervention for those who have been detached from education since an early age. 


\section{Table 22. Results summary of the impact of the intervention on education, marriage, sexual and reproductive health rights, livelihood, and gender perception}

\begin{tabular}{|c|c|c|c|c|c|}
\hline Impact area & Indicator & Arm & Baseline & Endline & $\begin{array}{l}\text { Direction of } \\
\text { change }\end{array}$ \\
\hline \multirow{8}{*}{ Education } & \multirow[t]{2}{*}{ Discontinued school } & Intervention & 20.9 & 16.7 & $\overline{\mathrm{INT}} \downarrow$ CON $\uparrow$ \\
\hline & & Control & 22.4 & 23.1 & \\
\hline & \multirow{2}{*}{$\begin{array}{l}\text { Discontinued school because of } \\
\text { marriage (among girls who } \\
\text { discontinued school) }\end{array}$} & Intervention & 67.6 & 67.4 & INT $\downarrow$ CON $\uparrow$ \\
\hline & & Control & 70.8 & 83.1 & \\
\hline & \multirow[t]{2}{*}{ Total competency score } & Intervention & 14.8 & 14.6 & $\mathrm{INT} \downarrow \mathrm{CON} \downarrow$ \\
\hline & & Control & 14.8 & 14.1 & \\
\hline & \multirow[t]{2}{*}{ Analytical score } & Intervention & 12.1 & 12.0 & INT $\downarrow$ CON $\downarrow$ \\
\hline & & Control & 12.0 & 11.6 & \\
\hline \multirow{12}{*}{$\begin{array}{l}\text { Marriage and sexual } \\
\text { and reproductive } \\
\text { health }\end{array}$} & \multirow[t]{2}{*}{ Ever married $(<18$ years old $)$} & Intervention & 18.5 & 17.4 & $\overline{\mathrm{INT}} \downarrow$ CON $\uparrow$ \\
\hline & & Control & 21.6 & 25.4 & \\
\hline & \multirow{2}{*}{$\begin{array}{l}\text { Marriage registration (among } \\
\text { ever married) }\end{array}$} & Intervention & 75.8 & 75.8 & $\mathrm{INT}-\mathrm{CON} \downarrow$ \\
\hline & & Control & 70.3 & 65.7 & \\
\hline & \multirow{2}{*}{$\begin{array}{l}\text { Can name at least three adverse } \\
\text { effects of child marriage }\end{array}$} & Intervention & 20.4 & 37.8 & INT $\uparrow \mathbf{C O N} \uparrow$ \\
\hline & & Control & 23.8 & 30.7 & \\
\hline & \multirow[t]{2}{*}{ Knowledge about FP methods } & Intervention & 39.8 & 57.1 & $\overline{\mathrm{INT} \uparrow} \uparrow \mathrm{CON} \uparrow$ \\
\hline & & Control & 41.8 & 55.1 & \\
\hline & \multirow{2}{*}{$\begin{array}{l}\text { Uses sanitary pad (among } \\
\text { menstruating girls) }\end{array}$} & Intervention & 48.8 & 67.8 & $\mathrm{INT} \uparrow \mathrm{CON} \uparrow$ \\
\hline & & Control & 51.6 & 71.8 & \\
\hline & \multirow{2}{*}{$\begin{array}{l}\text { Used contraceptive before first } \\
\text { pregnancy (among ever-married } \\
\text { girls) }\end{array}$} & Intervention & 59.5 & 66.6 & INT $\uparrow$ CON $\downarrow$ \\
\hline & & Control & 60.5 & 53.1 & \\
\hline \multirow{4}{*}{$\begin{array}{l}\text { Girls' exposure to } \\
\text { technology/media } \\
\text { and autonomy in } \\
\text { mobility }\end{array}$} & Watch TV & Intervention & 73.1 & 73.1 & INT $-\mathrm{CON} \downarrow$ \\
\hline & \multirow{3}{*}{$\begin{array}{l}\text { Allowed to go outside alone } \\
\text { after sunset }\end{array}$} & Control & 71.2 & 67.8 & \\
\hline & & Intervention & 11.3 & 15.6 & $\mathrm{INT} \uparrow \mathrm{CON} \downarrow$ \\
\hline & & Control & 13.4 & 12.4 & \\
\hline \multirow{3}{*}{$\begin{array}{l}\text { Livelihood/Economic } \\
\text { empowerment }\end{array}$} & \multirow{2}{*}{$\begin{array}{l}\text { Worked for income in last } 12 \\
\text { months }\end{array}$} & Intervention & 6.4 & 7.8 & INT $\uparrow \mathrm{CON} \uparrow$ \\
\hline & & Control & 6.0 & 7.5 & \\
\hline & Average hours worked in a & Intervention & 10.3 & 12.4 & INT $\uparrow \mathrm{CON} \uparrow$ \\
\hline
\end{tabular}




\begin{tabular}{|c|c|c|c|c|c|}
\hline Impact area & Indicator & Arm & Baseline & Endline & $\begin{array}{l}\text { Direction of } \\
\text { change }\end{array}$ \\
\hline & $\begin{array}{l}\text { week (among currently working } \\
\text { girls) }\end{array}$ & Control & 12.6 & 15.9 & \\
\hline & $\begin{array}{l}\text { Average monthly wages (Tk.) } \dagger \\
\text { (among currently working girls) }\end{array}$ & Intervention & $836 /=$ & $978 /=$ & INT $\uparrow \mathrm{CON} \downarrow$ \\
\hline \multirow{7}{*}{ Gender perception } & & Control & $1083 /=$ & $999 /=$ & \\
\hline & \multirow{2}{*}{$\begin{array}{l}\text { Girls are allowed to say "no" to } \\
\text { an arranged marriage }\end{array}$} & Intervention & 75.4 & 75.8 & \multirow[t]{2}{*}{$\overline{\mathrm{INT} \uparrow} \uparrow \mathrm{CON} \downarrow$} \\
\hline & & Control & 77.1 & 71.7 & \\
\hline & \multirow{2}{*}{$\begin{array}{l}\text { A woman deserves to be beaten } \\
\text { in some instances }\end{array}$} & Intervention & 48.9 & 45.7 & \multirow[t]{2}{*}{$\mathrm{INT} \downarrow \mathrm{CON} \downarrow$} \\
\hline & & Control & 54.2 & 49.4 & \\
\hline & \multirow{2}{*}{$\begin{array}{l}\text { Women could not refuse to } \\
\text { have sex with their husband }\end{array}$} & Intervention & 43.6 & 46.0 & \multirow[t]{2}{*}{$\mathrm{INT} \uparrow \mathrm{CON} \downarrow$} \\
\hline & & Control & 46.2 & 42.4 & \\
\hline
\end{tabular}

Note: Results highlighted in blue show indicators for which the DiD was significant and the intervention area performed better than the control area. $+(@ 84 T k=1 U S D)$.

\section{Limitations of the Study}

The design of the study as a repeated cross-sectional study as opposed to a longitudinal follow-up study limits us in some important ways. Data analysts are unable to assess to what extent migration out of the intervention and control areas may have affected the results. Instead, they are only able to answer what happens to adolescents who remain in the community. While we are confident that migration is unlikely to falsely bias the impact, we document indicators of interest to us, and they are unable to tell a complete story because migration to and from the community undoubtedly would give a more complete picture.

Data analysts are also unable to fully describe what about the intervention made a difference because the intervention included one year of a full-fledged in-person program and another year of a virtual intervention during the COVID-19 pandemic. The impact of COVID-19 cannot be denied, as described in Chapter 3 on the effects of COVID-19. Despite this, we note that COVID-19 affected both groups-control and intervention areas-so the positive impacts we are seeing are attributed to the intervention. An interim measure at the end of the first cohort would have provided a more complete picture.

\section{Implications for Future Programs}

These measurable successes in reducing marriage, raising critical awareness, and in behaviors of using contraception or earning money, despite the challenges of school closure and social distancing offers several important lessons. Possibly most relevant is the importance of recruiting program implementors from the local community, as seen in the experience of implementing the program during COVID-19. The ability of KGIS to adapt interventions to a virtual outreach mode during COVID-19 pandemic in 2020 and 2021 
would not have been feasible if mentors were not local. A second, relatively obvious program lesson centers around access to technology. In addition to being local, mentors had significant training on using laptops and social media that they were able to put to good use during the pandemic. The session monitoring data (see Appendix 1) clearly demonstrates that the sessions of the second year (group sessions run by mentors over the phone during COVID-19 pandemic) were more enjoyable for the girls and also more interactive. Mentors being from the local community meant the girls and the mentors were familiar with each other, and mentors had a better understanding of how to keep the girls connected. The mentors also had the parents' confidence as they had a good reputation in the community.

These results build on and complement findings from other evidence-based studies that demonstrate the importance of context in shaping the nature of interventions. That emphasis on context was highlighted by contrasting the variation in how similar program impacts had different results. The present study adds an additional dimension by showing how the shock of the COVID-19 pandemic influenced the intervention. Similar programs showed they were able to generate trends in child marriage decline where the current study shows how interventions prevented the kind of uptick in child marriage that was observed in control areas.

The non-effects of the program on a number of indicators around gender awareness, even while it succeeded in changing behavioral markers such as marriage, schooling, learning, and work may hold some lessons as well. In many previous assessments of similar programs, the opposite effects are seen, namely that while knowledge and attitudinal changes are easier to bring about, behavioral changes are harder.

It is nevertheless reassuring that we were able to demonstrate some protective effects of the program. While we cannot fully explain why the KGIS interventions were unable to impact the range of outcomes that the similarly designed BALIKA program was able to show, the net positive impact on foundational determinants of future well-being, such as child marriage and cognitive skills, provides strong justification for investing in skills to empower adolescents. 


\section{References}

Ainul, S., N. Talukder, M.I. Hossain, F.R. Noor, S. Amin, and U. Rob. 2020. Keeping Girls in Schools to Reduce Child Marriage in Rural Bangladesh: Baseline Report. Dhaka: Population Council.

Amin, S., U. Rob, S. Ainul, M.I. Hossain, F.R. Noor, I. Ehsan, and M. Manzur. 2020. "Bangladesh: COVID19 Knowledge, Attitudes, Practices \& Needs-Responses from Three Rounds of Data Collection Among Adolescent Girls in Districts with High Rates of Child Marriage." COVID-19 Research \& Evaluations Brief. Dhaka: Population Council.

Amin, S., J. Saha, and J. Ahmed. 2018. "Skills-building programs to reduce child marriage in Bangladesh: A randomized controlled trial,” Journal of Adolescent Health 63(3): 293-300.

Amin, S., J. Ahmed, J. Saha, M. Hossain, and E. Haque. 2016. “Delaying child marriage through community-based skills-development programs for girls: Results from a randomized controlled study in rural Bangladesh." New York and Dhaka, Bangladesh: Population Council.

Bangladesh Bureau of Educational Information and Statistics (BANBEIS). 2018. Bangladesh Education Statistics 2017. Dhaka: BANBEIS, Ministry of Education.

Chae, S. and T. Ngo. 2017. “The Global State of Evidence on Interventions to Prevent Child Marriage," GIRL Center Research Brief No. 1. New York: Population Council.

Directorate General of Health Services (DGHS). 2021. “COVID-19 Vaccination Dashboard for Bangladesh. Dhaka, Bangladesh: DGHS, Ministry of Health and Family Welfare." Retrieved 26 September 2021, from http://103.247.238.92/webportal/pages/COVID19-vaccination-update.php.

Gertler, P.J., S. Martinez, P. P., L.B. Rawlings, and C.M.J. Ver-meersch. 2011. “Difference-inDifferences," in Impact Evaluation in Practice. Washington, DC: World Bank, pp. 95-105.

Kalamar, A.M., S. Lee-Rife, and M.J. Hindin. 2016. “Interventions to prevent child marriage among young people in low- and middle-income countries: A systematic review of the published and gray literature," Journal of Adolescent Health 59(3 Suppl): 16-21.

Lee-Rife, S., A. Malhotra, A. Warner, and A.M. Glinski. 2012. "What works to prevent child marriage: A review of the evidence," Studies in Family Planning 43(4): 287-303.

Malhotra, A. and S. Elnakib. 2021. "20 years of the evidence base on what works to prevent child marriage: A systematic review," Journal of Adolescent Health 68(5): P847-862.

Hossain, M. B., A. Nabi, T. Ghafur and A. Haque. 2017. "Context of child marriage and its implications in Bangladesh", Department of Population Sciences, University of Dhaka.

United Nations Children's Fund (UNICEF). 2018. Child Marriage: Latest Trends and Future Prospects. New York: UNICEF.

United Nations International Children's Emergency Fund (UNICEF). 2021 "First day of school 'indefinitely postponed' for 140 million first-time students around the world - UNICEF." Press Release. New York/Dhaka: UNICEF. Retrieved September 26, 2021, from https://www.unicef.org/bangladesh/en/press-releases/first-day-school-indefinitely-postponed-140million-first-time-students-around-world. 
World Health Organization (WHO). 2021. Morbidity and Mortality Weekly Update (MMWU) No 82. Bangladesh: WHO. Retrieved September 26, 2021, from https://www.who.int/bangladesh/emergencies/coronavirus-disease-(COVID-19)update/coronavirus-disease-(COVID-2019)-bangladesh-situation-reports 


\section{APPENDIX 1: MONITORING}

This section reports the overall session status of the two-year intervention and describes how the intervention was monitored.

The section reports on the participation of girls over the course of the intervention-with monthly attendance of the program girls (both in-school and out-of-school)-as well as performances of the implementers (teachers and mentors), by selected indicators, and the overall quality of sessions.

Analysis of monitoring data also provides a comparative lens on sessions in terms of
The COVID-19 pandemic meant that the consecutive two-year program intervention differed in timing and deliberation modality, thereby the monitoring mechanism also had to adjust.

To evaluate the session attendance and quality, the monitored data of the two-year interventions was analyzed according to selected indicators.

quantity and quality and the program's outcomes by location. Comparisons are also made with pre-COVID and COVID period data.

From the two-year monitoring data, the intervention has been analyzed by selected indicators. Because of the pandemic, the two years of intervention differ in terms of session modality, duration, and number of participants. Therefore, the monitoring data are presented separately for the first year of intervention (pre-COVID-19) and the second year of intervention (during COVID-19) and analyzed with a comparative lens. Lessons learned are discussed in this chapter (see Table 3 to see how the intervention modality changed pre-COVID and during COVID-19).

\section{SESSION STATUS}

First-year intervention: The intervention session of the first year started in mid-April and was completed in December 2019. The in-school sessions were completed a bit early, in November 2019 because of the students' final exams in December 2019. As per the in-school and out-of-school lesson plans, a total of 5,184 sessions were successfully conducted in the first year.

Per the program plan, the total session hours for

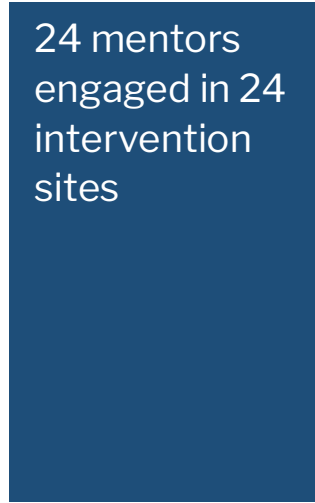

Mentor- Young woman aged $20-25$ recruited from her respective community, who worked as resource person and as leader for the program girls. 
all subjects for in-school and out-of-school girls groups was 72 hours and each session duration was one hour.

In the revised modality of intervention, mentors facilitated sessions by connecting the participating girls (in groups of no more than three) over a conference call twice a week for 15 minutes. Thus, for covering all of the enrolled girls in a particular group (like Grade seven/eight/out-of-school) for a single session, a mentor had to connect and facilitate as many group sessions as needed. To deliver a single session, mentors connected a minimum of 10 times for 30 participants as opposed to one time for in-person sessions.

Second-year intervention: In the second year, through phone-based remote sessions, a total of 18,162 remote group sessions (15,514 sessions for in-school girls and 2,648 sessions for out-of-school girls) were needed in three intervention districts to cover the selected topics for the respective girls' groups whereas 5,184 sessions were needed in the first year.

\section{GIRLS' ENROLLMENT FOR THE SESSION}

First-year intervention, 2019: The total enrollment for each in-school session was around 30 and for each out-of-school session it was around 15. However, the number of enrolled girls for in-school and out-of-school sessions was not similar for all intervention areas, as in some schools/areas, the number of girls meeting the selection criteria was inadequate.

A total of almost 1,700 girls enrolled for skill- and asset-building sessions from the 24 intervention areas in the first intervention year. The average enrollment for in-school sessions was $\mathbf{3 1}$ and for out-of-school sessions it was $\mathbf{9}$ in the 24 intervention areas.

Second-year intervention, 2020: As in the first year, group formation and the enrollment of the in-school and out-of-school girls in the second year was done at the beginning of 2020. Because of the COVID-19 pandemic, in 24 intervention areas across three districts, among the enrolled participants in the second-year (2020) intervention, just 60\% (around 1,000 program girls) could be covered by phone-based, remote-learning sessions, due to availability of girls and their access to a phone.

The average enrollment for in-school sessions was 19 and for out-of-school sessions was 5.

Table 23. Enrollment summary of the sessions pre- and during COVID-19

\begin{tabular}{|l|l|l|}
\hline Enrollment & $\begin{array}{l}\text { 2019 session } \\
\text { (Pre-COVID-19 period) }\end{array}$ & $\begin{array}{l}\text { 2020 phone-based session } \\
\text { (COVID-19 } \text { period) }\end{array}$ \\
\hline Total & $\begin{array}{l}\text { Around 1,700 girls enrolled from } \\
\text { the 24 intervention areas. }\end{array}$ & $\begin{array}{l}\text { Around 1,000 girls enrolled from } \\
\text { the 24 intervention areas. }\end{array}$ \\
\hline Average & $\begin{array}{l}\text { In-school sessions }=31 \text { and } \\
\text { Out-of-school sessions }=9\end{array}$ & $\begin{array}{l}\text { In-school sessions }=19 \text { and } \\
\text { Out-of-school sessions = 5 }\end{array}$ \\
\hline
\end{tabular}




\section{AVERAGE ATTENDANCE OF GIRLS}

In the first year of intervention sessions, the attendance rates for the enrolled in-school and out-of-school girls were $53 \%$ and $67 \%$, respectively. In the 2020 sessions, the average attendance rates of the in-school and out-of-school girls were higher than those of the first-year sessions.

In the second year, during pandemic, $60 \%$ of the enrolled girls could be reached through phone based remote sessions. Thus, considering the average attendance of the phonebased sessions with respect to the total number of girls originally enrolled for $2^{\text {nd }}$ year intervention, it could be said that the program was able to connect an average of $42 \%$ girls with their studies in this pandemic through phone based remote sessions.

Figure 9. Average attendance of girls (\%) in in-school and out-of-school sessions, 2019 and 2020

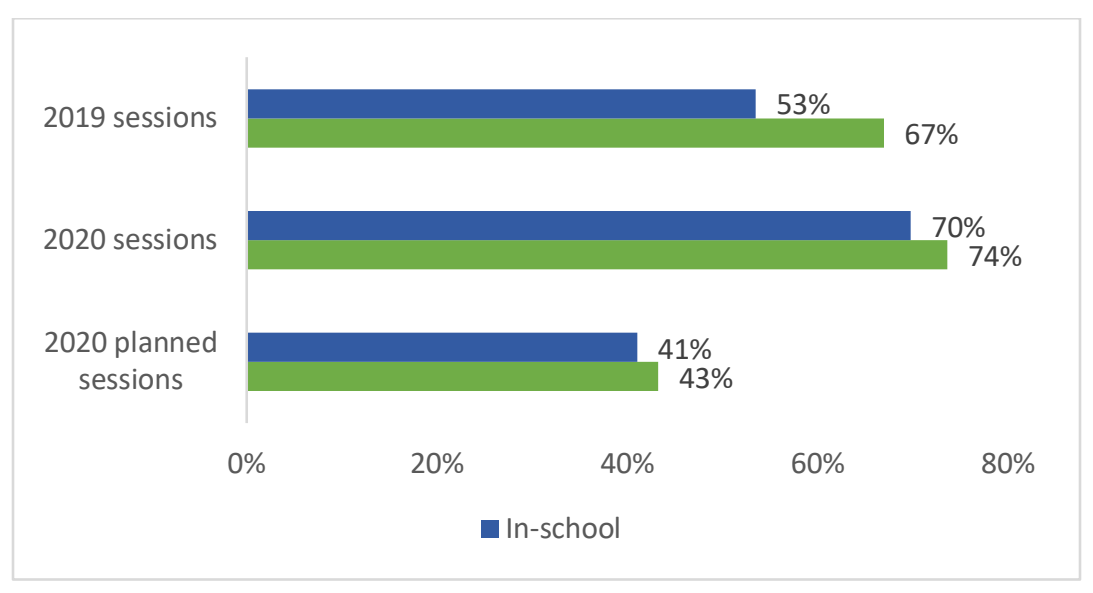

The above figure clearly reflects the fact that the out-of-school girls' attendance was higher than that of in-school girls in both years. It is interesting to see that the gap in attendance between the in-school and out-of-school girls was not that much in 2020. This may be the result of regular following-up of the girls by the mentors.

\section{Monthly average attendance}

The average number in attendance of in-school girls ranged from 13 to 19 (among average of 31 enrolled), while, the average attendance of out-of-school girls was between 4 and 7 (among average of 9 enrolled) in 2019. 
Figure 10. Average attendance of girls in in-school and out-of-school sessions by month, 2019

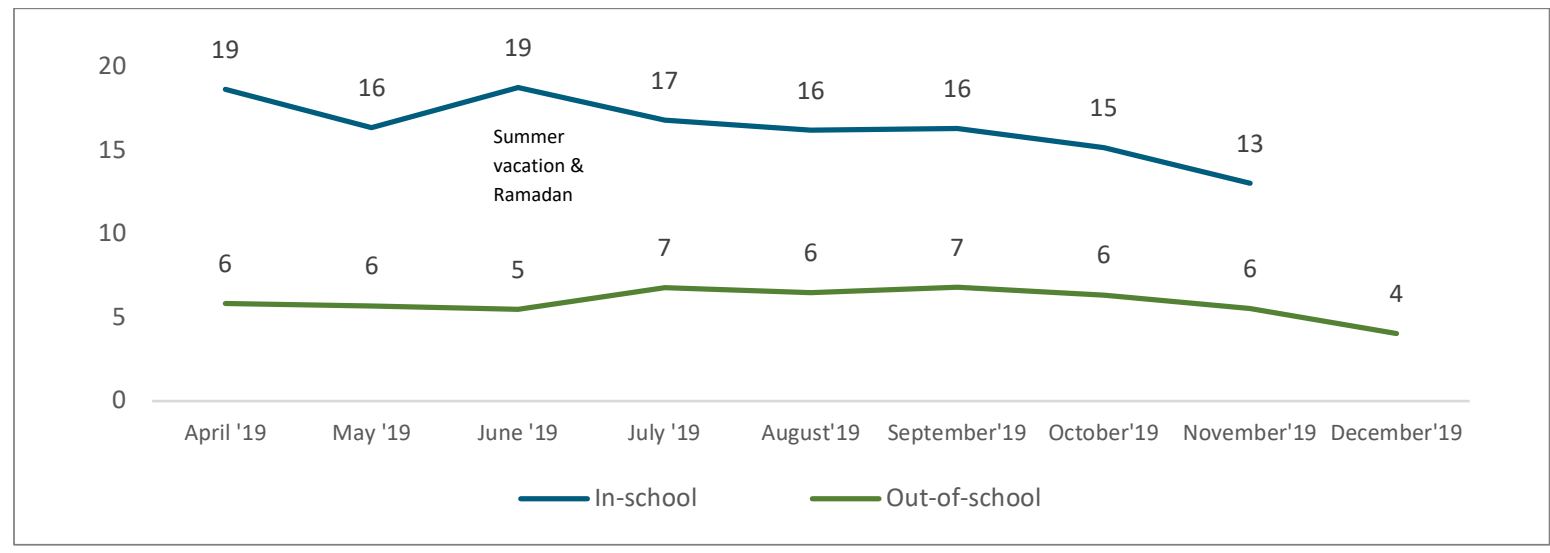

Figure 11 reveals that in the second-year remote sessions, the monthly average attendance was close to that of the previous year's remedial sessions for both in-school and out-ofschool groups. We observed that the average attendance was the highest in the month of November 2020.

Figure 11. Average attendance of girls in in-school and out-of-school sessions by month, 2020

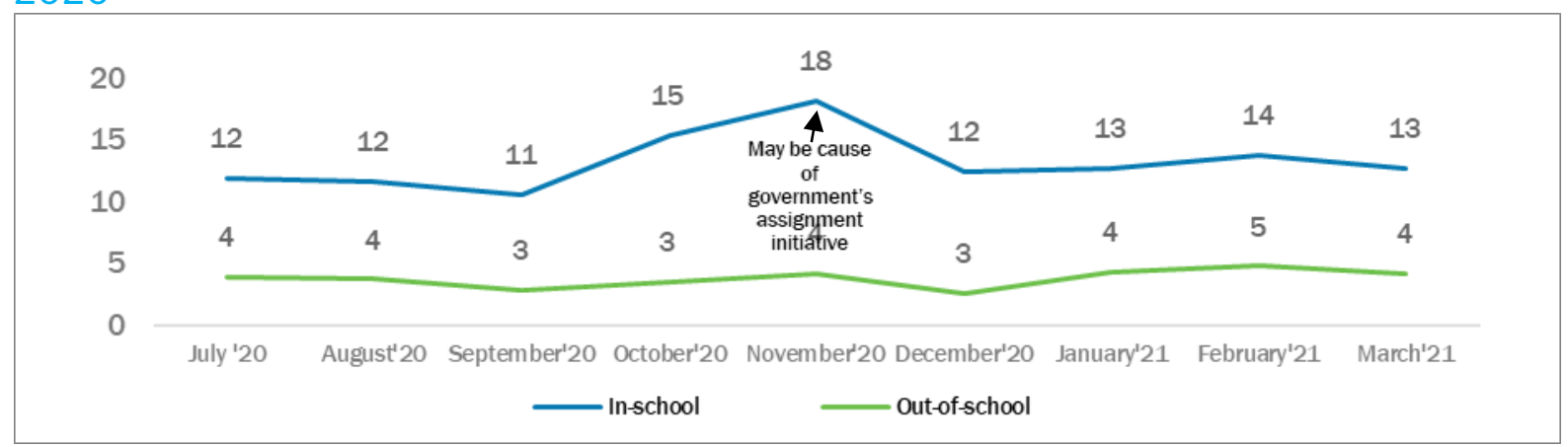

This may be the impact of girls being motivated to get back to their studies because of the government's initiative to evaluate the learning outcomes of the in-school students. The attendance of in-school girls ranged from 11 to 18 while the range for out-of-school it was between 3 to 5 . 
Table 24. Attendance summary of the sessions pre- and during COVID-19

\begin{tabular}{|c|c|c|}
\hline Average attendance & $\begin{array}{l}2019 \text { session } \\
\text { (Pre-COVID-19 period) }\end{array}$ & $\begin{array}{l}2020 \text { phone-based session } \\
\text { (COVID-19 period) }\end{array}$ \\
\hline (\%) & $\begin{array}{l}\text { In-school sessions }=53 \% \\
\text { Out-of-school sessions= } 67 \%\end{array}$ & $\begin{array}{l}\text { In-school sessions }=70 \% \\
\text { Out-of-school sessions= } 74 \%\end{array}$ \\
\hline \multirow[t]{2}{*}{ (\#) } & $\begin{array}{l}\text { In-school sessions = } 16 \text { (of an } \\
\text { average of } 31 \text { enrolled) } \\
\text { Out-of-school sessions = } 6 \text { (of an } \\
\text { average of } 9 \text { enrolled) }\end{array}$ & $\begin{array}{l}\text { In-school sessions }=13 \text { (of an } \\
\text { average of } 19 \text { enrolled) } \\
\text { Out-of-school sessions = } 4 \text { (of an } \\
\text { average of } 5 \text { enrolled) }\end{array}$ \\
\hline & $\begin{array}{l}\text { Chapainawabganj = } 12 \\
\text { Kushtia }=14 \\
\text { Sherpur }=12\end{array}$ & $\begin{array}{l}\text { Chapainawabganj }=10 \\
\text { Kushtia }=10 \\
\text { Sherpur }=10\end{array}$ \\
\hline
\end{tabular}

The data in Table 24 above, implied that higher attendance of out-of-school girls could be because the group was comparatively smaller than that of in-school girls, making follow-up easier. Girls were more comfortable with their mentors than with teachers. This could also be due to the feeling of getting back to a school environment and the scope of interacting with peers. Additionally, out-of-school girls were offered time compensation for attending the sessions.

\section{QUALITY OF THE SESSIONS}

The data analysis found that in 2019 , the district coordinators were able to monitor an average of $10 \%$ of sessions with the maximum coverage being $15 \%$. The coverage depended on the distance between the schools and the number of schools in the assigned district. It is also notable that in all districts, for time adjustment with the school, most of the remedial sessions were conducted at the same time in the different schools, i.e., on Thursday after school and on Friday morning. In the phone-based sessions in 2020, the district coordinators were able to monitor $18 \%$ of sessions by joining the conference call.

To assess the quality of the sessions, the following analysis of related indicators was done. It is worth mentioning that in 2019 , the in-school sessions were mostly conducted by teachers while the out-of-school sessions were conducted by mentors.

\section{PERFORMANCE OF FACILITATORS IN 2019}

Indicators such as preparation and facilitation by the teachers and mentors conducting sessions were analyzed and are presented graphically below. The dimensions included "prepares adequately before the session," "provides real life examples," "asking questions during the session," "passion to conduct session," and "use of digital material." 
Figure 12. Performance of teachers and mentors during session facilitation in selected quality dimensions, 2019

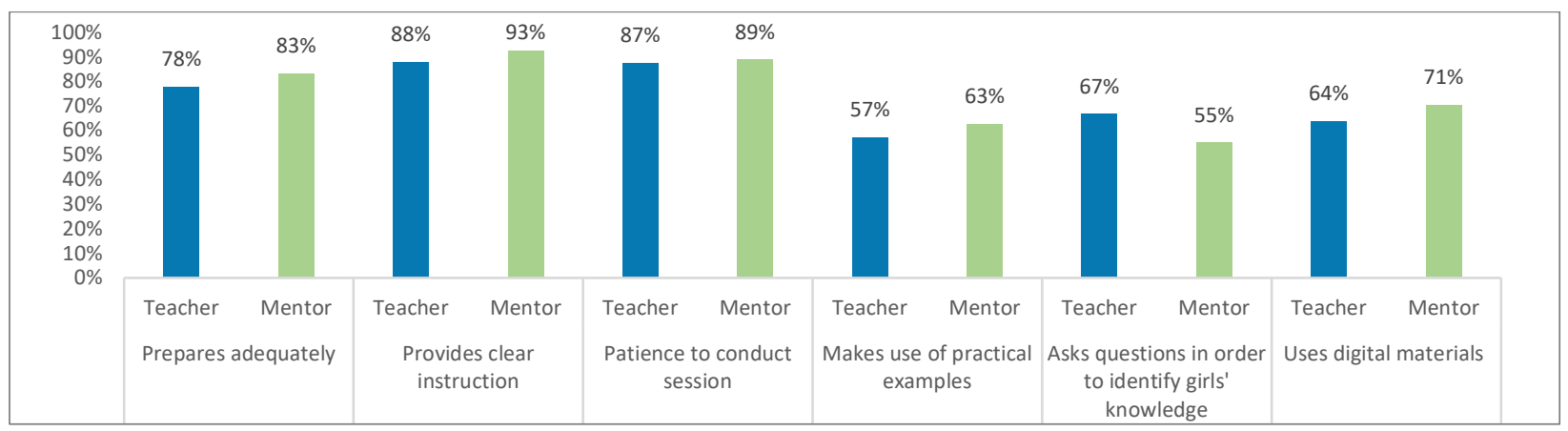

Data indicate that the overall performance of the mentors (in the dimensions mentioned) in conducting sessions was slightly better than teachers except in "asking questions to the girls in order to identify girls' knowledge during the session." The highest percentage (93\%) was for sessions conducted with clear instruction by mentors. On the other hand, the lowest percentage (57\%) was for sessions conducted using practical examples by the teachers.

This may be because the mentors were almost contemporary to the girls which allowed them to connect quickly, helping to create an enjoyable session environment within a very short period.

\section{PERFORMANCE OF FACILITATORS IN 2020}

The following findings were revealed for quality assessment of remote-learning sessions conducted in the second year of intervention. All subjects of both inschool and out-of-school sessions were facilitated by mentors.
In the second year of intervention, all subjects of both in-school and out-ofschool sessions were facilitated by mentors.

Figure 13. Performance of mentors during session facilitation in selected quality dimensions, 2020

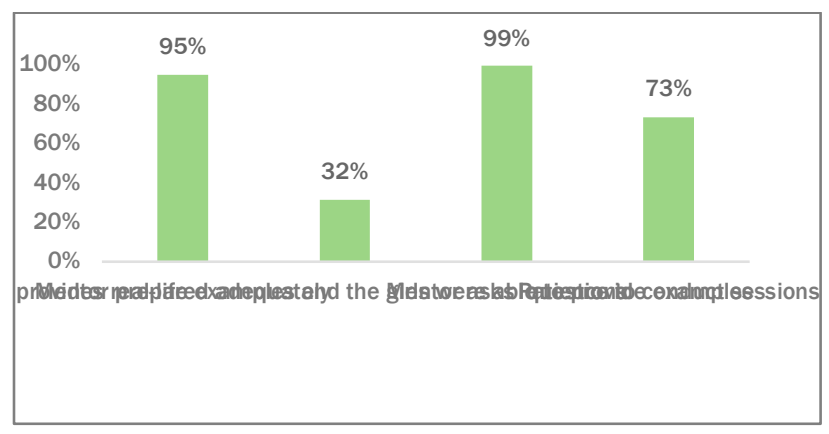

The data reflect that the score for the best quality in facilitation was "asks questions" (99\%), which was possibly to ensure that the girls were connected. On the other hand, the lowest quality for the session facilitation was "using practical examples," which may be due 
to a shortage of time. Data also reports that overall quality (in the dimensions mentioned) of the mentors in conducting sessions was more or less similar in the three districts (not shown).

\section{Session environment in 2019}

The session-monitoring indicators were analyzed to score the environment of the session considering " 1 " the poorest and " 5 " the highest. The average score was calculated on a 1-5 scale by monitors on several dimensions such as interactive/participation, enjoyability, and creativity, etc.

These findings enabled managers to provide feedback on performance to field monitors and respective implementers so that they could carry out sessions with the girls more efficiently. The figure below presents the overall impression of the quality of the session environment at a glance for all 24 intervention areas.

Figure 14. Average performance score (assessing quality of interaction between facilitators and students) for environment of in-school and out-of-school sessions by month, 2019

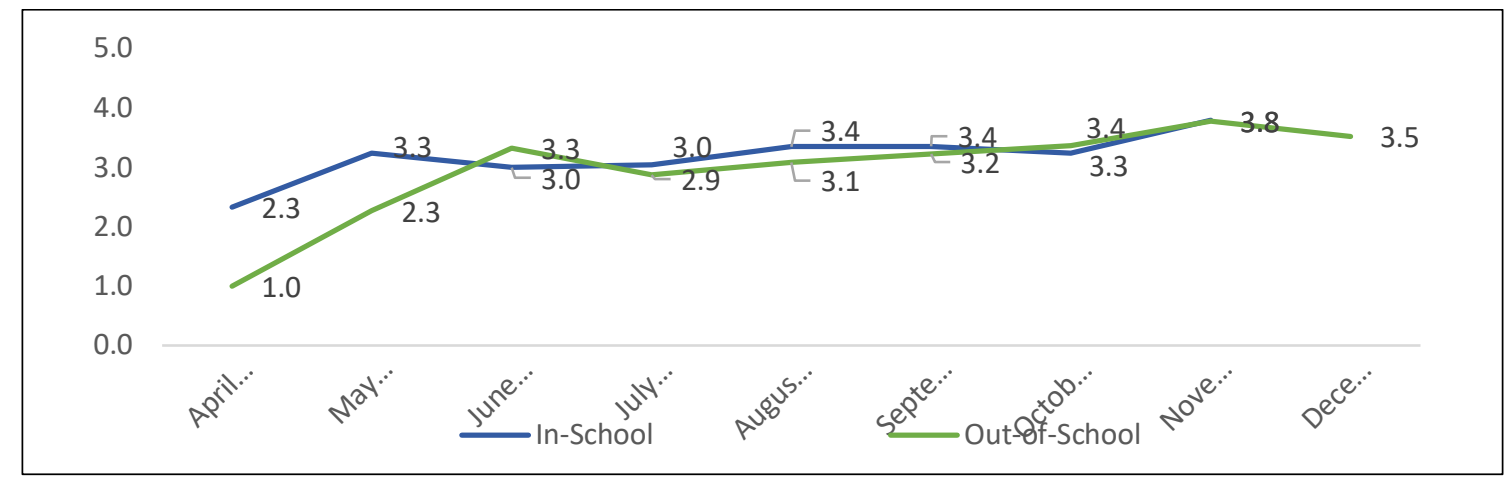

The average score for session environment performance was calculated monthly and we found that the quality of the participatory session environment increased from an average score of 2.3 to a score of 3.3 for in-school and from 1.0 to 3.5 for out-of-school sessions by the end of the intervention.

The performance of the out-of-school sessions was considerably low at the beginning because a smaller number of girls were enrolled. The performance of the out-of-school sessions increased gradually, though it was considerably low at the beginning because a smaller number of girls were enrolled. 
Figure 15. Average performance score for environment of the sessions (assessing quality of interaction between facilitators and students) by month and by district, 2019

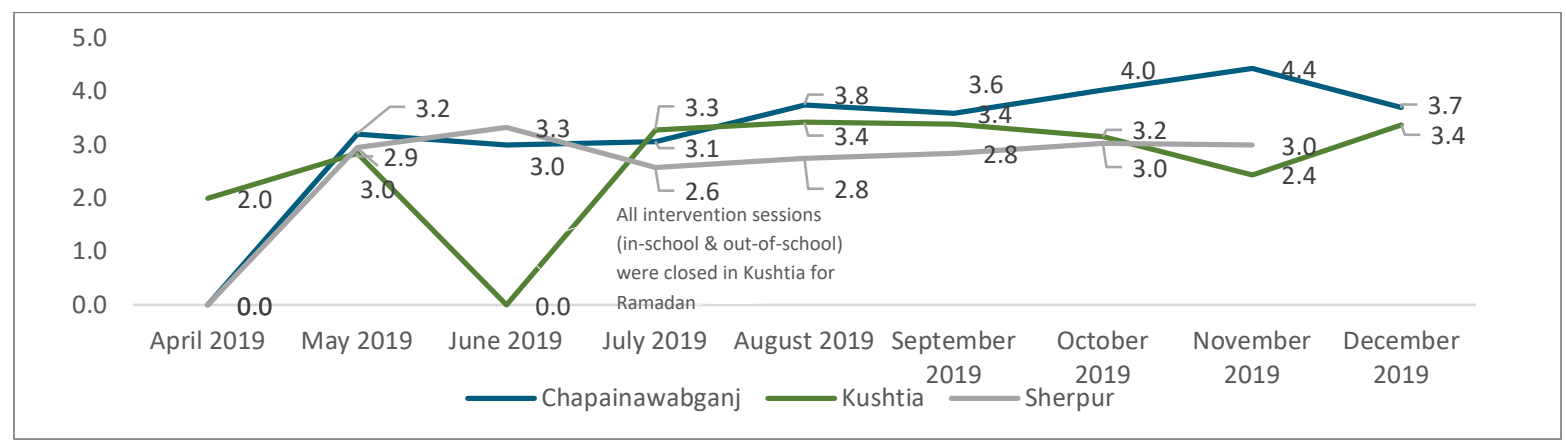

From the above figure, we note that the performance improved gradually over time. The figure also shows that the performance scores of Chapainawabganj and Sherpur were both zero in April 2019. This is because intervention had not yet begun in those districts. In June 2019, the performance score of Kushtia was zero as sessions were not conducted because of school closure for Ramadan and summer vacation.

\section{Session environment in 2020}

In the second year, the overall session performance was assessed using a score on a scale of 1 to 5 , where 1 is the poorest score and 5 is the highest. Figure 16 shows that the performance of the out-of-school sessions was comparatively higher than that of in-school sessions throughout the project period.

In the second year of intervention, all subjects of both inschool and out-ofschool sessions were facilitated by mentors.

We found that the in-school performance was lower in the beginning, which may reflect acceptance and adjustment issues, as mentors were conducting sessions instead of teachers. The data show that in-school performance improved gradually over the period. 
Figure 16. Average score for overall environment performance of the in-school and out-ofschool sessions, 2020

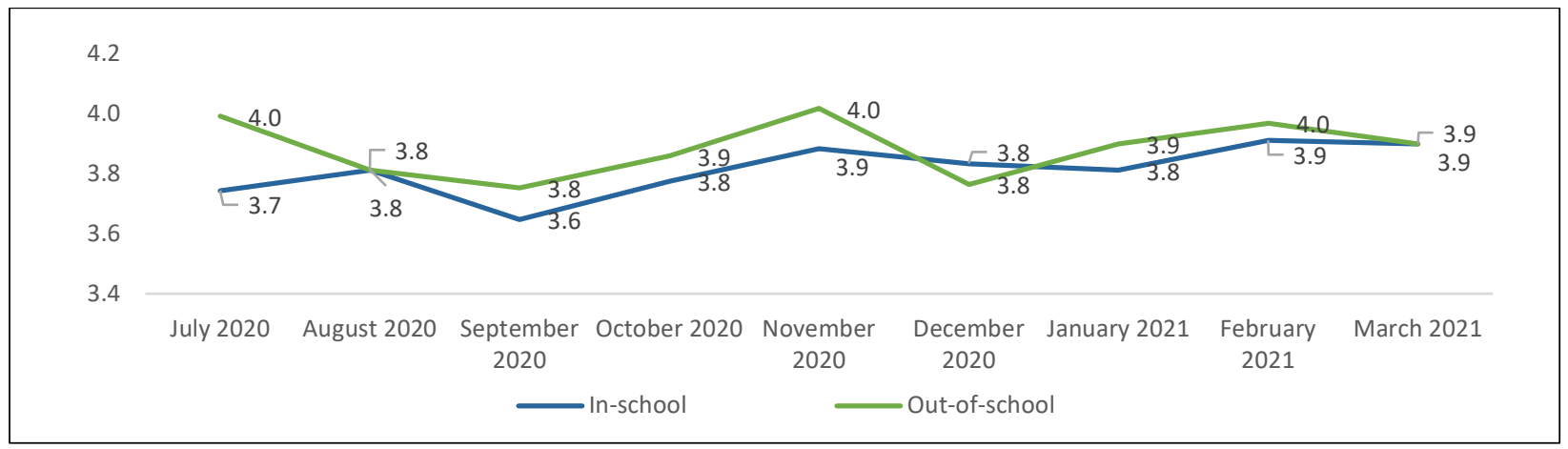

We found that performance of in-school sessions increased from an average score of 3.7 to a score of 4.0 and performance decreased slightly from 4.0 to 3.9 for out-of-school sessions over the period of the second-year intervention.

\section{Figure 17. Average score for overall environment performance of the sessions by month} and district, 2020

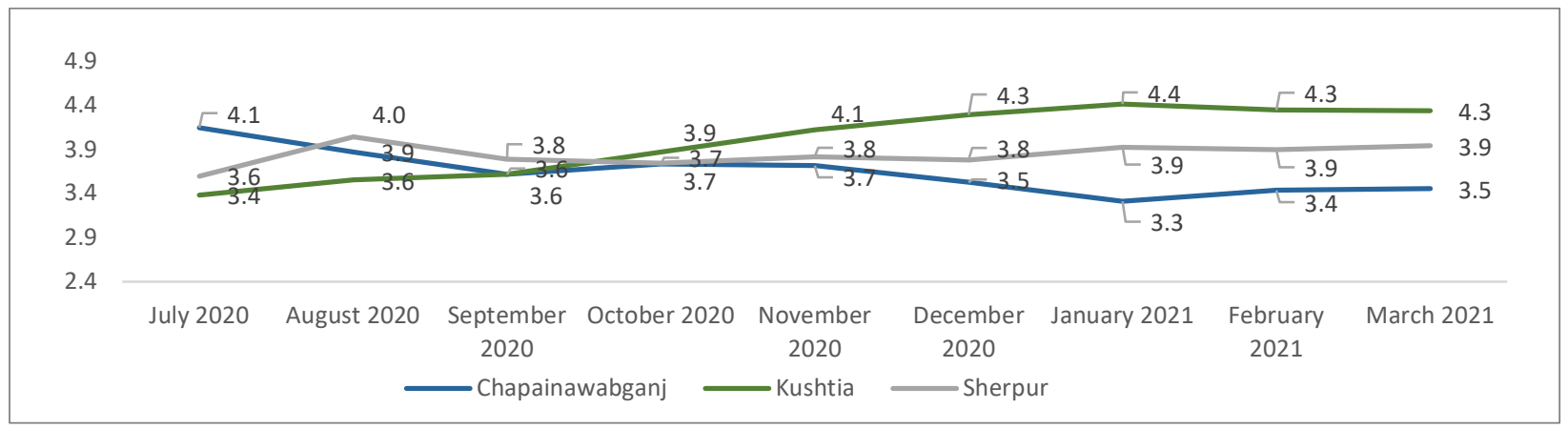

As shown in Figure 16, like the previous year before COVID-19, performance trends in all areas increased gradually by month except in Chapainawabganj. The trend fell slowly in Chapainawabganj from November 2021 and again increased slowly from February 2021. This may reflect girls' loss of interest in education and learning as they were auto promoted to next grade as per policy of Government, and some were in holiday mood. Furthermore, the phone connection was poorer in Chapainawabganj than in the other two districts.

\section{Performance scoring by session topic}

The average score of session environment performance was calculated by topic for the purpose of finding out which session topics were more interesting for the girls. 
Figure 18. Average performance score in "interactive" environment by session topic, 2019

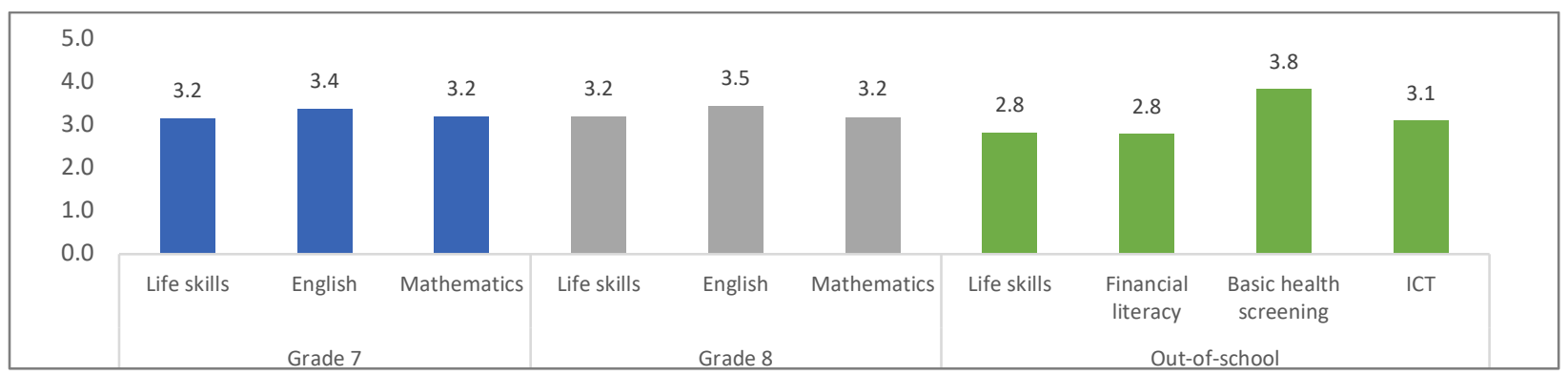

In the figure above, blue bars represent the subjects of Grade 7, gray bars Grade 8, and green bars the out-of-school girls' groups. The figure shows that the score varies from 2.8 to 3.8 for both in-school and out-of-school session topics. For in-school sessions, English was the most enjoyable (3.4 and 3.5, respectively) for both Grades 7 and 8 while other subjects were of the same interest level. For out-of-school sessions, basic health services scored the highest (3.8) in the enjoyable category and financial literacy scored the lowest (2.8).

In second-year in-school sessions, as shown in Figure 19, life skills and math were the most enjoyable (3.9) in both the grades, while English was less enjoyable (3.7). For out-of-school sessions, almost all of the subjects were of the same interest to the girls.

It is worth mentioning again that due to school closures, all sessions for in-school and outof-school groups were facilitated by mentors in the second year, unlike in the first year when experienced subject teachers conducted the in-school math and English sessions.

Figure 19. Average overall performance score by session topic, 2020

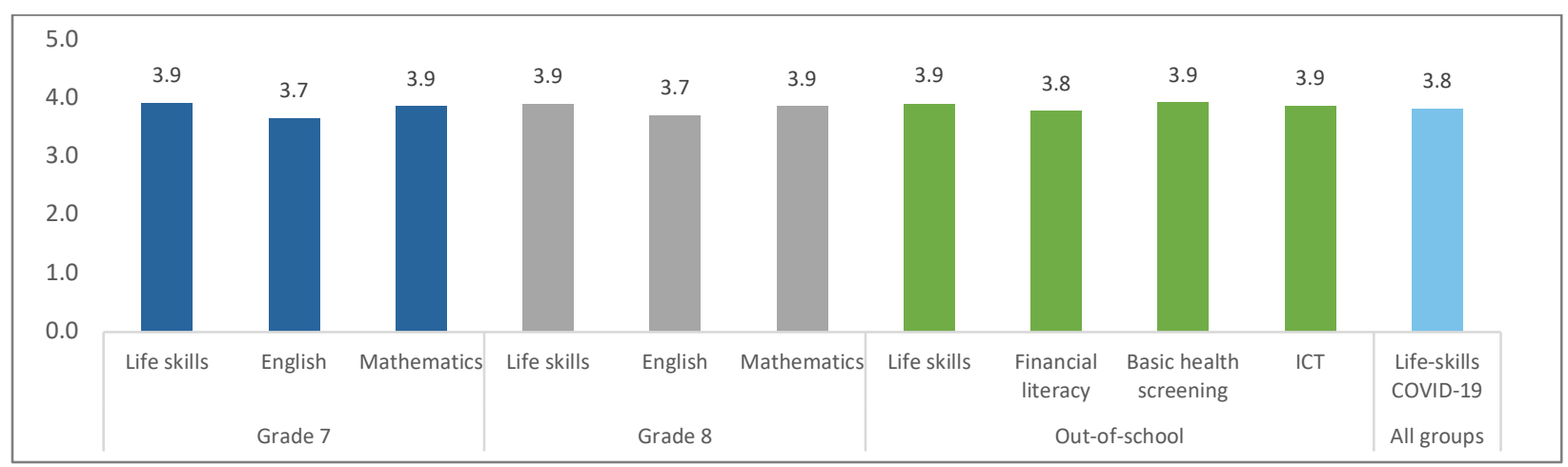

The quality of the remote-learning sessions was also subject to various factors like connectivity issues (of phone), device problems, sharing of phone set with others, availability of phone on time, coordination of the girls' times for the conference call, no physical presence of mentors (issues of eye contact between learners and facilitators), short duration of sessions, etc. 
Table 25. Quality of the sessions at a glance

\begin{tabular}{|l|l|l|}
\hline & $\begin{array}{l}\text { 2019 session } \\
\text { (Pre-COVID-19 period) }\end{array}$ & $\begin{array}{l}\text { 2020 phone-based session } \\
\text { (COVID-19 period) }\end{array}$ \\
\hline Facilitator & Teacher and mentor & Mentor \\
\hline $\begin{array}{l}\text { Prepared adequately } \\
\text { before conducting } \\
\text { session }\end{array}$ & $\begin{array}{l}\text { Teacher }=78 \% \text { sessions and } \\
\text { Mentor }=83 \% \text { sessions }\end{array}$ & Mentor = 95\% sessions \\
\hline $\begin{array}{l}\text { Patience to conduct } \\
\text { session }\end{array}$ & $\begin{array}{l}\text { Teacher }=87 \% \text { and } \\
\text { Mentor }=89 \%\end{array}$ & Mentor = 73\% \\
\hline $\begin{array}{l}\text { Average score of overall } \\
\text { session environments }\end{array}$ & $\begin{array}{l}\text { In-school }=3.2 \text { (out of 5) } \\
\text { Out-of-school = 2.9 }\end{array}$ & $\begin{array}{l}\text { In-school = 3.8 (out of 5) } \\
\text { Out-of-school = 3.9 }\end{array}$ \\
\hline $\begin{array}{l}\text { Most } \\
\text { enjoyable/interesting } \\
\text { topic }\end{array}$ & $\begin{array}{l}\text { For in-school = English } \\
\text { For out-of-school = Basic health } \\
\text { care }\end{array}$ & $\begin{array}{l}\text { For in-school = Life skills \& math } \\
\text { For out-of-school= Life skills, basic } \\
\text { health care, \& ICT }\end{array}$ \\
\hline
\end{tabular}

\section{Lessons learned from two-year implementation experiences}

- From the above analysis and discussion of the session data, we note that the intervention was fully implemented in all intervention areas in the first year according to the program design. In the second year, because of the onset of the pandemic resulting in school closures, the newly adopted phone-based remote sessions could provide 14 hours of sessions instead of 72 hours for each of the program girls. The reduced time in direct sessions was supplemented with learning materials and worksheets distributed by mentors, and thus engagement was topped up.

- Though session hours and the number of sessions were reduced, this did not curtail the opportunity for the girls to learn and interact with their peers. This meant that they continued to have a virtual "safe space" for sharing and learning from mentors and peers.

- The attendance rate was better in the second year of intervention, as the mentors would follow up with the girls and tried to confirm targeted girls' participation. Thus around $70 \%$ attendance was possible among girls in both the in-school and out-ofschool sessions. The attendance rate was around 60\% for in-school sessions in the first year of intervention in comparison.

- A number of reasons may account for the achievement of better attendance for outof-school sessions in both years. The group was comparatively smaller than that of in-school girls, thus follow-up was easier. Girls were more comfortable with their mentors than with teachers. This could also reflect the feeling of getting back to a school environment and the scope of interacting with peers. Additionally, out-ofschool girls were offered compensation for attending the sessions.

- If the findings are compared with another of the Population Council's flagship interventions-BALIKA, implemented in 2014-15-we find that the overall average 
attendance in the in-school and out-of-school settings was almost the same for these two projects (16 and 6 in the first year and 13 and 4 in the second year, respectively, for this project while it was 15 and 6 , respectively, in the BALIKA project).

- Like the BALIKA project, this program also experienced similar interactions among facilitators (teachers/mentors) and the participating girls with regard to the issue of quality. And the quality score for "interaction" is slightly less for out-of-school girls than that of in-school girls. The reason was again the same: there was inconsistent attendance and more dropout for out-of-school girls than for in-school girls. Furthermore, as in the BALIKA sessions, the out-of-school girls' performance increased considerably in the later part of the intervention period.

- In terms of "overall environment," the performance was slightly better in "interaction and enjoyability" for in-school groups in the first year but in the second year, the performance was better for out-of-school sessions. In the second year, in-school performance was lower at the beginning which may reflect acceptance and adjustment issues, as mentors were conducting sessions previously held by teachers. The data show that in-school performance improved gradually over the period.

From the discussion points mentioned above, we can infer two things. One, as facilitators, mentors performed better than teachers, possibly because the mentors were almost contemporary to the girls which helped connect with them quickly, thus creating an enjoyable session environment within a very short period of time. Two, adolescent girls need a "safe space" where they have the opportunity to share and address their personal issues, experiences, and curiosities, and can learn from each other and from the mentors. The opportunity for regular interaction with peers through "safe spaces" could reduce girls' social isolation as well as vulnerability (high risk of depression, violence, child marriage, etc.). Finally, we can conclude that this type of intervention is required not only for girls' better schooling but also for improving the lives of girls in these communities. 


\section{APPENDIX 2: COST ANALYSIS}

This section presents estimates of the cost of the intervention. A cost-ingredient approach identified and categorized each segment that is required to implement the programmatic activities for scaling up the project effectively. The cost analysis reviewed and analyzed the budget and accounting reports to categorize costs under different sections. The costs associated with this project are based on the experience of implementing the program in $\mathbf{2 4}$ secondary schools located in six upazilas under three districts in two intervention years. Total costs are distributed broadly under four main components:

- Center setup costs: Costs for purchasing digital equipment and other instruments for setting up a safe space/center in the schools.

- Capacity-building training costs: Training costs for teachers and mentors.

- Implementation costs: Personal costs of teachers and mentors and sessionfacilitating costs.

- Monitoring costs: SurveyCTO software subscription and maintenance costs, travel, and personal costs.

\section{CENTER SETUP COSTS}

Costs under this heading included expenses related to technological equipment and health-screening instruments for conducting education and skill-building sessions in the safe space/center. As school premises were used for safe spaces, no infrastructural development cost was incurred.

Average per center setup costs for each intervention area - 1815 USD Primarily teachers and mentors used school equipment in each center for tutoring purposes. The following table demonstrates the approximate cost for setting up a safe space/center in a classroom.

Table 26. Center setup cost (per center)

\begin{tabular}{lrrr}
\hline Item & $\begin{array}{r}\text { Unit cost } \\
\text { (USD) }\end{array}$ & Units & $\begin{array}{r}\text { Costs } \\
\text { (USD) }\end{array}$ \\
\hline Laptop & 540 & 48 & 25920 \\
Multimedia projector and screen & 355 & 24 & 8520 \\
Blood pressure monitor machine & 40 & 24 & 960 \\
Blood sugar test machine & 25 & 24 & 600 \\
Weight scale & 15 & 24 & 360 \\
Smartphone for monitoring session attendance & 300 & 24 & 7200 \\
Total costs & & & 43560 \\
Per center setup cost & & & $\mathbf{1 8 1 5}$ \\
\hline
\end{tabular}

(@ 1USD=84Tk) 


\section{CAPACITY-BUILDING TRAINING COSTS}

From each school, four subject teachers and one mentor received capacity-development training and refresher training (Training of Trainers - TOT). Expert trainers from Teachers Training Colleges facilitated the three-day ToT of teachers. Mentors received a twoweek ToT on life skills, computer technology, financial literacy, and basic health. Costs associated with capacity-building training covers the training allowance for participants, transportation costs, compensation of trainers, logistics and training materials, venue, and food-related costs and personal costs (partial salary) of project staff who were involved in organizing, managing, and facilitating the trainings. The following table shows the summary of costs associated with training:

Table 27. Total training cost

\begin{tabular}{lr}
\hline Item & Costs (USD) \\
\hline Training cost of teachers (ToT) & 24348 \\
Refresher training cost of teachers & 14807 \\
Training cost of mentors & 16065 \\
Refresher training cost of mentors & 11383 \\
Total costs & $\mathbf{6 6 6 0 2}$ \\
\hline
\end{tabular}

(@1USD=84Tk)

\section{IMPLEMENTATION COSTS}

Following the study design, the intervention allocated human resources and programmatic components to provide tutoring and life-skills education support to $\mathbf{6 0}$ in-school girls and 15-20 out-of-school girls in each intervention school per year. However, fewer adolescent girls participated in the intervention than anticipated.

\section{Cost for in-school girls}

Operation costs for conducting in-person sessions cover costs associated with compensation of four schoolteachers per school, monthly salary of one mentor, partial costs for equipment maintenance, monthly internet charges and phone bills, etc. The following table shows the summary of implementation costs associated with running the intervention for inschool girls per center in the first year of intervention:
Average virtual session costs

for per in-school girl per year:

46 USD (second year, during COVID-19)

Total Teachers

Total Mentors

96

24 
Table 28. Implementation costs for conducting sessions per center for in-school girls

\begin{tabular}{|c|c|c|c|c|}
\hline Item & $\begin{array}{r}\text { Unit cost } \\
\text { (USD) }\end{array}$ & $\begin{array}{r}\text { Charged } \\
(\%) \\
\end{array}$ & $\begin{array}{r}\text { Units/ } \\
\text { month } \\
s \\
\end{array}$ & $\begin{array}{r}\text { Costs YR1 } \\
\text { (USD) }\end{array}$ \\
\hline Monthly salary of mentor & 48 & $50 \%$ & 12 & 288 \\
\hline Compensation of two English teachers & 4 & $100 \%$ & 48 & 384 \\
\hline $\begin{array}{l}\text { Compensation of two math teachers } \\
\text { Equipment maintenance, phone bill, internet } \\
\text { charges }\end{array}$ & 30 & $100 \%$ & 48 & 384 \\
\hline TOTAL & & & & 1344 \\
\hline Average cost per in-school girl & & & 60 & 22 \\
\hline
\end{tabular}

(@1USD=84Tk)

The intervention changed its implementation modalities in the second year from in-person to virtual tutoring session because of the COVID-19 pandemic. Among the enrolled participants for the second-year (2020) intervention, 60\% (around 1,000 program girls) girls participated in the phone-based remote-learning sessions in 24 intervention areas in three districts. On average $\mathbf{1 9}$ in-school girls participated in the virtual tutoring sessions during the second year of intervention. Due to school closures for pandemic, the intervention incurred lower costs for teachers' compensation and incurred additional costs for phone bills for implementing phone-based virtual sessions by mentors.

\section{Cost for out-of-school girls}

Human resources and programmatic components targeted 15-20 out-of-school girls in each center per year. However, the intervention reached an average of nine out-of-school girls per center in the first year. In the second year, an average of five girls participated in remote-learning sessions. Mentors conducted life-skills education, financial literacy, computer, and basic health education sessions among outof-school girls. Operation costs for conducting sessions among out-of-school girls mainly covered costs associated with the partial salary of the mentor, local transportation costs for out-ofschool girls for attending each session, and partial costs for equipment maintenance, phone bills, and internet charges. Among the costs, the transportation allowance for session attendance was a variable cost that would fluctuate according to an increase or decrease in the number of girls who attended in the sessions.

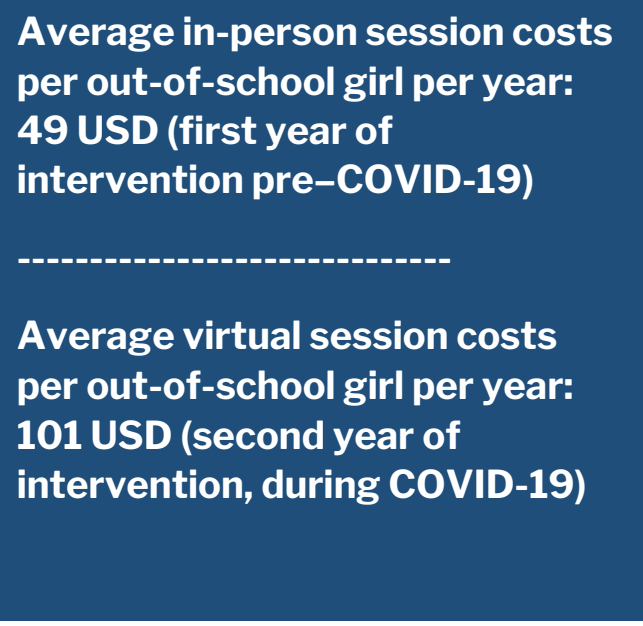




\begin{tabular}{lrrrr}
\hline Item & $\begin{array}{r}\text { Unit cost } \\
\text { (USD) }\end{array}$ & $\begin{array}{r}\text { Charge } \\
\text { d (\%) }\end{array}$ & $\begin{array}{r}\text { Units/ } \\
\text { months }\end{array}$ & $\begin{array}{r}\text { Cost } \\
\text { YR1 } \\
\text { (USD) }\end{array}$ \\
\hline $\begin{array}{l}\text { Monthly salary of mentor } \\
\begin{array}{l}\text { Transportation costs for out-of-school girls per } \\
\text { center }\end{array}\end{array}$ & 48 & $50 \%$ & 12 & 288 \\
$\begin{array}{l}\text { Equipment maintenance \& monthly internet } \\
\text { charges }\end{array}$ & 5 & $100 \%$ & 72 & 386 \\
TOTAL & 26 & $20 \%$ & 12 & 62 \\
Average cost per out-of-school girl & & & & $\mathbf{7 3 6}$ \\
\hline @1USD=84T) & & & 15 & $\mathbf{4 9}$ \\
\hline
\end{tabular}

\section{MONITORING COSTS}

Regular monitoring and evaluation are critical for ensuring effective and efficient use of resources and ensuring quality of intervention. It is also useful to make necessary adjustments during implementation of the intervention and measurement of the impacts and outcomes. The Population Council developed a real-time online monitoring system to visualize data and to enable data reporting on multiple levels. Attendance of the students and quality of the Average monitoring cost for per center in first year of intervention- 1120 USD sessions were monitored through real-time online attendance and monitoring systems. Every girl is provided with an ID card containing a unique barcode. Each barcode represents a unique ID for each program participant. Before the session, mentors scanned the cards using a barcode scanner through their smartphone and the system noted their attendance dates. Monitoring costs mainly covered the monthly subscription fees of SurveyCTO software; personal costs of project staff for development and maintenance of the software; and data monitoring, travel costs for monitoring visits, and personal cost of field staff for physically monitoring programmatic activities. The following table illustrates the costs across the intervention for monitoring and evaluation activities:

Table 30. Monitoring costs of YR1

\begin{tabular}{lrrrr}
\hline Items & $\begin{array}{r}\text { Unit cost } \\
\text { (USD) }\end{array}$ & $\begin{array}{r}\text { Charged } \\
\text { (\%) }\end{array}$ & $\begin{array}{r}\text { Units/ } \\
\text { months }\end{array}$ & $\begin{array}{r}\text { Costs YR1 } \\
\text { (USD) }\end{array}$ \\
\hline SurveyCTO software monthly subscription fees & 220 & $100 \%$ & 12 & 2640 \\
SurveyCTO development \& maintenance (personal & 2872 & $2 \%$ & 3 & 172 \\
costs) & 625 & $80 \%$ & 12 & 6000 \\
Travel costs for monitoring visits & 250 & $100 \%$ & 24 & 6000 \\
Mobile phone set for monitoring sessions & 1915 & $10 \%$ & 6 & 1149 \\
Personal costs for data monitoring & 606 & $50 \%$ & 36 & 10908 \\
Personal costs of district coordinators & & & $\mathbf{2 4}$ & $\mathbf{2 6 8 6 9}$ \\
TOTAL monitoring cost for 24 intervention areas & & & & \\
Average monitoring cost for per intervention area & & & &
\end{tabular}


The intervention allocated resources for monitoring estimated the number of girls (60 inschool and 15-20 out-of-school girls) for all centers in 24 intervention areas in three districts. The monitoring costs would not significantly fluctuate with changes in the number of program participants, as the intervention was designed to reach an anticipated number of girls.

\section{SUMMARY}

The overall cost analysis provides an estimation of average costs for implementing such a program in a similar setting. Average costs were used for this analysis for a broader cost outline, although the cost to implement the intervention may be changed for various reasons. The following table is the summary of total costs:

Average cost for per center: USD 10034

Average cost for per girl: USD 89

Table 31. Summary of costs for the project implementation (March 2019 to March 2021)

\begin{tabular}{lr}
\hline Items & Costs \\
\hline Center setup cost (24 centers) & 43560 \\
Operation costs for conducting sessions (compensation costs for teachers and & \\
mentors and session-facilitating costs) & 82976 \\
Training cost of teachers (ToT \& refresher) & 39155 \\
Training cost of mentors (ToT \& refresher) & 27448 \\
Monitoring costs (over the project duration) & 47681 \\
TOTAL & $\mathbf{2 4 0 8 2 0}$ \\
Average cost per center for the project's duration (total costs/24 centers) & $\mathbf{1 0 0 3 4}$ \\
Average cost per girl enrolled for the project's duration (total costs/2,700 girls) & $\mathbf{8 9}$ \\
Average cost per girl in the community (total costs/5,281 girls) & $\mathbf{4 6}$ \\
\hline (@ 1USD=84Tk) &
\end{tabular}

To replicate this intervention in other places of Bangladesh or elsewhere, equipment, implementation, training, and monitoring costs may vary, depending on whether the implementing organization or secondary schools had already obtained equipment and could share the costs. For instance, equipment cost for laptops and projectors can be minimized if schools allow use of existing digital equipment. Most secondary schools in Bangladesh are being gradually equipped with digital equipment under different development schemes to ensure ICT usage in the classroom. Monitoring costs can be reduced if personal smartphones are used for monitoring session attendance by mentors. The return from the cost of training and capacity-development of implementors can be viewed in a wider term as it would have a long-term impact on improving the quality of teaching and skills of both teachers and mentors, and certainly would be diffused among other girls of the schools and community beyond the program participants. 


\section{APPENDIX 3: OUTCOME INDICATORS}

Table 32. Main outcomes with indicators used to measure impact of the intervention

\begin{tabular}{|c|c|c|}
\hline Impact & Outcome & Indicator \\
\hline \multirow{4}{*}{$\begin{array}{l}\text { - Increased social } \\
\text { and human capital }\end{array}$} & $\begin{array}{l}\text { Improved educational } \\
\text { attainment }\end{array}$ & $\begin{array}{l}\text { - Currently attending school } \\
\text { - Discontinued school } \\
\text { - Reason for discontinuation of school was } \\
\text { marriage } \\
\text { - Total competency score (language and } \\
\text { analytical) } \\
\text { - Analytical score }\end{array}$ \\
\hline & $\begin{array}{l}\text { Improved knowledge } \\
\text { and behavior on SRH } \\
\text { and well-being }\end{array}$ & $\begin{array}{l}\text { - Can name at least three adverse effects of } \\
\text { child marriage } \\
\text { - Knowledge about FP methods } \\
\text { - Knowledge about fertile period } \\
\text { - Knowledge about timing of first birth } \\
\text { - Uses sanitary pads } \\
\text { - Agree that girls have the right to say “no" to an } \\
\text { arranged marriage } \\
\text { - Ever married before } 18 \text { years of age } \\
\text { - Marriage registration } \\
\text { - Used contraceptive before first pregnancy } \\
\text { - Age at first pregnancy } \\
\text { - Gave birth at a facility for last pregnancy }\end{array}$ \\
\hline & $\begin{array}{l}\text { Improved mobility } \\
\text { and social solidarity }\end{array}$ & $\begin{array}{l}\text { - Access to mobile phone (personal and/or HH) } \\
\text { - Watches TV } \\
\text { - Listens to music/news through mobile phone } \\
\text { - Allowed to go outside alone after sunset } \\
\text { - Experiencing harassment }\end{array}$ \\
\hline & $\begin{array}{l}\text { Improved economic } \\
\text { aspiration }\end{array}$ & $\begin{array}{l}\text { - Ever worked for income } \\
\text { - Worked for income in the last } 12 \text { months } \\
\text { - Average hours worked in a week } \\
\text { - Average monthly wages } \\
\text { - Have control over expenses } \\
\text { - Can save money } \\
\text { - Ever received livelihood training }\end{array}$ \\
\hline
\end{tabular}




\section{APPENDIX-4: IRB APPROVAL}

Institurional Review Board

Population Council

1230 York Avenue

Now York. NY 10065

APPROVAL OF PROTOCOL

DATE: April 27,2018

TO: $\quad$ U. Rob, S. Amin, Principal Investigators

FROM: $\begin{aligned} & \text { Nick Gontarz, IRB Administrator, on behalf of } \\ & \text { John Bongaarts, Chairman }\end{aligned}$

Institutional Review Board (IRB)

RE: Approval of Protocol 846 - Operations Research on Keeping Girls in Schools to Reduce Child Marriage in Rural Bangladesh

The Institutional Review Board (IRB) on human research of the Population Council has approved the above request to involve humans as research subjects.

DATE OF IRB APPROVAL:

APRIL 18, 2018

ADVERSE REACTIONS/COMPLICATIONS/UNANTICIPATED PROBLEMS: All serious andor unexpected side effects and unanticipated problems must be reported immediately by email to the Population Council's SAE Desk (SafetyapopoounciLong) which will notify the IRB of the Population Council.

MODIFICATIONS: All Protocol changes involving subjocts must have prior IRB approval.

If this project is to continue, it must be renewed as specified by the IRB. THE EXPIRATION DATE FOR THIS PROJECT IS MAY 16, 2018. This renewal application consists of a brief status report summarizing the results obtained during the past period and a short statement of the research plan for the coming year.

If you have any questions, please contact Nick Gontarz at telephone number [212] 327-7112, email ngontarz@popeouncil.ong.

ce: IRB Records and Reports File for Protocol 846 


\section{population COUNCIL \\ Ideas. Evidence. Impact. \\ popcouncil.org}

